\title{
Georges Demartial
}

\section{$(1931)$ \\ Le mythe \\ des guerres \\ de légitime défense}

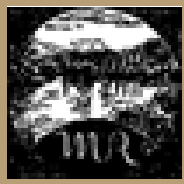

Un document produit en version numérique par Jean-Paul Murcia, bénévole, professeur de philosophie, titulaire-remplaçant rattaché au Lycée Montchapet à Dijon

Courriel : j.p.murcia@free.fr

Dans le cadre de la collection: "Les classiques des sciences sociales"

Site web: http://www.uqac.uquebec.ca/zone30/Classiques_des_sciences_sociales/index.html

Une collection fondée et dirigée par Jean-Marie Tremblay, professeur de sociologie au Cégep de Chicoutimi.

Une collection développée en collaboration avec la Bibliothèque

Paul-Émile-Boulet de l'Université du Québec à Chicoutimi

Site web: http://bibliotheque.uqac.uquebec.ca/index.htm 
Cette édition électronique a été réalisée par Jean-Paul Murcia, bénévole, professeur de philosophie, titulaire-remplaçant rattaché au Lycée Montchapet à Dijon. : j.p.murcia@free.fr

à partir de :

\section{Georges Demartial (1931)}

\section{Le mythe des guerres de légitime défense}

Une édition électronique réalisée à partir du livre de Georges Demartial, Le mythe des guerres de légitime défense. Paris : Librairie des sciences politiques et sociales Marcel Rivière, 1931, 162 pages.

Polices de caractères utilisée :

Pour le texte: Times, 12 points.

Pour les citations : Times 10 points.

Pour les notes de bas de page : Times, 10 points.

Édition électronique réalisée avec le traitement de textes Microsoft Word 2001 pour Macintosh.

Mise en page sur papier format

LETTRE (US letter), 8.5' x 11'')

Édition complétée le 29 octobre 2003 à Chicoutimi, Québec. 


\title{
Table des matières
}

\author{
Avant-propos
}

Chapitre I Le mythe de la légitime défense a joué un rôle capital dans la guerre européenne

Chapitre II Le mythe de la légitime défense et l'explosion de la guerre en France

Chapitre III Le mythe de la légitime défense et l'explosion de la guerre en Allemagne

Chapitre IV Des gouvernements français et allemand, lequel a le plus exploité le mythe de la légitime défense?

Chapitre V Le mythe de la légitime défense pendant la guerre

Chapitre VI Le mythe de la légitime défense depuis la guerre

Chapitre VII Au mythe de la légitime défense, il faut opposer la vérité sur l'explosion de la guerre, et sa conséquence : plus de guerre sans un vote du peuple

Chapitre VIII La vérité peut-elle être faite sur l'explosion de la guerre?

Chapitre IX Requête à la Fondation Carnegie

Appendice 
Georges Demardial

\section{Le mythe des guerres de légitime défense}

Paris : Librairie des sciences politiques et sociales Marcel Rivière, 1931, 162 pages.

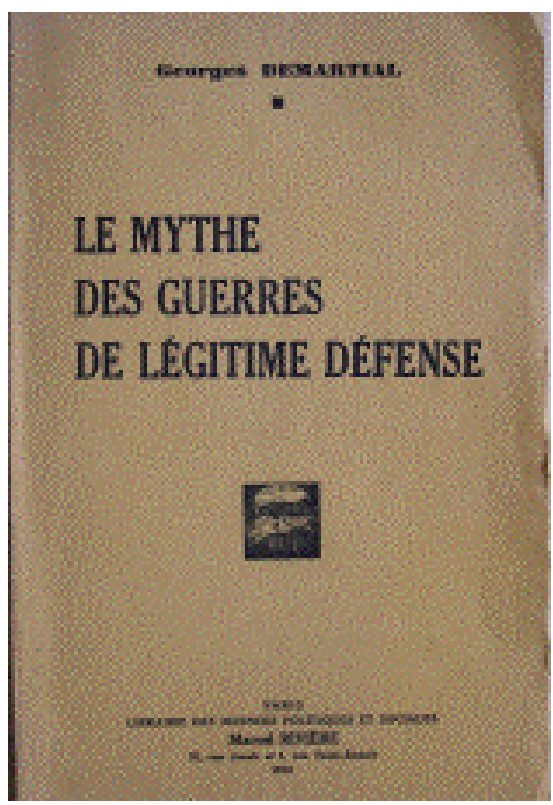

$\underline{\text { Retour à la table des matières }}$ 


\section{Avant-propos}

\section{$\underline{\text { Retour à la table des matières }}$}

La Fédération Parisienne des Anciens Combattants Républicains a émis, dans son Congrès du 29 mars 1931, le vœu que la question des responsabilités de la guerre soit soumise par la C. I. A. M. A. C. (Confédération Internationale des Associations des Mutilés et Anciens Combattants de la guerre), à l'examen d'une Commission internationale. Puisse cette initiative trouver ici un encouragement! « Vous aurez des droits sur nous », disait inlassablement l'arrière aux combattants. Le premier de leurs droits n'est-il pas de savoir pourquoi ils se sont battus, et d'empêcher que leurs enfants, sinon eux-mêmes, ne soient exposés à se battre encore pour de fausses raisons ? Si les anciens combattants des deux camps s'unissaient pour réclamer la vérité, qui oserait les en blâmer? 


\section{Chapitre I}

\section{Le mythe de la légitime défense a joué un rôle capital dans la guerre européenne}

Personne ne contestera qu'en 1914 la guerre était considérée comme un attribut nécessaire et légitime de la souveraineté des États, seuls juges de leurs intérêts et des moyens à employer pour leur protection. Partout elle était, suivant le mot du général Clausevitz, admise «comme une des formes de la politique »; partout les hommes qui la choisissaient comme profession étaient honorés entre tous ; partout les peuples étaient prêts à en supporter le poids, consacraient à sa préparation le plus clair de leurs ressources, la plupart même acceptant le service militaire comme une obligation sacrée. Pour beaucoup de gens, la guerre avait même un caractère religieux, soit que, comme Joseph de Maistre, ils ne pussent se l'expliquer autrement que par l'effet d'une volonté supérieure aux hommes, soit qu'ils lui trouvassent une vertu purificatrice. Quoi qu'il en soit, dans les vingt années précédant 1914, il n'y avait pas eu moins de dix guerres sur tous les points du globe, les trois dernières en Europe même ; on s'y était battu en 1911, en 1912, en 1913. L'idée ne vint à personne 
de traiter de criminel, d'excommunier du monde dit civilisé tel ou tel des belligérants, sous le prétexte « qu'il avait commencé »; au contraire, les sympathies se portèrent sur les républiques boërs, le Japon, les États balkaniques, dont c'était le cas.

Des sages, des pacifistes comme Fénelon et Montesquieu avaient même admis qu'un État fît préventivement la guerre à un autre en passe de devenir trop puissant. «Une plus longue paix, disait Montesquieu, mettrait cet autre en état de le détruire, et l'attaque est alors le seul moyen d'empêcher cette destruction » (L'Esprit des Lois, chapitre X). C'est sur cette idée que reposait le principe de l'équilibre européen, au nom duquel avaient eu lieu, depuis quatre siècles, sous les prétextes les plus divers, toutes les guerres de coalition, jusques et y compris la guerre de Crimée.

On avait bien réuni à la Haye, en 1899 et en 1907, les fameuses conférences dites « de la paix ». Elles accouchèrent d'une réglementation de la guerre. On décida notamment qu'on ne devrait pas la commencer sans une déclaration en forme, qui la rendait licite si cette formalité était accomplie. Ainsi la guerre avait ses lois, comme le mariage et la propriété. Elle était le moyen extrême par lequel deux États tranchaient un conflit quand les négociations n'y suffisaient pas, absolument comme des individus recourent à un procès quand ils ne peuvent s'entendre à l'amiable.

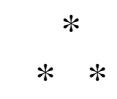

Comme la guerre est une affaire de force, et non de judicature, il importe moins à des États en guerre d'avoir raison qu'à des particuliers dans un procès. « Right or wrong, my country ». Qu'il ait tort ou raison, je suis pour mon pays. C'est en effet le vainqueur qui a raison ; la force fait le droit. Mais on n'aime généralement pas avouer qu'on a tort, et qu'on ne doit son droit qu'à la force! Un État en guerre essaie donc tout de même de mettre le droit de son côté, soit en arguant qu'il n'a pas commencé les hostilités, soit en disant qu'il a été provoqué s'il les a commencées. C'est l'argument de la légitime défense. Comment un État aurait-il tort s'il ne fait que se défendre ? N'est-ce pas la preuve qu'il est innocent de la guerre?

Toutefois, en raison de la difficulté de savoir si une guerre est vraiment défensive ou non, on n'attachait pas jusqu'ici à cet argument une grande importance. Comment établir qui a tiré le premier coup de feu, ou qui a le premier franchi la frontière, ou qui a, par ses armements, mis l'autre en état de légitime défense ? Suivant les conditions géographiques, politiques, militaires, des prépara- tifs de guerre peuvent signifier la guerre dans tel cas et pas dans 
tel autre. La difficulté est encore plus grande de savoir quel État a politiquement provoqué la guerre, c'est-à-dire lequel aurait dû s'incliner devant les prétentions de l'autre, chacun pouvant avoir, au point de vue de ses intérêts, une excellente raison de ne pas céder. En fait, si on excepte les expéditions coloniales, on peut se demander s'il n'y a jamais eu, dans les temps modernes, une guerre entre États indépendants dont on ait pu dire qu'elle était purement défensive, comme celle que Rabelais, dans son Gargantua, fait soutenir par Grandgousier contre Pichrocole. Mais il a fallu précisément qu'il l'imagine.

Je dis dans les temps modernes par prudence. Dans un article du vaillant hebdomadaire américain Unity (28 mai 1928), j'ai lu qu'en 1815 un citoyen de ce pays, Noah Worcester, qui pensait que seule la guerre défensive peut se concilier avec les principes du christianisme, fit une étude des causes des guerres principales depuis Constantin, afin de voir combien remplissaient cette condition ; il trouva que sur deux-cent-quatre vingt six guerres, aucune n'était vraiment défensive.

Pour qu'on pût parler de guerres agressives et de guerres défensives, il faudrait admettre comme un principe hors de discussion que l'État qui déclare une guerre est toujours l'agresseur de celui auquel il la déclare, et qui serait, lui, toujours innocent par définition. Mais l'iniquité d'un pareil régime l'a toujours fait repousser. On lit dans la Grande Encyclopédie, à l'article Guerre : "Au point de vue du droit, la guerre offensive est celle qui est soutenue par le parti dont les agissements l'ont provoquée et rendue inévitable, alors même qu'il n'aurait pas accompli les premiers actes d'hostilité ». Les diplomates, les gouvernements, ne pensent pas autre- ment. Dans le traité du $1^{\mathrm{er}}$ novembre 1902 par lequel la France et l'Italie se garantissaient mutuellement leur neutralité, la garantie était étendue au cas « où l'une d'elles se trouverait réduite, par suite d'une provocation directe, à prendre l'initiative d'une déclaration de guerre ». Qu'est-ce à dire, sinon que le véritable agresseur peut très bien être un État qui se fait déclarer la guerre ? Par là même on reconnaît l'impossibilité de distinguer les guerres agressives et les guerres défensives. Car si l'État qui en a provoqué un autre à l'attaquer est le véritable agresseur, il reste cependant l'attaqué de fait, il est à la fois agresseur et attaqué, de même que son adversaire, bien qu'ayant été provoqué à la guerre, n'en restera pas moins l'agresseur de fait, et sera lui aussi à la fois attaqué et agresseur.

Observons enfin, et c'est de première importance, que l'agression suppose la clandestinité de la préparation chez l'agresseur, la surprise et l'absence de toute raison de se battre chez l'attaqué. Or, ces conditions sont toujours absentes d'une guerre moderne. Où a-t-on vu un gouvernement s'endormir le soir dans une paix profonde, et apprendre en se réveillant qu'il est attaqué par un autre ? La véritable agression n'existe pas d'État à État. C'est pourquoi, parlant du droit de la guerre, Voltaire a eu raison de dire : «Il n'y a certaine- 
ment dans ce monde que des guerres offensives; la défensive n'est autre chose que la résistance à des voleurs armés ${ }^{1} \gg$. Et, en effet, une guerre vraiment défensive serait celle d'un État qui serait attaqué par un autre État comme un individu peut l'être par un voleur à main armée. Mais à moins de remonter aux guerres de clans, jamais une guerre n'a le caractère de résistance à des voleurs armés. Quelle comparaison peut-il y avoir entre le passant inoffensif, victime surprise d'un bandit, et l'État qui, un litige s'élevant entre lui et un autre État, préfère la guerre à l'abandon de ce qu'il considère comme son droit ou son intérêt. Si la guerre a une analogie, c'est avec le duel dans les pays où le duel est permis ou toléré. Or, on n'a jamais eu l'idée d'assimiler le duel à une agression, puisqu'il est accepté par les deux champions. Bref, en 1914, un État auquel la guerre était déclarée ne pouvait se dire victime d'une agression criminelle, d'une part parce que la guerre étant légale ne pouvait être criminelle, de l'autre parce que la guerre moderne suppose non-seulement un État qui la déclare ou la commence, mais un État qui l'accepte, et que celui qui l'accepte peut en être, soit quant à ses causes lointaines, soit quant aux circonstances de l'explosion, autant et même plus responsable que l'autre.

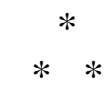

S'il y a une guerre qui ait consacré ces vérités, c'est bien celle de 1914. Il sautait aux yeux qu'elle n'aurait pas eu lieu si la Serbie avait accepté la note de l'Autriche, ou si l'Autriche avait expurgé cette note comme le voulait la Russie, ou si la Russie n'était pas intervenue, ou si l'Allemagne avait abandonné l'Autriche, ou si la France avait abandonné la Russie, ou si l'Angleterre avait abandonné la France. Une seule défection l'eût empêchée. Mais tous sacrifièrent la paix à ce qu'ils considéraient leur droit ou leur intérêt. Aucun ne fut donc innocent. Et puisque la guerre faisait partie du droit international, s'ils furent tous responsables, aucun ne fut juridiquement coupable, aucun n'avait commis de « crime ».

Il n'en résulte évidemment pas qu'ils avaient tous également raison ou tous également tort. Il fallait, comme pour toute guerre, apprécier les motifs pour lesquels chacun avait pris les armes. Celui-ci pouvait en avoir de meilleures que celui- là. Mais aucun assurément ne pouvait prétendre «n'avoir pas voulu la guerre ».

1 Entretiens philosophiques, article Droit de la guerre. 
Cependant, à peine la guerre commencée, on vit les belligérants d'un des camps se draper précisé- ment dans cette attitude d'innocence absolue, repousser avec horreur, comme un crime, l'idée qu'ils auraient pu délibérément avoir recours à la guerre, affirmer qu'ils n'avaient d'ailleurs aucune raison de se battre, mais y avaient été forcés par une agression soudaine de l'Allemagne, dont ils vouèrent le gouvernement et le peuple à l'exécration universelle.

Jamais la raison humaine n'avait subi pareil attentat. Tous les belligérants étaient armés jusqu'aux dents ; leur correspondance prouve que, pendant que leurs peuples s'initiaient au tango, ils voyaient tous la guerre venir. À partir de l'assassinat de l'archiduc d'Autriche, tous furent sur le qui-vive. Dès que la note autrichienne à la Serbie fut connue, la Russie commença à mobiliser. «L'Allemagne ne veut pas prendre la responsabilité de la guerre, dit le gouvernement allemand, et ne mobilisera que si la Russie mobilise contre elle ; mais alors ce sera la guerre à la Russie et à la France, car l'armée allemande, qui n'a de chance de vaincre dans cette guerre sur deux fronts qu'en essayant de battre ses adversaires séparément, ne peut attendre qu'ils soient prêts à l'attaquer simultanément ». La Russie et la France n'en mobilisèrent pas moins, et quand l'Allemagne, après les avoir vainement sommés d'arrêter leur mobilisation, leur déclara la guerre, hurlèrent à l'agression traîtresse. Le gouvernement anglais feignit de les croire. Et la légende de l'agression de l'Allemagne, seule responsable de la guerre, se répandit sur la terre, ameutant contre cette puissance jusqu'à vingt-quatre États grands et petits. Naturelle- ment, le gouvernement allemand protesta de toutes ses forces que, s'il y avait quelqu'un d'attaqué, c'était bien l'Allemagne, contre laquelle la Russie et la France avaient mobilisé malgré tous ses avertissements que ce serait la guerre.

L'argument de la légitime défense a donc tenu dans la grande guerre, des deux côtés, une place capitale. On se propose de démontrer ici par l'étude des faits, en prenant comme exemples la France et l'Allemagne, les deux pays qui se la sont le plus renvoyé, qu'il ne fut qu'un mensonge, destiné à faire avaler la guerre par les peuples, et que s'il y a une leçon à tirer de la grande guerre, c'est précisé- ment l'inanité de la distinction entre guerres agressives et guerres défensives. 


\section{Chapitre II}

\section{Le mythe de la légitime défense et l'explosion de la guerre en France}

\section{$\underline{\text { Retour à la table des matières }}$}

Lors de la crise marocaine, en 1911, la Russie avait dit à la France : «Pas de guerre pour le Maroc ». On admettra bien, j'imagine, que si la France avait dit en 1914 à la Russie : "Pas de guerre pour la Serbie », il n'y aurait pas eu de guerre européenne en 1914. Affirmer que la France n'a aucune responsabilité dans la guerre, c'est dire une chose qui n'est pas seulement contredite par cent documents qu'on feint d'ignorer, mais est contraire au raisonnement le plus élémentaire.

On admettra bien aussi que, si le gouverne- ment français a accepté l'éventualité de se battre pour la Serbie, ce n'était pas pour ses beaux yeux. Il l'aurait dit qu'on ne l'aurait pas cru. Voyez-vous Viviani annonçant au Parlement qu'il entreprenait cette guerre effroyable, pour éviter au gouvernement serbe l'humiliation que des agents autrichiens coopérassent avec la police serbe à la recherche des origines et des complices du complot de Serajevo ? Quel tollé n'aurait-il pas soulevé ! Le 29 juillet, les cent députés socialistes 
français avaient solennellement déclaré «que la France ne pouvait se laisser entraîner à un conflit dont la Serbie serait l'enjeu ». Comme une guerre pour la Serbie eût été plus impopulaire encore en Angleterre, Grey eut même soin, le 3 août, d'affirmer aux Communes «avec la plus absolue certitude, que la France était bien le dernier pays à avoir songé à se battre pour la Serbie ».

La Serbie n'était que l'occasion. De même que la Russie allait sa battre pour Constantinople dont le chemin, disaient les nationalistes russes, «passait maintenant par l'Allemagne », de même que l'Angleterre allait se battre pour l'empire des mers que lui contestait l'Allemagne, de même la France allait se battre pour reprendre l'Alsace que lui avait prise l'Allemagne.

Outre ces raisons particulières d'hostilité contre l'Allemagne, les trois puissances avaient le grief commun qu'habituées jusqu'au milieu du XIX siècle à régenter l'Europe, elles avaient vu cette parvenue s'installer à leur table dans un rang égal au leur, et menacer, par sa prospérité insolente, ce qu'elles appelaient l'équilibre européen.

Les Détroits, le sceptre de Neptune, le Rhin, l'Équilibre, étaient les enjeux traditionnels, donc avouables, des guerres européennes. Pourquoi les gouvernements de l'Entente n'ont-ils pas avoué que c'était là, cette fois encore, leurs buts de guerre ? Pourquoi notamment le gouvernement français n'a-t-il pas demandé au Parlement, comme la Constitution lui en faisait un devoir, l'autorisation de promettre à la Russie l'appui de la France si la Russie entrait en guerre contre l'Allemagne. La Russie n'était-elle pas, depuis plus de vingt ans, « la grande amie et alliée » prônée dans toutes les occasions ? Et l'idée de la revanche de 1870 n'était-elle pas, comme l'a déclaré avec orgueil M. Lavisse, cultivée jusque dans les écoles ? ${ }^{1}$. Certains ont pu déplorer la guerre ; personne n'a pu s'en étonner. Alors, pourquoi les députés, les journalistes et les académiciens n'ont-ils cessé de repousser comme abominable la seule pensée que la France ait pu vouloir la guerre, et d'affirmer qu'elle n'y serait jamais entrée sans l'agression de l'Allemagne ? L'explication est bien simple.

Aujourd'hui, un gouvernement ne peut entre- prendre la guerre qu'en se faisant allouer par des représentants de la nation les crédits nécessaires. Il faut donc qu'il donne publiquement ses raisons. S'il s'agit d'une simple expédition, il trouve facilement une majorité pour l'approuver, et l'opposition de la minorité ne compromet pas son succès. Mais il s'agit d'une grande guerre, d'une mobilisation générale, c'est autre chose. La guerre est devenue plus meurtrière et plus coûteuse que jamais, englobe toute la population mâle

Voir La Mobilisation des consciences, page 105. Je me permettrai de me référer, quand il $\mathrm{y}$ aura lieu, à mes ouvrages antérieurs, pour ne pas me répéter, et éviter au lecteur qui les connaîtrait de retrouver ici ce qu'il sait déjà. 
valide. Dans tous les pays un parti nouveau et influent, le parti socialiste, est pacifiste, internationaliste par doctrine. Un gouvernement ne peut donc venir dire à la tribune : «nous allons attaquer tel grand État dans tel intérêt ». Si important que fût cet intérêt, le gouvernement rencontrerait une trop forte opposition. Et même si le Parlement votait une telle guerre, elle ne serait pas populaire, parce qu'il n'y a jamais d'intérêt pour les masses à faire la guerre.

Pour faire accepter la guerre par son peuple, et éventuellement par les peuples alliés, avec l'ensemble et l'élan nécessaires à sa bonne fin, un gouvernement doit aujourd'hui s'arranger de manière à pouvoir la présenter comme rendue inévitable par une attaque ou une provocation équivalente de l'adversaire. Nous sommes en état de légitime défense, c'est la meilleure explication qu'un gouvernement peut donner d'une guerre, parce qu'elle le dispense d'en donner d'autre. D'où la règle : doit être présentée comme défensive toute guerre que ses vrais motifs ne suffiraient pas à justifier aux yeux du peuple.

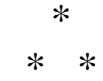

Le 4 janvier 1912, l'attaché militaire russe en France rendait compte à son gouvernement d'un entretien avec le général Dubail, chef de l'état-major général français : " Il croit à la guerre pour le printemps, s'y prépare en conséquence et m'a dit que, la double et la triple alliance ayant un caractère défensif, l'art de la diplomatie serait de présenter la France comme attaquée ${ }^{1}$.

C'est à quoi s'est employé, remarquablement servi d'ailleurs par les circonstances, le gouvernement français en 1914. S'il était venu demander au Parlement l'autorisation de faire la guerre pour rendre à la France l'Alsace et son rang d'avant 1870 en Europe, il est probable qu'il ne l'aurait pas obtenue, ou aurait rencontré une opposition qui aurait frappé à l'avance la guerre de discrédit. Il fallait qu'il puisse dire : «L'Allemagne nous attaque », car alors il n'avait plus d'autorisation à demander. Mais, loin de vouloir attaquer la France, l'Allemagne avait prévenu Pétersbourg, Paris et Londres que sa politique serait de localiser le conflit austro-serbe, d'empêcher qu'il ne « s'européanisât », et leur avait exprimé l'espoir qu'ils s'abstiendraient d'intervenir. Donc elle n'irait pas les attaquer. Il fallait l'y amener. Deux moyens s'offraient.

1 Documents militaires russes, reproduits dans la revue américaine Current History, septembre 1930. 
Si la Russie déclarait la guerre à l'Autriche, il n'était pas douteux que l'Allemagne, dont le traité, public depuis 1887, l'obligeait à soutenir l'Autriche en cas d'attaque par la Russie, la déclarerait à la Russie. Il n'était pas non plus douteux qu'à moins d'en obtenir une déclaration de neutralité, elle la déclarerait aussi à la France, alliée notoire de la Russie, comme le droit international l'y autorisait pleinement, et comme la stratégie le lui commandait. Dans les milieux diplomatiques et militaires, on savait depuis longtemps, puisque la fameuse alliance franco-russe, qui datait de 1892, n'avait eu d'autre but que de parer à cette éventualité, on savait que dans une guerre contre la Russie et la France, dans cette guerre sur deux fronts qui était déjà le cauchemar de Bismarck, l'Allemagne ne comptait pour vaincre que sur la rapidité de ses mouvements, qu'elle attaquerait donc le plus vite possible un de ses adversaires, dans l'espoir de les battre séparément avant qu'ils ne pussent l'écraser simultanément, et que l'adversaire qu'elle attaquerait d'abord, ce serait la France, à la fois parce qu'elle le considérait comme le plus dangereux, et parce que c'était celui avec lequel elle pouvait le plus vite s'empoigner à fond. Les deux puissances pourraient donc se dire attaquées. Mais attaquées pourquoi ? Parce que la Russie aurait déclaré la guerre à l'Autriche. On retombait dans la guerre pour la Serbie.

De plus, dans ce cas, la France ne serait entrée dans la guerre qu'à titre d'alliée de la Russie, et le gouvernement français aurait été embarrassé pour justifier son appui à la Russie, car son alliance avec elle était expressément limitée au cas où l'attaque viendrait de l'Allemagne ou de l'Autriche soutenue par l'Allemagne, et ne jouait par conséquent pas si la Russie attaquait l'Autriche. Le 29 juillet, le groupe socialiste parlementaire avait d'ailleurs déclaré que «la France ne pouvait se laisser entraîner dans la guerre par l'interprétation plus ou moins arbitraire de traités secrets ». Quel avantage si elle pouvait y être entraînée sans que l'alliance fût en cause !

Il fallait donc provoquer l'Allemagne à déclarer la guerre non seulement à la Russie, mais à la France. Le coup des mobilisations y pourvut. Traitant ici uniquement de la question de la légitime défense, je ne puis exposer en détail toutes les circonstances de l'explosion de la guerre, et dois les supposer connues. Une foule de documents de toutes provenances et de tous genres prouve que les gouvernements des deux pays savaient que, si l'Allemagne venait à mobiliser contre la Russie et la France alliées, sa mobilisation, pour des raisons de stratégie élémentaire, serait accompagnée de l'ouverture immédiate des hostilités. Si donc ils mobilisaient sans ouvrir les hostilités euxmêmes, et c'est ce qu'en novembre 1912, alors que la guerre européenne était déjà à craindre, avait décidé le gouvernement russe, ils amèneraient l'Allemagne non seulement à mobiliser elle-même, mais à prendre à son compte les 
déclarations de guerre. Ils pourraient se dire en état de légitime défense, bien qu'en fait c'est eux qui auraient provoqué la guerre ${ }^{1}$.

Hypothèse, dira-t-on. Sans doute, et il serait préférable que nous eussions sous les yeux les procès-verbaux des séances du Conseil des Ministres pendant la semaine tragique. Mais on ne les aura jamais, pour cette bonne raison qu'ils n'existent pas. Le Conseil des Ministres, par une tradition constante, ne laisse aucune trace de ses délibérations. C'est ce qu'on appelle la responsabilité ministérielle. Nous avons sur la guerre des procès-verbaux de Conseils des Ministres autrichien, allemand, russe. Mais les séances du nôtre sont secrètes, si secrètes que rien n'en a jamais transpiré. Nous connaissons les délibérations du cabinet anglais lors de l'explosion de la guerre par le Mémorandum on résignation (Mémoire sur ma démission) de John Morley. Aucun des ministres français n'a jamais révélé un mot des délibérations du nôtre. "Par le suffrage universel, disait Jaurès dans un discours du 21 décembre 1893, nous avons fait politiquement de tous les citoyens une assemblée de rois ». De rois aveugles, alors !

Il est vrai qu'en 1928, dans son volume L'union sacrée, M. Poincaré, qui n'en avait rien dit dans son livre Les origines de la guerre publié en 1921, a fait cette révélation étourdissante que la Russie avait mobilisé non seulement sans, mais contre l'avis de la France (page 404). Elle est contraire à tout ce qu'on sait par ailleurs. Dans sa controverse avec M. Gerin ${ }^{2}$, M. Poincaré l'a renouvelée. « Ni les Ministres ni moi, dit-il, nous n'avons exactement connu en 1914, ni même avant la fin de la guerre, ce qui s'était passé en Russie du 24 au 31 juillet, et particulièrement dans la journée du 30 ». La Russie aurait donc poussé la France, «sa grande et chère amie », par derrière dans la fournaise. C'est ce que M. Poincaré, dans son message du 4 août aux Chambres, appelait «avoir été fidèlement secondés par notre alliée, et traîtreusement attaqués par l'Allemagne ». Je me refuse à croire que la France soit entrée ainsi dans la guerre. Ce serait effroyable. Tant que n'aura pas été levé le voile impénétrable qui recouvre les rapports des gouvernements français et russe à ce moment, je continuerai à penser que si la Russie a mobilisé sans ouvrir les hostilités, c'était afin de provoquer l'Allemagne à les ouvrir, qu'elle savait pouvoir compter sur l'appui de la France, et que si la France n'a pas donné sur le bras de la Russie le coup qui l'aurait arrêtée, c'est qu'elle y trouvait son compte. S'il y a une autre explication des événements qui satisfasse la raison, qu'on la donne !

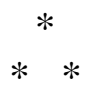

Voir L'Évangile du Quai d'Orsay, pages 111 et suivantes.

Les responsabilités de la guerre. Quatorze questions, quatorze réponses, page 88. 
Le stratagème réussit pleinement. Rappelons-nous ce qui se passa. Appuyé de la farce du « recul des dix kilomètres ${ }^{1}$, et de l'affiche que «la mobilisation n'était pas la guerre, mais le meilleur moyen d'assurer la paix », l'invocation de la légitime défense fit si bien rentrer sous terre toute opposition à la guerre que, de tous les parlements, le parlement français, où un assassin providentiel venait de supprimer Jaurès, fut le seul où les crédits de guerre furent votés sans un mot. On ne l'avait réuni que lorsque les dés étaient jetés, et il ne se réunit que pour se taire. En Serbie, en Russie, en Allemagne, en Angleterre, des socialistes exprimèrent des protestations ou des réserves émouvantes. En France, rien. Un député socialiste allemand était venu le $1^{\text {er }}$ août à Paris proposer à ses collègues français une action commune contre la guerre; on lui répondit qu' «en cas de guerre défensive » les socialistes français voteraient les crédits. Quatre ans avant, le socialiste Gustave Hervé avait publié son livre Leurs crimes, où il racontait comment il avait, en plein tribunal, raillé la façon dont les gouvernements présentent toujours leur guerre comme défensive, «afin de faire marcher les pauvres gens ignorants au doigt et à l'œil ». Les pauvres gens ignorants, c'était les cent députés socialistes et lui-même.

La thèse de la guerre défensive avait un autre énorme avantage : elle résolvait l'épineuse question de l'alliance russe. En manœuvrant de façon à se faire attaquer par l'Allemagne, le gouvernement français pouvait laisser le traité dans la majestueuse enveloppe où l'avait mis le Président Félix Faure. « Si le gouvernement invoque son traité avec la Russie, venait de s'écrier Jaurès à Bruxelles, nous invoquerons, nous, notre traité avec l'humanité ». La prétendue agression de l'Allemagne arrangeait tout. Les chefs de l'État et du gouvernement rentraient de Russie. On admit qu'ils n'y étaient allés que pour causer de la pluie et du beau temps. Il ne se trouva pas un député pour demander si l'alliance russe n'était pas pour quelque chose dans l'entrée de la France dans la guerre à côté de la Russie. Le texte du traité, fait inouï, ne fut même pas publié dans le Livre jaune sur l'explosion de la guerre. Il ne fut révélé qu'en 1918, parce que le gouvernement révolutionnaire russe allait le publier.

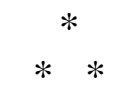

Tout de même, le fait d'avoir mobilisé contre l'Allemagne, même sans ouvrir les hostilités, pouvait difficilement se concilier avec la thèse de la légitime défense absolue. En France, où l'état de siège permettait de museler

1 Voir L'Évangile du Quai d'Orsay, pages 77-86. 
la presse, qui, d'ailleurs, ne demandait qu'à l'être, les objections n'étaient guère à craindre. Mais il n'en était pas de même en Angleterre, où se manifestait une forte opposition à la guerre, opposition dont le gouvernement anglais ne pouvait triompher que s'il pouvait montrer la Russie et la France attaquées par l'Allemagne sans provocation. C'est alors que, pour blanchir l'ordre de mobilisation russe, Paris écrivit à Londres que cet ordre avait été provoqué par la mobilisation générale autrichienne et des préparatifs secrets de l'Allemagne, affirmation si fausse qu'on dut fabriquer de faux documents, en Russie comme en France ${ }^{1}$, pour l'étayer. C'est pour Londres que fut donné avec ostentation l'ordre aux troupes françaises de se tenir à dix kilomètres de la frontière. C'est pour Londres qu'on afficha sur les murs de Paris la proclamation où la mobilisation était présentée «comme le meilleur moyen, dans les circonstances présentes, d'assurer la paix » (Livre jaune, $\mathrm{n}^{\text {os }} 106$ et 127). Pour faire croire qu'une guerre est défensive, tout est bon. Au milieu de la nuit du 31 juillet, notre Ambassadeur à Londres fit réveiller le Secrétaire général du ForeignOffice pour lui remettre un télégramme de Paris portant que les Allemands avaient confisqué des locomotives françaises, coupé des voies et des fils télégraphiques, violé la frontière. Le lendemain le Secrétaire général du Foreign-Office manda à Lord Grey : «Ces faits dénoncent clairement l'Allemagne comme l'agresseur. Il n'y a plus à hésiter. Je suis sûr que le pays comprendra qu'ils nous imposent de venir en aide à nos amis. Il faudrait mobiliser le corps expéditionnaire aujourd'hui même » (Doc. anglais, $n^{\circ} 446$ ). Ainsi, bien avant la déclaration de guerre de l'Allemagne à la France et la violation de la neutralité belge, le Foreign-Office était prêt à prendre texte, et prétexte, d'incidents de frontières aussi insignifiants qu'incontrôlables, dont certains ont même été reconnus faux, pour regarder l'Allemagne comme l'agresseur de la France, et entrer en guerre contre elle.

Peut-être même le gouvernement français comptait-il trouver dans ces incidents un prétexte à entrer en guerre sans attendre la déclaration de guerre de l'Allemagne, si elle eût trop tardé. Le 2 août, l'Ambassadeur de Russie à Paris télégraphiait à son gouvernement : «Les Allemands franchissent par petits groupes isolés la frontière française, et il y a déjà quelques escarmouches en territoire français. Cela donnera la possibilité au gouvernement de déclarer aux Chambres, convoquées pour mardi, que la France est victime d'une agression, et d'éviter une déclaration formelle de guerre » (Livre russe authentique, tél. 226).

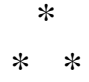

Et même en Angleterre, comme je le démontre dans une étude intitulée Histoire d'un mensonge, et qui vient de paraitre dans la revue Évolution. 
Il ne restait plus qu'à expliquer, car il le fallait bien, pourquoi l'Allemagne se jetait ainsi sur la France pacifique. «Ce que veut l'Allemagne, expliqua Viviani aux Chambres, c'est confisquer les libertés de l'Europe ». Voilà bien une de ces phrases qui font d'autant plus d'effet qu'elles ne signifient exactement rien. Qui l'expliquera ? Est-ce aux institutions démocratiques qu'en voulait l'Allemagne? On ne savait pas qu'elles eussent tant de valeur. Les événements ont prouvé que, précisément en temps de guerre, elles ne valaient pas un liard, et en tous cas on ne voit pas quelles libertés l'Allemagne aurait pu confisquer en Russie. Est-ce leur indépendance que l'Allemagne voulait ravir aux États européens ? Pour quel but et comment? N'a-t-on pas dit cent fois d'ailleurs, et les statistiques prouvent que c'était relativement vrai, que sa force d'expansion économique lui assurait une sorte d'hégémonie pacifique ? Que pouvait-elle vouloir de plus ? Si elle voulait subjuguer l'Europe, pourquoi avait-elle laissé passer depuis le commencement du siècle des occasions autrement favorables ? Et si la Russie et la France ne voulaient pas être «subjuguées », c'était si facile ; elles n'avaient qu'à juger le conflit austro-serbe du point de vue du « juste rigide », comme dit Montesquieu, et le juste rigide ne leur commandait certainement pas de mettre le feu à l'Europe pour la note de l'Autriche à la Serbie. Cette explication de l'agression de l'Allemagne était une moquerie. Les Chambres l'acclamèrent.

Les falsifications du Livre jaune firent le reste ${ }^{1}$. Dans un de ses ouvrages, Mark Twain a montré comment c'est toujours une minorité audacieuse qui pousse à la guerre la masse d'abord récalcitrante. Il termine ainsi son tableau : «Enfin les hommes d'Etat inventent de grossiers mensonges pour rejeter les responsabilités sur la nation attaquée. Chaque citoyen est alors heureux de sentir sa conscience apaisée par ces pièces fausses, s'empresse de les étudier, refuse d'examiner les objections, se persuade bientôt que la guerre est juste, et remercie Dieu pour le bon sommeil que lui procure ce grotesque procédé d'autosuggestion » (The mysterions stranger, cité par Unity).

$1 \quad$ Voir L'Évangile du Quai d'Orsay, qui leur est consacré. 


\section{Chapitre III}

\section{Le mythe de la légitime défense et l'explosion de la guerre en Allemagne}

Le 22 juillet, avant même que l'Autriche eût publié sa note à la Serbie, le gouvernement allemand avait prévenu les puissances de l'Entente qu'à son avis la propagande panserbe, dont le drame de Serajevo venait de montrer la puissance destructrice, menaçait l'intégrité et l'existence de l'empire austrohongrois, que les mesures qu'allait prendre celui-ci pour obtenir du gouvernement serbe l'arrêt de cette propagande étaient équitables et modérés, que s'il était forcé par le refus du gouvernement serbe à des actes de coercition, fussent-ils d'ordre militaire, il fallait éviter toute intervention d'une autre puissance, car elle entraînerait, par le jeu des alliances, « des conséquences incalculables ». Le gouvernement allemand a publié cette note dans le Livre blanc remis au Reichstag le 3 août, donc ne s'en est pas caché. 
Les puissances de l'Entente n'imitèrent pas cette franchise. Quand la note de l'Autriche parut, «C'est la guerre », dit Sazonov à son entourage ${ }^{1}$, se dirent Paléologue et Isvolsky ${ }^{2}$, dirent à Grey ses conseillers ${ }^{3}$. Pourquoi, si les trois gouvernements étaient décidés à la guerre pour soutenir la Serbie, ne l'ont-ils pas dit franchement à Berlin ? Pourquoi Paris notamment ne lui a-t-il pas dit : « Nous vous remercions de votre avis, mais devons vous prévenir que, si la Russie estime que les exigences de l'Autriche ne sont ni équitables ni modérées, et soutient la Serbie, le jeu des alliances nous obligera à soutenir la Russie comme vous soutenez l'Autriche, et que par conséquent une action militaire de l'Autriche contre la Serbie aurait les conséquences incalculables que vous redoutez ». Alors il n'aurait été question de légitime défense d'aucun côté ; le problème des responsabilités se serait réduit à savoir de quel côté était le bon droit : l'Autriche ou la Russie. Mais ni la France ni ses alliées n'eurent cette loyauté, et, tout en armant le plus secrètement possible, laissèrent le gouvernement allemand dans l'incertitude de leurs intentions.

Or, celui-ci tenait tout autant qu'eux à avoir la légitime défense de son côté. Loin d'apporter dans ses actes l'esprit de décision que laissait supposer sa note circulaire du 22 juillet, il se mit à louvoyer. Il était entré dans le Rubicon, mais s'attarda au milieu. On aurait pu s'attendre à ce qu'il mobilisât dès qu'il apprit les premiers préparatifs de la mobilisation russe, c'est-à-dire dès le 26 juillet (l'ordre de préparation à la guerre avait été lancé à Pétersbourg dans la nuit), ou au plus tard le 29, quand le gouvernement russe annonça publiquement la mobilisation contre l'Autriche des deux tiers de son armée d'Europe, soit le double des forces autrichiennes. L'Autriche l'en pressait. Mais, ainsi que le Chancelier l'avait annoncé dès le 26 au gouvernement russe, la mobilisation allemande signifierait la guerre à la Russie et à la France. Or, le gouvernement russe présentait sa mobilisation contre l'Autriche comme une simple mesure « de neutralité armée ».

Le gouvernement allemand se trouvait dans une situation tragique. S'il mobilisait, il s'exposait au reproche d'avoir déchaîné prématurément la guerre européenne, d'être l'agresseur. S'il ne mobilisait pas, il s'exposait à ce que la Russie, après avoir achevé ses préparatifs de guerre, la déclarât à l'Autriche. Alors l'Allemagne devrait à son tour déclarer la guerre à la Russie et à la France, mais après avoir perdu sa principale, pour ne pas dire sa seule chance de victoire, qui était sa plus grande rapidité de mobilisation que la Russie.

Contrairement à l'avis de l'état-major, qui voulait répondre à la mobilisation russe contre l'Autriche au moins par la proclamation de l'état de danger de guerre, le gouvernement allemand résolut de ne mobiliser que si la Russie

Journal du Ministère des Affaires étrangères russe, page 65.

Paléologue, «La Russie des Tsars » Revue des Deux-Mondes, 15 janvier 1921.

Doc. anglais, 101. 
mobilisait contre l'Allemagne elle-même, car alors il pourrait se dire en état de légitime défense. Dans l'espèce, il était militairement, stratégiquement vrai que la mobilisation russe contre l'Allemagne équivalait à un acte de guerre. Mais c'était ignoré du grand public. Pourquoi la mobilisation russe contre l'Allemagne entraînait-elle la guerre, alors que contre l'Autriche elle ne l'avait pas entraînée ? ${ }^{1}$. Dès le 26 juillet, le chancelier allemand aurait dû, dans une communication à toutes les agences de presse du monde, exposer pourquoi, si la Russie mobilisait contre l'Allemagne, l'Allemagne ne pourrait, comme la Russie, se contenter de mobiliser et attendre, et devrait marcher non seulement contre la Russie, mais aussi et d'abord contre la France. Certes les livres diplomatiques allemand et anglais, publiés le 3 et le 6 août, suffisaient à éclairer le drame. Mais le public ne lit pas les livres diplomatiques, il lit les journaux. Faute de cette précaution, le gouvernement allemand laissa à ses adversaires toute facilité de le faire passer pour l'agresseur. Son ambassadeur eut beau dire le 31 juillet au gouvernement français que la mobilisation « signifierait inéluctablement la guerre » (Doc. all. 491). Personne n'en sut rien, et le gouvernement français n'en afficha pas moins le $1^{\text {er }}$ août dans toute la France que « la mobilisation signifiait la paix ».

Le seul résultat qu'obtint le gouvernement allemand, en attendant la mobilisation générale russe pour mobiliser lui-même, fut d'être accusé par nombre d'Allemands d'avoir perdu la guerre, avant même qu'elle ne fût commencée, en laissant ses adversaires prendre les devants. C'est en effet seulement le 31 juillet, au reçu du télégramme annonçant la mobilisation générale russe, qu'il proclama l'état de danger de guerre, et seulement le $1^{\text {er }}$ août, la Russie n'ayant pas répondu à la sommation d'arrêter sa mobilisation, qu'il ordonna la mobilisation générale. Or, ses adversaires avaient montré autrement de décision. Le texte de la note autrichienne fut connu le 24 ; dans la nuit du 25 au 26, le gouvernement russe lança l'ordre de préparation à la guerre ; le 27, le gouvernement français faisait embarquer les troupes africaines; le 29, le warning telegram (l'avis avant-coureur de la mobilisation) fut envoyé à la flotte anglaise.

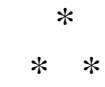

La France étant l'alliée notoire de la Russie et ayant, à la demande de l'Allemagne si elle resterait neutre, répondu qu'elle « ferait ce que ses intérêts lui commanderaient », Berlin était absolument fondé, d'après le droit international, à lui déclarer la guerre en même temps qu'à la Russie, s'il jugeait que « l'intérêt de l'Allemagne lui commandait » de ne pas laisser à l'armée

1 Voir L'Évangile du Quai d'Orsay, pages 178-182. 
française le choix du moment de l'attaquer. Mais, quand il eut déclaré la guerre à la Russie, le Chancelier allemand se vit reprocher, et particulièrement par les militaires, d'avoir bénévolement, en déclarant la guerre à la Russie, donné à l'Allemagne l'apparence d'être l'agresseur. Dix ans avant, le Japon, en fait de déclaration de guerre à la Russie, avait torpillé ses vaisseaux à l'ancre. Qui le lui avait reproché ? Si l'Allemagne, sans déclarer la guerre, avait laissé les hostilités sortir d'elles-mêmes des mobilisations, ce qui était inévitable, on n'aurait pas pu mettre en doute que l'agresseur était l'État qui avait mobilisé le premier. Le matin du 2 août n'apprit-on pas à Berlin que des Cosaques avaient franchi la frontière dès la veille, donc avant d'avoir pu connaître la déclaration de guerre de l'Allemagne ? (Doc. all. 629).

Le Chancelier répondit avec raison que, puisque d'une part l'Allemagne était stratégiquement obligée de commencer les hostilités par la France, et même de passer par la Belgique, puisque de l'autre les conventions de la Haye imposaient de déclarer la guerre avant de la commencer, il ne voyait pas comment il aurait pu se dispenser de déclarer la guerre. En commençant les hostilités sans la déclarer, il aurait simplement encouru le reproche justifié d'avoir agi déloyalement, et Dieu sait le parti que les ennemis de l'Allemagne en auraient tiré. Cependant, il résolut d'essayer tout au moins, puisque l'entrée de la France dans la guerre ne faisait pas l'ombre d'un doute, de lui laisser la charge de la déclarer. Au lieu d'envoyer à Paris le télégramme de déclaration de guerre qui était tout prêt, qui était irréprochable puisqu'il invoquait les mobilisations russe et française, le refus de la France de se déclarer neutre et sa mobilisation, le danger pour l'Allemagne de laisser à la France le choix du moment de l'attaque, le Chancelier le remit dans son tiroir, et fit porter à l'empereur une note où il disait : « Le Ministre de la guerre et l'état-major estiment qu'il n'y a pas pour le moment de nécessité militaire à remettre une déclaration de guerre à la France. Nous ne l'enverrons donc pas encore, espérant que les Français nous attaqueront » (Doc. all. 629).

Or, que se passait-il au même moment à Paris ? L'Ambassadeur de Russie avait couru, dans la nuit, demander à l'Elysée l'exécution de la promesse, d'ailleurs complètement inconnue de tout le monde en France, que la France avait faite à la Russie d'attaquer l'Allemagne si l'Allemagne attaquait la Russie. «Vous pouvez y compter absolument, répondit le Président, mais puisque tout fait prévoir que l'Allemagne déclarera la guerre à la France, attendons. Il serait préférable que la déclaration de guerre vînt, non de la France, mais de l'Allemagne » (Livre russe authentique, tél. 222).

Quel instructif, quel saisissant dyptique forment ces deux documents, où on voit chacun des deux adversaires «espérer » que l'autre lui déclarera la guerre, afin de pouvoir dire qu'il a été attaqué. Si les soi-disant éducateurs de la démocratie l'étaient vraiment, est-ce qu'ils ne devraient pas, à la place des 
lieux-communs habituels, les publier à chaque anniversaire de la guerre, sous le titre : Ce qu'on appelle une guerre défensive ?

On sait ce qui arriva. La France pouvait attendre, car la Russie était plus lente à mobiliser, et il importait que l'action des armées alliées contre les deux fronts de l'Allemagne fût aussi simultanée que possible. L'Allemagne ne pouvait pas attendre, car elle avait au contraire intérêt à attaquer la France avant que la Russie fut prête. Elle déclara la guerre à la France le soir du 3 août, lui épargnant ainsi la charge d'avoir à la déclarer elle-même.

Mais, comme dans l'intervalle avaient eu lieu des incidents de frontières, le gouvernement de Berlin, qui voulait à tout prix se créer l'alibi de la légitime défense, eut l'idée de les donner comme motifs de sa déclaration de guerre! Sa malchance voulut que certains, comme le fameux survol de Nuremberg par un avion militaire français, aient été, par la suite, reconnus par les Allemands eux-mêmes n'avoir pas eu lieu. Ce survol eût-il été réel que le fait de s'en emparer pour déclarer la guerre n'en eût pas moins été un mensonge. Quand on ne veut pas la guerre, on ne la déclare pas pour des incidents de frontières. On demande des explications à l'autre État.

Puisque l'état de guerre existait en fait depuis le 2 août entre l'Allemagne et la France, ainsi que le constataient nos propres journaux du matin de ce jour, ce mensonge n'eut d'autre conséquence que de fournir aux hypocrites adversaires de l'Allemagne une arme terrible. Ils exploitèrent «l'avion de Nuremberg » avec toute la perfidie et toute la férocité dont sont capables des hommes, quand ils prétendent lutter « pour le Droit». Mais l'histoire retiendra que le Foreign-Office était prêt, s'il n'avait pas eu le meilleur prétexte de la violation de la neutralité belge, à entrer en guerre sous celui que les Allemands avaient, le 31 juillet, installé des mitrailleuses à Pagny en territoire français, ce qui était faux. Et la France a motivé sa déclaration de guerre à l'Autriche sous le prétexte que des troupes autrichiennes avaient été dirigées sur le front allemand de l'ouest ${ }^{1}$, ce qui n'était pas moins faux, et était démenti depuis trois jours par Vienne.

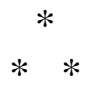

En somme, le gouvernement allemand a tout autant cherché que le gouvernement français à se dire attaqué. A la vérité, il l'a été ; ce sont ses adversaires

1 Documents autrichiens, $\mathrm{III}^{\mathrm{e}}$ partie, $\mathrm{n}^{\mathrm{o}} 175$. Cette déclaration de guerre, qui est du 12 août, est absente du Livre jaune. Pendant douze jours, les deux gouvernements luttèrent à qui ne déclarerait pas la guerre. 
qui, en mobilisant malgré ses avertissements, ont ouvert les hostilités. Mais peut-il dire qu'il était en état de légitime défense ? Non. Si les mots ont un sens, l'état de légitime défense suppose chez la victime la surprise, l'impossibilité de discuter, de se protéger autrement que par l'usage immédiat de la force, l'absence de toute autre raison de se battre, et par conséquent l'absence d'intention de retirer de la lutte un avantage quelconque, sauf celui de sauver sa vie. Le gouvernement allemand ne remplissait aucune de ces conditions. Fut-il surpris par la mobilisation russe ? Non, puisqu'il avait prévenu la Russie que cette mobilisation serait la guerre. Avait-il été dans l'impossibilité de l'éviter par une discussion? Depuis huit jours on ne faisait que discuter, et il aurait évité la guerre s'il avait mis l'Autriche dans l'alternative ou de céder à la Russie, ou de rester seule en face d'elle. N'avait-il d'autre recours que de répondre à la mobilisation russe par la sienne ? Un État peut toujours répondre à une déclaration de guerre, et par conséquent à une mobilisation qu'il préfère céder que se battre. N'attendait-il de la guerre aucun avantage ? Certainement si, autrement il ne s'y serait pas résolu. C'est donc à tort que l'Empereur dit à son peuple, le 4 août : "In aufgedrungener Notwehr, mit reinem Gewissen und reiner Hand ergreifen wir das Schwert. - Acculés à l'état de légitime défense, c'est la conscience et les mains pures que nous tirons l'épée ». Il pouvait peut-être penser, c'est ce que nous allons examiner, que sa cause était juste. Il ne pouvait pas dire qu'il faisait une guerre purement défensive. 


\section{Chapitre IV}

\section{Des gouvernements français et allemand, lequel a le plus exploité le mythe de la légitime défense?}

Quand se réunit à la Haye, en 1907, la seconde Conférence de la paix, où on tenta d'instituer l'obligation de l'arbitrage, on reconnut, et c'est la principale des raisons qui firent échouer le projet, car il devenait dès lors à peu près sans portée, que l'obligation ne pouvait s'étendre aux conflits dans lesquels une puissance estimerait que ses intérêts vitaux étaient en cause. Ainsi non seulement la guerre était alors un droit, mais un État qui y recourait pour la défense d'intérêts vitaux n'encourait aucune réprobation morale. Si les gouvernements de 1914 n'avaient pas été hantés par le souci de se présenter devant leurs peuples en état de légitime défense, ils n'auraient donc eu, pour se justifier d'entreprendre la guerre, qu'à en donner les vraies raisons, et à montrer qu'ils n'auraient pu reculer sans compromettre les intérêts vitaux de leur pays.

Or, dans l'exposé des causes de la guerre placé en tête du Livre blanc distribué au Reichstag le 3 août, il est dit : « De tout cœur nous assurâmes à l'Autriche que l'action, qu'elle jugeait nécessaire pour mettre fin à l'agitation 
dirigée en Serbie contre son existence, aurait toutes nos sympathies. Nous savions bien que, si l'Autriche en venait à des actes d'hostilités contre la Serbie, la Russie descendrait peut-être dans la lice, ce qui nous entraînerait nous-mêmes dans la guerre aux côtés de notre alliée. Mais nous ne pouvions, sachant qu'il s'agissait pour elle de défendre des intérêts vitaux, l'abandonner. Nous le pouvions d'autant moins que nos propres intérêts se trouvaient au plus haut point menacés par les menées de la Serbie... Une Autriche affaiblie n'eût plus été pour nous une alliée sur laquelle nous puissions compter comme nous le devions, étant donné l'attitude de plus en plus menaçante de nos voisins de l'est et de l'ouest. Nous laissâmes par conséquent l'Autriche entièrement libre d'agir à sa guise vis-à-vis de la Serbie ».

Par cette franchise, le gouvernement de Berlin a racheté en partie son tort d'avoir présenté son entrée en guerre comme purement défensive. Il est clair que, s'il était décidé à soutenir par les armes contre la Russie l'action entreprise par l'Autriche contre la Serbie, et s'il prévoyait que cette action pouvait entraîner une guerre entre l'Autriche et la Russie, il ne faisait pas une guerre purement défensive. Un État qui reconnaît avoir risqué la guerre reconnaît qu'il n'a pas fait une guerre purement défensive.

Pourquoi, dans ses déclarations au Parlement, le gouvernement français n'a-t-il pas dit aussi :

"Nous savions bien que, si la Russie en venait à des actes d'hostilité contre l'Autriche, l'Allemagne, qui nous en avait prévenus, descendrait sûrement dans la lice, ce qui nous entraînerait nous-mêmes dans la guerre aux côtés de notre alliée. Mais nous ne pouvions, sachant qu'il s'agissait pour celle-ci de défendre des intérêts vitaux, l'abandonner ». N'est-ce pas parce qu'il lui eût été impossible de montrer en quoi la note de l'Autriche à la Serbie menaçait les intérêts vitaux de la Russie, qui au surplus n'avait aucune obligation contractuelle de soutenir la Serbie, tandis que l'Allemagne était tenue par un traité public de soutenir l'Autriche ? N'est-ce pas aussi parce que, si la Russie en venait à des actes d'hostilité contre l'Autriche, le traité franco-russe ne jouait pas? On s'explique alors qu'il ait préféré ne pas dire un mot de l'appui qu'il avait promis à la Russie, et donner comme cause de la guerre l'agression de l'Allemagne contre « la Russie et la France surprises »!

La manière dont les deux gouvernements ont exploité le mythe de la légitime défense a donc été très différente. Le Français l'a imposé à son peuple dans toute la plénitude de sa stupidité : «Je ne voulais pas la guerre, et ne sais pas pourquoi je la fais, sinon parce qu'on m'a sauté dessus ». Il a traité les Français en crétins, et ils lui ont, hélas, donné raison par leur crédulité. L'Allemand a fait à son peuple l'honneur de penser qu'il ne serait pas tout de même assez bête pour croire qu'un gouvernement fait la guerre sans savoir pourquoi. Et s'il a accusé ses adversaires de l'avoir attaqué, du moins a-t-il 
reconnu qu'il s'était exposé à leur attaque délibérément, parce qu'il croyait de l'intérêt vital de l'Allemagne de leur tenir tête.

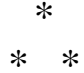

Mais, objectera-t-on, où est la preuve de la sincérité du gouvernement allemand? N'était-il pas manifestement exagéré de dire que l'Autriche était menacée dans son existence par la propagande et les menées pan-serbes ? S'il a mis tant d'ostentation à dire que Vienne et Berlin luttaient pour des intérêts vitaux, n'était-ce pas surtout pour le faire croire ? L'assassinat de l'Archiduc n'aurait-il pas été un prétexte qu'il aurait saisi pour faire éclater la guerre européenne, son but réel étant de devenir le maître de l'Europe ?

Voici des documents qui permettent de raisonner non sur des suppositions, mais sur des réalités. Et d'abord une pièce connue dès le début de la guerre puisque le gouvernement de Berlin, bien qu'elle portât la marque confidentielle, l'a publiée dans le Livre blanc paru le 3 août 1914. C'est la note adressée le 28 juillet par le Chancelier de l'empire allemand aux différents gouvernements allemands, sans l'approbation desquels la guerre ne pouvait être entreprise, pour leur exposer la situation. La conclusion porte en substance : «Si la Russie croit devoir intervenir pour la Serbie, c'est certes son droit. Mais elle en fera un mauvais usage en attaquant l'Autriche, qui défend son existence contre les menées destructives de la propagande pan-serbe, n'entend poursuivre que cette suppression, et a donné l'assurance qu'elle respecterait l'intégrité territoriale de la Serbie. Tandis que l'Allemagne fera un juste usage du sien en soutenant l'Autriche, sans laquelle elle resterait complètement isolée en face de la Triple-Entente. Les deux Empires lutteront pour des intérêts vitaux. Ce n'est pas le cas de la Russie. C'est donc celle-ci, si contre toute attente elle attaque l'Autriche, qui portera la responsabilité de la guerre européenne, à laquelle l'Allemagne ne se résignera qu'à la dernière extrémité, mais la conscience tranquille ».

À moins de soutenir que le Chancelier allemand voulait tromper les gouvernements allemands et les supposait susceptibles de l'être, on avouera que s'il leur exposait ainsi les raisons pour lesquelles l'Allemagne pouvait se trouver entraînée dans la guerre, c'était celles-là et pas d'autres, et qu'il croyait vraiment que l'Allemagne avait des intérêts vitaux en jeu. Reste à savoir, pour apprécier sa responsabilité morale, si c'est avec satisfaction ou regret qu'il a vu la guerre s'offrir à lui. 
Voici d'autres documents qui permettent de répondre à cette question. Mais comme ils sont beaucoup moins connus, font partie de collections assez peu répandues et que leur volume empêche de l'être, on en reproduira ici, par exception, des passages assez longs.

Le gouvernement autrichien a publié, l'année dernière, les archives diplomatiques de l'ancien Empire austro-hongrois, pour la période allant de 1908, année de l'annexion à la Bosnie, à l'explosion de la guerre européenne. Au cours d'une lettre du 2 juillet 1909, le chef d'état-major général Conrad de Hœtzendorf avait exprimé au Ministre des affaires étrangères Aerenthal une sorte de regret qu'en présence de l'opposition violente qu'avait faite la Serbie à cette annexion, le gouvernement impérial n'ait pas saisi l'occasion de faire à la Serbie une guerre qu'il faudrait faire tôt ou tard. Dans un long rapport du 15 août suivant, remis à l'Empereur, à l'héritier présomptif, au Ministre de la guerre et au chef d'état-major général, le Ministre des affaires étrangères, après avoir rappelé que la question de savoir si une guerre est opportune ou non est du ressort non des militaires, mais des diplomates, passe en revue la politique extérieure des différentes puissances, et expose celle de la Doublemonarchie.

«Elle doit, dit-il, maintenant que la crise dite de l'annexion a été résolue pacifiquement, être une politique de recueillement, qui exclut tout projet d'agrandissement aux dépens des Slaves des Balkans. Cette politique est en plein accord avec celle de l'Allemagne, notre plus naturel, notre plus sûr allié. Il ne faut pas perdre de vue que l'Empereur Guillaume est un souverain éminemment pacifique, et désire entretenir avec toutes les grandes puissances les relations les plus amicales. Une orientation impérialiste de notre politique ne trouverait pas auprès de lui et de son peuple le même appui chaleureux que dans l'hiver dernier, et y éveillerait peut-être même un sentiment de jalousie.

La situation politique dans et hors de l'Europe est dominée par la rivalité économique et politique entre l'Angleterre et l'Allemagne. Mais bien des circonstances s'opposent à ce qu'elle se traduise par la guerre. D'abord on peut penser que la France et la Russie se refuseraient à tirer les marrons du feu pour l'Angleterre. D'autre part l'Empereur Guillaume est un trop grand admirateur du génie du peuple anglais pour se décider sans des raisons impérieuses à une entreprise susceptible d'avoir pour l'Allemagne les conséquences les plus graves. Enfin il est possible que, pour faire contre-poids aux ententes douanières que l'Angleterre tend à conclure avec ses colonies ou avec les États-Unis, il se fasse une Union économique des États continentaux, en première ligne de ceux de la Triple alliance et peut-être même de la France, union qui ne pourrait être qu'un facteur de paix.

Si la monarchie a besoin d'une forte armée, ce n'est pas pour résoudre par une guerre préventive des conflits qui peuvent devenir aigus plus tard, mais 
seulement pour défendre l'honneur et l'intégralité de l'Empire, ou des intérêts vitaux qui ne pourraient l'être par des moyens pacifiques $»\left(n^{\circ} 1.720\right)$.

Ce n'est pas là le langage d'un « gouvernement de proie ». Et si sévèrement qu'on juge son action contre la Serbie en 1914, l'honnêteté force à admettre que, s'il a alors préféré la guerre à la paix, c'est qu'il a cru de bonne foi qu'il y allait de ses intérêts vitaux, et qu'ils ne pouvaient être protégés par des moyens pacifiques.

Au cours de l'automne de 1912, dans des circonstances que tout le monde connaît, de graves difficultés s'élèvent de nouveau entre la Serbie et l'Autriche, qui envisage alors l'éventualité de la guerre. Mais l'Allemagne la retient, ainsi qu'il ressort de documents contenus dans le grand recueil des archives diplomatiques allemandes de 1871 à 1914. Le 9 novembre 1912, l'Empereur Guillaume précise à son Ministre des affaires étrangères, dans une note de sa main, comment il comprend l'alliance austro-allemande : «La Serbie veut une sortie et un port sur l'Adriatique, l'Autriche s'y oppose. La Russie semble soutenir la prétention serbe ; il peut en résulter qu'elle attaque l'Autriche. C'est alors le casus foederis pour l'Allemagne, c'est-à-dire la mobilisation et la guerre sur deux fronts, c'est-à-dire, avant de marcher sur Moscou, la nécessité de prendre d'abord Paris, qui sera sans doute soutenu par Londres. Ainsi l'Allemagne entrera contre trois grandes puissances dans une lutte où elle risquera tout, même son existence, et où elle peut être écrasée. Tout cela, parce que l'Autriche ne veut pas voir les Serbes en Albanie ou à Durazzo. Ce n'est pas pour une pareille guerre que l'Allemagne a donné sa parole, que le peuple allemand s'enflammera, etc., etc. » ( $\left.n^{\circ} 12.349\right)$.

Le 10 février 1913, le Chancelier Bethmann-Hollweg, dans une lettre privée au Ministre des affaires étrangères autrichien, dit: «Au cas où l'Autriche entrerait en conflit avec la Serbie, il faut compter comme certain que les forces qui se tiennent derrière la meute panslaviste l'emporteraient. Un examen objectif conduit à la conclusion qu'étant données les relations traditionnelles de la Russie avec les États balkaniques, il lui serait presque impossible de rester, sans une perte considérable de prestige, indifférente à une action militaire de l'Autriche contre la Serbie. Les partisans d'une politique pacifique comme Sazonow et Kokovtzov seraient emportés par le courant de l'opinion publique, s'ils voulaient s'y opposer. Une intervention russe conduirait à un conflit entre la Triplice, où l'Italie ne figurerait qu'avec un enthousiasme très relatif, et la Triple-Entente. L'Allemagne y porterait tout le poids d'une attaque française et anglaise $\gg\left(n^{\circ} 12.818\right)$.

Le lendemain 11, le chef de l'état-major général allemand Moltke mit aussi son collègue autrichien Conrad en garde contre les risques d'une guerre qui ne serait pas absolument justifiée : «Votre Excellence sait très bien qu'une guerre dans laquelle se joue l'existence d'un État exige le sacrifice volontaire 
et l'enthousiasme du peuple. Le sentiment de la fidélité à son alliée l'Autriche est certainement vivace en Allemagne, et se manifesterait avec une force élémentaire, si l'existence de l'Autriche était menacée par une attaque russe. Il en serait autrement si l'Autriche provoquait une guerre dont la cause ne serait pas complètement comprise par le peuple allemand. Je continue à croire que surviendra tôt ou tard une guerre européenne, qui sera en dernière analyse un combat entre le slavisme et le germanisme. Mais l'attaque doit venir des Slaves. Et pour cette guerre, il faudra l'union de toutes les forces, l'utilisation de toutes les chances, la complète intelligence par les peuples de son importance pour l'histoire du monde $\gg\left(\mathrm{n}^{0} 12.824\right){ }^{1}$.

De ces documents il résulte que les trois hommes, dont dépendait principalement la politique extérieure et militaire de l'Allemagne, considéraient qu'une guerre contre la Russie serait aussi une guerre contre la France et l'Angleterre, c'est-à-dire une guerre où l'Allemagne pourrait succomber, donc que l'Autriche devait, à moins de pouvoir invoquer la défense d'intérêts vitaux et d'avoir manifestement tout le droit pour elle, s'abstenir d'engager contre la Serbie une action susceptible d'entraîner une intervention de la Russie.

Ces trois hommes étaient encore au pouvoir en juillet 1914. C'est eux qui, en donnant carte blanche à l'Autriche contre la Serbie, ont délibérément risqué contre la Russie et ses alliées la guerre même qu'ils redoutaient. Elle n'était pas devenue moins redoutable. C'est donc bien la situation créée par le drame de Serajevo qui a produit leur revirement. Ils ne désiraient pas plus la guerre qu'un an avant, mais ont cru que cette fois l'Autriche était vraiment en danger si elle ne maîtrisait pas la Serbie, et que le sort de l'Allemagne était lié à celui de l'Autriche. Le 18 juillet, le Ministre des affaires étrangères Jagow disait dans une lettre particulière à l'Ambassadeur d'Allemagne à Londres : " Notre alliance avec cette puissance, qui apparaît de plus en plus en décomposition, est-elle de notre avantage ? Cela peut se discuter. Mais pour changer d'ami, il faut en trouver un autre ». Et dans cette lettre de trois pages il lui expose, avec une sorte de résignation fataliste, pourquoi l'Allemagne, si on la lui impose, devra accepter la guerre, plutôt que d'abandonner l'Autriche. Le 29, le chef d'état-major général Moltke, dans une note émouvante, montre au Chancelier comment la Russie va provoquer la guerre en se donnant les apparences d'être attaquée : «Cette guerre anéantira la civilisation européenne pour un siècle », dit-il. Mais, dans la conviction que tout le droit, tout le devoir sont cette fois de leur côté, il estime que l'Allemagne n'a pas autre chose à faire que de soutenir l'Autriche. Quant au Chancelier, à mesure que les événements se

On sait par les documents russes qu'à la même époque le chef du gouvernement et le ministre de la guerre français, M. Poincaré et M. Millerand, dans leurs entretiens avec l'Ambassadeur de Russie et l'attaché militaire russe, s'étonnaient que la Russie parût hésiter à en venir aux mains avec l'Autriche, et ne cessaient de l'assurer que, dans ce cas, elle pouvait compter sur l'appui de la France dès que l'Allemagne entrerait en lice. C'est un fait établi, et qu'on ne peut cacher sans malhonnêteté, que dans cet automne critique de 1912, les Allemands retenaient les Autrichiens, et que les Français excitaient les Russes. 
précipitent, il s'abandonne lui aussi à la fatalité : «L'avalanche s'est ébranlée » répète-t-il.

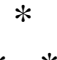

On ne peut donc pas dire que le drame de Serajevo a été un prétexte sur lequel a sauté le gouvernement allemand pour déchaîner une guerre que, suivant la formule consacrée, « il préparait depuis quarante ans ». Ce drame a au contraire été la raison pour laquelle il a risqué une guerre qu'il avait jusquelà tout fait pour éviter. Et c'est le sentiment que les intérêts vitaux de l'Autriche, et par contre-coup ceux de l'Allemagne, venaient d'être mis en jeu, qui lui a fait prendre le 3 août, à la face du monde, la responsabilité d'avoir promis l'appui de l'Allemagne à l'Autriche contre la possibilité d'une intervention russe.

Son tort, si c'en est un, est d'avoir sous-estimé cette possibilité. Il a cru que la Russie n'irait pas se ranger du côté des régicides. Dans la note du 21 juillet par laquelle il exprimait aux trois puissances de l'Entente l'espoir qu'elles n'interviendraient pas dans le conflit austro-serbe, il avait ajouté, à l'exemplaire destiné à la Russie, un paragraphe où il était fait appel au sentiment monarchique ; cet argument revient fréquemment dans sa correspondance, surtout sous la plume de l'Empereur. Il croyait aussi que la Russie, où était en chantier un grand programme militaire dont l'exécution ne devait être terminée qu'en 1917, que la France, où la loi de trois ans n'avait pas encore fait son plein effet, et venait d'être désapprouvée par la majorité des électeurs, ne risqueraient pas la partie. Il croyait que l'Angleterre, avec laquelle les rapports étaient alors bons, n'irait pas faire la guerre pour cette dynastie serbe née d'un autre assassinat, et que le gouvernement de Londres n'avait reconnue qu'avec tant de répugnance.

Ici encore il est nécessaire de citer quelques documents, mais très brefs, et qui n'étaient assurément pas non plus destinés à la galerie. Le 16 juillet, le Chancelier écrivait au représentant impérial en Alsace-Lorraine : «Nous avons des raisons de supposer que, comme nous le désirons, la France, actuellement accablée de préoccupations de toutes sortes, fera tout pour détourner la Russie d'une attaque »(Doc. all. 58). Le 18, le Ministre de Bavière à Berlin écrivait à son gouvernement : «A moins qu'elle ne veuille la guerre à tout prix, la Russie n'ira pas couvrir de sa protection une politique qui consiste à lancer des bombes et à tirer des coups de revolver. La France et l'Angleterre agiront dans un sens pacificateur. La Russie menacera peut-être, mais ne tirera 
pas l'épée ». Le 27, il écrit : «La France fera tout son possible pour détourner la Russie de toute "action guerrière ». Le 28 : «Il n'est pas douteux que la France et l'Angleterre interviendront énergiquement à Pétersbourg en faveur de la localisation du conflit austro-serbe (Id. Annexe IV, 2, 11, 12). Les premières communications reçues de Paris et de Londres après la remise de la note autrichienne à Belgrade avaient confirmé le gouvernement allemand dans cette croyance (id., 154, 235, 374), et le Chancelier avait télégraphié le 25 juillet à l'Empereur, alors en croisière : "À Paris et à Londres, on travaille activement à la localisation du conflit » (id., 191). Cet état d'esprit était connu. Le 29, l'Ambassadeur de France à Rome télégraphiait : "Le Ministre des affaires étrangères m'a dit que malheureusement la conviction de l'Autriche et de l'Allemagne avait été et est encore que la Russie ne marcherait pas » (Livre jaune, p. 96).

Si cependant, la Russie «voulait la guerre à tout prix », si ses alliées saisissaient une si immorale occasion de déchaîner la guerre européenne, alors c'est qu'elles voulaient la peau de l'Allemagne, et saisiraient un autre prétexte dès qu'il s'offrirait. Alors mieux valait pour l'Allemagne se résigner à la guerre maintenant, que d'attendre le moment où la disproportion des forces entre les deux camps se serait encore accentuée. Et le destin de l'Allemagne s'accomplit.

Il est facile, et c'est vrai en partie, de dire aujourd'hui que cette politique fut celle de Gribouille, qui se jetait à l'eau pour éviter la pluie. Mais elle n'était pas sans excuse. Il y a une phrase qui revient constamment dans les explications que donnent les hommes d'État autrichiens et allemands de leur attitude dans la crise : "La propagande panserbe menaçait l'empire austrohongrois dans son existence ». Elle n'avait pas été imaginée pour la galerie. Un an déjà avant la guerre, dans de longues instructions secrètes à l'ambassadeur d'Allemagne, le Ministre des affaires étrangères autrichien exposait les appréhensions que lui causait la politique serbe : «Elle touche au plus près nos intérêts vitaux, disait-il ; sa solution dans le sens grand serbe serait de nature à mettre en question nos conditions d'existence » (Doc. aut., $\mathrm{n}^{\circ}$ 8.157). Aujourd'hui qu'on connaît les dessous de la politique russo-serbe d'avantguerre, dont il ne devait pas tout ignorer, on ne peut pas dire qu'il se soit exagéré le danger. Qu'après le drame de Serajevo, son allié ait fini aussi par y croire, c'est au moins compréhensible.

C'est pourquoi Berlin ne s'est pas contenté de plaider la légitime défense. Croyant à la bonté de sa cause, il a loyalement dit au Reichstag (trop tard il est vrai, mais la constitution de l'Empire ne l'obligeait pas à le consulter) qu'il avait résolu de risquer la guerre plutôt que d'abandonner l'Autriche. Il a donc moins trompé son peuple que le gouvernement républicain français qui, ne pouvant sérieusement soutenir qu'il faisait la guerre pour l'existence de la Russie, et ne voulant pas dire qu'il la faisait pour prendre sa revanche de 1870, 
est parti en guerre sans consulter le Parlement, lui a caché ses promesses d'appui à la Russie, et a tout mis sur le compte de la légitime défense.

Mais la franchise du gouvernement allemand a été retournée contre lui. Depuis M. Hanotaux au début de la guerre jusqu'à M. Poincaré dans ses dernières publications, on a pris texte ici de ces délibérations du Chancelier allemand pour dire qu'on avait l'aveu, signé de lui, de la responsabilité de l'Allemagne, comme si cette responsabilité excluait celle de ses adversaires. En Allemagne, on l'a accusé de sottise. Dans le troisième volume de ses Mémoires, le prince de Bulow fait dire à la reine douairière d'Italie, en 1915, que «si les gouvernants allemands de 1914 n'avaient pas voulu la guerre, ils étaient les plus gros ânes que le monde ait jamais vus ». Alors on songe à la fable des Animaux malades de la peste.

Mais parlons sérieusement. Ce qu'il faut retenir de ce chapitre, c'est ceci. Si sévèrement qu'on juge l'Allemagne, on ne peut, si on la juge justement, l'accuser, pour employer les formes du traité de Versailles, «d'être seule responsable de la guerre par son agression ». Si désireux qu'on puisse être d'absoudre la France, on ne peut dire qu'elle n'est entrée en guerre « qu'à cause de cette agression ». Mais le gouvernement français, qui employa à fond l'argument de la légitime défense, fut déclaré innocent. Le gouvernement allemand, qui reconnut avoir risqué la guerre, fut déclaré coupable. La leçon ne sera pas perdue. Le mensonge total sera plus que jamais une nécessité de la guerre moderne. Les intérêts vitaux eux-mêmes ne seront plus une justification. Une seule comptera : c'est l'autre qui a commencé. Et personne ne saura qui a commencé. 


\section{Chapitre V}

\section{Le mythe de la légitime défense pendant la guerre}

On a peut-être remarqué que, dans sa note du 28 juillet aux gouvernements allemands, le Chancelier impérial avait reconnu que, si la Russie attaquait l'Autriche pour soutenir la Serbie, « ce serait certes son droit». Puisque la guerre était alors légale, honorée, l'ultime moyen de régler les conflits internationaux quand l'irréductibilité des prétentions rivales ne permettait pas une solution pacifique, puisqu'en vertu de sa souveraineté, un État était seul juge de la légitimité des raisons pour lesquelles il recourait à la guerre, chaque camp était en effet dans son droit en y recourant. Si la guerre était un droit, l'État qui la provoquait, la déclarait ou la commençait en était, suivant les circonstances, plus ou moins responsable, il n'était pas un coupable. Le gouvernement qui se prétendait attaqué pouvait bien dire à son peuple qu'il était innocent de la guerre, mais il ne pouvait pas accuser l'État adverse d'en être coupable, car on n'est pas coupable d'exercer un droit.

Le gouvernement allemand, tout en attribuant à ses adversaires l'ouverture des hostilités, se garda donc de les outrager. Dans sa déclaration de guerre à la Russie, après avoir constaté que «la Russie avait refusé de suspendre sa 
mobilisation contre l'Allemagne », il disait simplement : «L'Allemagne relève le défi ». Ses déclarations au Reichstag furent empreintes de la même modération. «C'est le cœur oppressé, dit l'Empereur, que j'ai dû me résigner à mobiliser contre la Russie, avec laquelle l'Allemagne était liée par une longue amitié. Cédant à la poussée d'un nationalisme insatiable, cet État a pris fait et cause pour un gouvernement qui, par la protection qu'il a accordée à des complots criminels, a provoqué la catastrophe de cette guerre. Quant à la France, nous ne pouvons être surpris de la voir aux côtés de notre adversaire. Trop souvent, nos efforts pour établir avec la république française des relations plus amicales se sont heurtés à des espérances et à une rancune qui ne voulaient pas désarmer ».

Tout autre fut l'attitude du gouvernement français. On vit tout de suite que, s'il avait manœuvré de façon à se faire déclarer la guerre, c'était pour faire, de sa prétendue innocence et du prétendu crime de l'Allemagne, le pivot de toute sa politique de guerre. Relisez l'exposé des causes de la guerre fait aux Chambres le 4 août, et qui restera le modèle inégalable du mensonge dit patriotique. La fausseté maîtresse, autour de laquelle gravitent toutes les autres, est que la déclaration de guerre de l'Allemagne a «surpris » la Russie et la France pacifiques. «La conduite de l'Allemagne a été un insolent défi au droit des gens, elle a déclaré subitement la guerre à la Russie, elle a essayé de surprendre traîtreusement la France en pleine conversation diplomatique », dit le chef de l'État dans son message. «La France pacifique est obligée de défendre sa frontière contre une agression dont la soudaineté calculée souligne l'odieuse injustice », dit le chef du gouvernement dans son discours. S'il avait dit la vérité, il aurait dit : «L'Allemagne avait prévenu dès le 26 juillet la Russie qu'elle riposterait à une mobilisation russe par la guerre à la Russie et à la France. Ses déclarations de guerre nous ont d'autant moins surpris que nos préparatifs de mobilisation avaient commencé ce même 26 juillet, et que notre mobilisation générale était ordonnée depuis quarante-huit heures ; elle n'a fait que devancer celle que nous aurions dû adresser à l'Allemagne pour remplir la promesse d'appui que nous avions faite à la Russie ». Je défie qu'on trouve dans l'histoire un autre exemple d'un État qui ait été plus injustement accusé d'agression traîtresse.

C'est ainsi que commença, en même temps que la guerre au canon, une guerre de plume, non moins implacable, qui allait exploiter inlassablement ce thème : la guerre faite par l'Allemagne est criminelle parce qu'agressive, et la guerre faite par les Alliés est sainte parce que défensive. Tous les mensonges qui allaient inonder la terre découlent en effet de ce postulat, qu'on fortifia en forgeant de faux documents diplomatiques. N'était-il pas naturel que le droit, la liberté et la civilisation fussent du côté des États qui ne faisaient que se défendre, et la barbarie du côté de celui qui les avait attaqués à l'improviste ? Cette guerre prodigieuse, où se mêlaient toutes les races, toutes les passions, tous les intérêts, qui avait ses racines dans un demi-siècle de l'histoire de 
l'Europe et du monde, fut ainsi ramenée aux proportions d'un fait divers, au crime de l'apache (le mot a-t-il assez servi!), qui se jette sur un passant inoffensif. Je demandai un jour à un soldat nègre, dans l'ambulance dont je m'occupais, pourquoi il se battait : «Méchant Guillaume », me répondit-il. Les blancs n'en savaient pas davantage. Le mensonge de l'agression de l'Allemagne répondait à tout. Il n'avait pas seulement été la pilule destinée à faire digérer l'ordre de mobilisation; il fut la drogue qui devait hébéter les peuples pour la durée de la guerre, ou, pour employer la savoureuse expression des empoisonneurs, soutenir « leur moral ». Car, puisque seule l'Allemagne avait voulu, donc seule préparé la guerre, comment en imputer les horreurs, les atrocités, à d'autres qu'à elle ? De déductions en déductions, il fut entendu une fois pour toutes, suivant l'expression de l'homme d'État français qui était chef du gouvernement en juillet 1914, que cette guerre était « la lutte de toutes les forces rayonnantes du bien contre les puissances ténébreuses du mal », ou, comme le disait avec plus de simplicité le Président de la république d'alors, que l'Allemagne était « l'ennemie du genre humain ».

Contrairement au principe si sage et si humain de Rousseau, dans son Contrat social (Livre I, chap. IV), « que la guerre n'est point une relation d'homme à homme, mais d'État à État, dans laquelle les particuliers ne sont ennemis qu'accidentellement, non point comme hommes, ni même comme citoyens, mais comme soldats », ces anathèmes s'étendaient en effet à toute la population allemande. On fit le serment de ne plus avoir avec les Allemands aucun commerce intellectuel, disaient les uns, ni même matériel, disaient les autres ${ }^{1}$; on ne devait plus s'asseoir à une table où il y en avait un. On ne les approcherait plus que pour toucher, probablement avec des pincettes ou des gants, le tribut d'expiation auquel ils seraient condamnés à perpétuité. On trouvait même dans un grand journal anglais le souhait qu'on tuât assez d'Allemands pour qu'un Allemand devint en Europe un animal féroce aussi rare qu'un serpent ou un tigre. C'est probablement dans cet espoir qu'un grand journal français demandait qu'on égorgeât les prisonniers. Mais il est aussi impossible de représenter le degré d'ignominie atteint par la propagande de guerre que de représenter l'infini. Ce qu'il faut avoir toujours présent à l'esprit, c'est que cette propagande reposait sur l'axiome liminaire que les Alliés menaient une guerre exclusivement défensive. Le moindre doute à cet égard, et elle n'était pas possible. Aussi, alors que d'autres fourberies furent plus ou moins abandonnées, - celle-ci ne le fut jamais.

On sait par exemple que le gouvernement anglais prétendit n'être entré dans la guerre que pour défendre deux choses : la France attaquée sans raison (wantonly attacked), et le traité qui faisait de la Belgique un État conventionnellement neutre. Il affecta de croire que jusqu'alors on n'avait jamais

Voir dans La mobilisation des consciences le Non possumus de M. LAVISSE et les pages 133-139. 
violé un traité, et qu'il avait fallu le vampire allemand pour consommer un pareil attentat. Le 6 août 1914, le premier Ministre affirmait avec l'accent d'une absolue sincérité que l'Angleterre entrait dans cette guerre, non par intérêt, mais uniquement pour défendre «the sanctity of the treaties ». Mais, dès le 8 mars 1915, le Times s'étonnait qu'il y eut encore tant d'Anglais pour croire cette histoire, et demandait qu'on reconnût enfin que l'Angleterre se battait, non pour les autres, mais pour elle, qu'elle se battait contre l'Allemagne comme elle s'était battue contre l'Espagne, la Hollande, la France, la Russie : pour le maintien de l'équilibre européen auquel ses intérêts restaient indissolublement liés. Il n'eût pas été plus difficile de renoncer à la légende de l'agression de l'Allemagne. Elle resta inexpugnable.

Puisqu'ils prenaient le ciel et la terre à témoins qu'ils avaient tout fait pour éviter la guerre et ne se battaient que pour se défendre, les gouvernements de l'Entente furent également amenés à dire qu'ils faisaient cette guerre sans merci par amour de la paix. Cette Russie tentaculaire, cette France de Louis XIV et des Napoléons, cette Angleterre qui faisait avec tant de raison graver sur ses canons Ubique, se transformèrent tout à coup en paladins du pacifisme. Ils avaient des chants nationaux encore plus orgueilleux que ceux de l'Allemagne, on ne sait combien de monuments érigés au souvenir de leurs guerres, comme l'Allemagne, étaient entrés dans cette guerre armés jusqu'aux dents, comme l'Allemagne, avaient le même culte de leurs généraux et de leurs amiraux que l'Allemagne, des académiciens employés à célébrer les vertus de la guerre comme en Allemagne, et pendant quatre mortelles années de carnages sans nom, eurent le triste courage d'affirmer inlassablement : « Dieu, nous te rendons grâce de ne pas nous avoir fait semblables à ce vil publicain ». Voilà où peut conduire le mythe de la légitime défense !

Certes les Allemands se défendirent aussi d'avoir voulu la guerre, se firent plus innocents qu'ils n'étaient. Pas plus sur ce terrain que sur celui des responsabilités on ne prétend, et pourquoi le prétendrait-on, innocenter les Allemands. Mais ici encore la vérité oblige à dire qu'ils ne firent que riposter. Quand ils se virent accusés d'être seuls responsables de la guerre, puis sous ce prétexte outragés comme jamais peuple ne le fut, traînés aux gémonies devant le monde entier, comment n'auraient-ils pas renvoyé leurs accusations aux accusateurs ? A-t-on assez flétri le fameux manifeste des Quatre-vingt-treize illustres intellectuels allemands : «Il n'est pas vrai que, etc. ». Mais était-il vrai que... ? Et pourquoi les intellectuels allemands seraient-ils restés «audessus de la mêlée », alors que les plus vénérés de nos grands professeurs les accusaient sans relâche de «mentir comme ils respiraient», d'avoir « fait du mensonge leur principale industrie », tout en mentant eux-mêmes chaque jour beaucoup plus qu'eux ${ }^{1}$.

1 Cf. La mobilisation des consciences. On y trouvera les textes et les noms. 


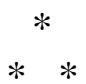

Ici on m'objectera peut-être que je suis illogique. Le mensonge de la légitime défense avait pour but de gagner la guerre. Or, puisqu'en 1914 la guerre était licite, les mensonges faits pour son succès l'étaient aussi. Le droit de tuer ne renferme-t-il pas celui de mentir ? C'était des mensonges pieux, faits pour la Patrie, m'ont dit les hommes les plus respectables.

Je réponds qu'un procès est aussi chose licite. Cependant personne ne soutiendra qu'une des parties peut pieusement gagner son procès en accumulant contre l'adversaire les mensonges et les pièces fausses, en lui attribuant tous les torts, ceux qu'on a soi-même. Pourquoi serait-ce pieux dans une guerre ? Sur les drapeaux de nos régiments et sur la dunette de nos navires de guerre flamboie cette devise : Honneur et Patrie. C'est donc que la guerre doit être faite avec honneur. Si elle ne peut pas être faite avec honneur, ces inscriptions ne sont que de la farce.

Si encore ces mensonges ne nuisaient qu'à l'ennemi! Mais ils ne nuisent pas moins aux peuples dans le prétendu intérêt desquels on les fait, puisque leur but est de les amener à supporter les souffrances, les horreurs d'une guerre dont ils n'auraient pas voulu s'ils avaient su la vérité. Si c'est là un mensonge pieux, on voudrait bien savoir ce qu'est un mensonge impie.

«Le propre du militaire, disait Figaro du soldat de son temps, c'est de se battre pour des intérêts qu'il ignore ${ }^{1} \gg$. Le mercenaire n'avait pas en effet à se demander si la guerre était offensive ou défensive. Mais aujourd'hui la guerre est faite par le soldat-citoyen, phénomène né de l'accouplement du suffrage universel et de la conscription. Pour décider le citoyen à consentir comme souverain à la guerre où il laissera ses os comme soldat, on le pousse à la frontière en lui disant qu'il est attaqué. Allez, enfants de la Patrie! Mais quelles sont donc les premières victimes du mensonge patriotique, sinon les enfants de la Patrie?

Finalement, quand l'Allemagne eut été vaincue, les Alliés, toujours acharnés à l'accuser d'être « seule responsable de la guerre par son agression », ne trouvèrent rien de mieux que de l'obliger, sous menace de recommencer la guerre et malgré ses protestations désespérées, à l'avouer dans le traité de paix. Il y avait alors «chose jugée ». Tout a été dit sur cette effronterie judiciaire

1 Le Mariage de Figaro, de Beaumarchais. 
dont l'histoire n'offre pas d'exemple ${ }^{1}$. On n'en tirera ici que quelques réflexions qui achèveront de juger la thèse de la guerre défensive.

«Vous êtes ici devant vos juges, pour répondre du plus grand crime de l'histoire », dit Clemenceau aux délégués allemands, en les recevant à la Conférence de la paix. En quoi étaient-ils plus criminels que leurs juges ? Estce que ceux-ci ne venaient pas de la faire, eux aussi, la guerre ? Est-ce que ce sadique vieillard de Clemenceau, depuis qu'il était au pouvoir, n'avait pas continuellement à la bouche, pour s'excuser de tout : Je fais la guerre ? La différence était donc bien toujours la même que le 4 août 1914 ; le crime de l'Allemagne c'était de l'avoir déclarée. Or l'Allemagne n'avait déclaré la guerre que parce qu'elle y avait été matériellement provoquée par la mobilisation russe, et si même elle l'avait déclarée sans provocation, elle n'aurait commis aucun crime puisque la guerre était un droit. Où était son crime particulier?

Le 27 juillet 1916, l'Ambassadeur des États-Unis à Londres eut avec le Ministre des Affaires étrangères d'Angleterre un entretien sur les divergences de vues qui existaient alors entre les deux gouvernements. L'une venait de ce que le Président Wilson avait dit, dans un de ses discours, que les causes et les buts de la guerre ne le regardaient pas. Grey dit à Page : «Parmi les conditions de paix à imposer à l'Allemagne, mon intention est de comprendre la suivante. La question : Qui a commencé la guerre et en porte la responsabilité ? sera soumise à une Commission neutre. Toutes les puissances belligérantes devront lui remettre leurs documents et autres pièces probantes. La décision sera bien entendu publiée $»^{2}$. Or, le 27 novembre 1918, c'est à dire dans le mois même de l'armistice, le gouvernement allemand proposa à ses vainqueurs, par l'intermédiaire de la Suisse, de soumettre la question des responsabilités à une Commission neutre, la solution de cette question «lui paraissant la condition essentielle d'une réconciliation des peuples ». Mais il n'y avait plus de Wilson à convertir à la guerre du Droit. La Commission neutre, ce fut l'assemblée des vainqueurs encore fumants de la terrible lutte. Et Lloyd George eut l'aplomb de dire aux Communes : « Je demande à n'importe qui de montrer un point où une Cour impartiale n'aurait pas statué comme le Traité » (3 juillet 1919).

Ce tribunal de carnaval était surtout composé d'États qui avaient euxmêmes déclaré la guerre : l'Angleterre, le Japon, l'Italie, la Roumanie, les États-Unis, etc., etc. Mais ils se considéraient comme de vaillants gendarmes accourus au secours des victimes du guet-apens de l'Allemagne. Leurs déclarations de guerre, loin d'être criminelles, étaient saintes. On comprend qu'avec

1 Voir La mobilisation des consciences : troisième partie, le chapitre II qui lui est consacré.

2 Extrait des documents officiels publiés en 1930 par le gouvernement des États-Unis sur leur politique extérieure en 1916. Reproduit dans la revue allemande Berliner Monatshefte fur internationale Aufklärung de janvier 1931. 
une pareille élasticité, le mythe de la guerre défensive soit si apprécié des gouvernements.

On retrouve aussi le nom de ces juges intègres sur la liste des auteurs des guerres qui avaient précédé la guerre européenne : la Serbie, l'Italie, la France, la Russie, l'Angleterre, les États-Unis, le Japon. Pourquoi n'avait-il pas été, eux aussi, jugés ? Sans doute ces guerres furent petites à côté de la guerre européenne. Mais, si effrontés que fussent les gouvernements russe, français et anglais, ils ne pouvaient cependant pas nier que, sans leur intervention, il n'y aurait eu en 1914 qu'une insignifiante guerre austro-serbe, ou plutôt pas de guerre du tout. Il est établi que, sans la promesse formelle d'appui de la Russie, la Serbie aurait accepté la note autrichienne. Si les empires centraux avaient à répondre d'une guerre austro-serbe, les États de l'Entente devaient répondre de sa transformation en guerre européenne. Ils auraient donc dû être au banc des accusés. Mais ils escaladèrent l'estrade du tribunal, et s'érigèrent en juges, en juges de leurs adversaires, à qui ils fermèrent la bouche !

«Quand on a vu ça, a écrit Dupin, c'est comme après le bouquet du feu d'artifice, il n'y a plus qu'à aller se coucher ». Boutade d'une expressive vérité ! Quand on a vu ce que peut donner le mythe de la légitime défense aux mains des États modernes, on peut dire qu'on a vu l'hypocrisie, la bêtise et la méchanceté humaines à leur apogée. 


\section{Chapitre VI}

\section{Le mythe de la légitime défense de l'après-guerre}

\section{$\underline{\text { Retour à la table des matières }}$}

Après une guerre générale, les gouvernements songent toujours à faire jouir leurs peuples d'une paix éternelle. On ne fait la guerre, n'est-ce pas, que pour avoir la paix. Plus une guerre a été sanglante, plus la paix doit être durable. Les vainqueurs de 1919 ont d'autant moins manqué à cette heureuse tradition que le spectre de la guerre aérienne et chimique, la probable difficulté de trouver désormais des souscripteurs aux emprunts de guerre, leur faisaient une obligation particulière de la suivre. Depuis dix ans, l'organisation de la paix est devenue leur principale industrie. Mais sur quelle base veulentils fonder la paix ? On peut à peine le croire : sur cette même distinction entre les guerres agressives et les guerres défensives, qui leur a servi à justifier cinquante-deux mois de carnage.

La Société des Nations a en effet introduit dans son pacte constitutif cet article : «Les membres de la Société s'engagent mutuellement à protéger leur intégrité territoriale et leur indépendance politique contre toute agression de l'extérieur. Dans le cas ou devant la menace d'une telle agression, le Conseil avisera aux moyens de remplir cet engagement ». À la session de 1927, la 
Société a solennellement condamné « toute guerre d'agression ». Certains, surtout en France 1, veulent même doter la Société des Nations d'une armée qui lui permettrait de châtier l'agresseur ; il faut «lui donner des dents », disent-ils. Avouons qu'ils sont logiques. Du moment qu'on assimile la guerre à l'agression d'un homme inoffensif par un malfaiteur, il faut des gendarmes pour mettre la main au collet de l'État agresseur. Mais c'est précisément cette assimilation qui est absurde.

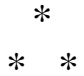

Et d'abord parce que, nous le savons, l'État qui prend matériellement l'initiative d'une guerre n'est pas forcément un criminel, n'est pas forcément l'État qui doit en supporter la responsabilité. Si pacifiste qu'on soit, et je dirai même plus on est pacifiste, plus on doit tenir compte de cette constatation de l'expérience et de la raison, parce que le vrai pacifisme consiste non pas à imaginer un système de paix à tout prix, mais à faire régner entre les nations la justice, sans laquelle il n'y a pas de paix possible.

J'ai lu sous la plume d'un Américain ${ }^{2}$ cette judicieuse réflexion que, sous le régime de la guerre générale à tout prétendu agresseur, la France aurait pu être obligée de participer à une action de force contre les colonies anglaises d'Amérique au lieu de venir à leur secours. «Or, dit cet Américain (qui est cependant un pacifiste intégral, puisqu'il s'est fait emprisonner à l'âge de vingt ans pendant la guerre pour son refus de la faire), il pourrait arriver qu'un État commît un acte d'agression au sens technique du mot sans être pour cela dans son tort, et il ne serait pas de l'intérêt de la justice, de la liberté et de l'humanité de faire boycotter, affamer ou mettre hors la loi cet État par l'univers, ou par quelques nations qui voudraient lui imposer leur volonté au nom de l'univers et de la paix ».

Aussi n'est-ce aucunement la justice, mais le plus hypocrite égoïsme qui a inspiré aux fondateurs de la Société des Nations l'idée de proscrire la guerre d'agression. Leur but avoué est d'assurer par les armes le maintien de l'ordre des choses établi par les traités de Versailles, tout comme, un siècle avant, la Sainte-Alliance des rois avait entendu assurer par les armes le maintien de l'ordre de choses établi par les traités de Vienne. Au mythe de la SainteTrinité ils ont substitué celui de la légitime défense, c'est toute la différence.

Voir par exemple l'Ordre du jour du parti radical-socialiste dans le grand débat sur la politique étrangère à la Chambre, novembre 1930.

2 M. BRENT DOWN ALLISON, membre du département des sciences politiques à l'Université de Chicago, dans la revue Unity du 21 avril 1930. 
Écoutons un autre Américain. Le professeur Warren S. Thompson, direction de la Fondation Scripp pour l'étude des problèmes de la population à l'Université de Miami, a publié un livre intitulé : Danger spots in world population (Les points névralgiques de la question de la population mondiale) Il y dit : "C'est un côté bien curieux de notre morale internationale que toute guerre d'agression soit condamnée indistinctement, par cela seule qu'elle est agressive, tandis que le maintien du statu quo, qui peut tenir dans la souffrance des millions d'hommes, paraît avoir l'approbation générale. Naturellement, c'est l'intérêt des peuples qui ont tout ce qu'ils désirent de rejeter la charge de la responsabilité morale d'une guerre sur ceux qui n'ont pas les mêmes raisons d'être satisfaits, et seront, par là même, amenés à rechercher dans la force la modification du statu quo. Mais nous devrions arriver à une suffisante connaissance des méthodes et des conditions dans lesquelles ont eu lieu les acquisitions de territoire dans le passé, pour ne pas regarder la simple possession comme un droit indiscutable à les garder quelles que soient les circonstances $\gg .{ }^{1}$

Écoutons un troisième Américain : «J'ai toujours été pacifiste, mais si la paix ne doit pas être autre chose que la soumission à une domination militaire, je la repousse. Il y a une chose au monde plus chère que la paix, c'est la liberté et la justice ». Voilà ce que, le 22 janvier 1926, dans le débat sur l'entrée des États-Unis à la Cour de justice internationale, disait au Sénat américain M. Borah, Président de la Commission des Affaires étrangères, assurément le personnage officiel le plus sincèrement et le plus ardemment pacifique qu'il y ait au monde. Et il ajoutait : "Cette domination militaire serait d'autant plus odieuse que les peuples, du sort desquels on a disposé à Versailles, seraient dans l'impossibilité d'obtenir le redressement des torts qu'on leur a faits. C'est la plus horrible combinaison de force jamais conçue par l'esprit humain contre la liberté et la justice».

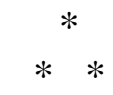

Le côté moral de la question ainsi réglé de main de maître, examinons le système au point de vue pratique.

«Pour prévenir la guerre, dit la Société des Nations, jurons de nous coaliser contre l'agresseur ». Mais si une guerre éclate, à quoi reconnaîtra-t-elle l'agresseur? Elle s'est bien gardée de le dire, et pour cause.

1 Page 238, citée dans Unity du 8 décembre 1930. 
En 1914, les grands États européens étaient partagés en deux groupes liés chacun par un système d'alliances purement défensives. Pour justifier le casus foederis il fallait une agression non provoquée. Si le système avait été loyalement appliqué, il aurait dû éviter la guerre. Un des contractants n'aurait jamais déchaîné la guerre puisque c'eût été se priver de l'appui de ses alliés. Mais le système n'a rien évité du tout parce que, lorsqu'ils ont cru devoir engager la guerre, tous ont commencé par se déclarer en état de légitime défense ou par soutenir que leur allié y était. C'est qu'en effet l'état de légitime défense se prête à toutes les interprétations.

Quelques exemples. Le $1^{\text {er }}$ août 1914 le gouvernement français fit afficher cette proclamation : «La mobilisation n'est pas la guerre». Donc elle ne met pas l'État contre qui elle est dirigée en état de légitime défense ; c'est un « acte de politique intérieure », suivant l'expression savoureuse de M. Poincaré. Mais à la séance de la Chambre du 3 mars 1927, comme on demandait à M. Paul Boncour, rapporteur du fameux projet de loi sur « la mobilisation nationale», et alors expert à la Société des Nations, de définir le cas de légitime défense visé par ce projet, il répondit: "Quand un État voit son sol envahi, ou préparer les moyens de l'envahir ». Si la mobilisation n'est pas la guerre, elle est certainement la préparation de la guerre, qui consiste à envahir le sol de l'adversaire. Alors, si un État mobilise, quelle interprétation choisira le Conseil de la Société des Nations : qu'une mobilisation met le pays contre qui elle est dirigée en état de légitime défense, ou qu'elle ne l'y met pas ?

Le 30 juillet 1914, l'Ambassadeur de France à Londres avisait le gouvernement anglais que la France s'attendait à une agression de l'Allemagne, l'avertissant que «cette agression prendrait la forme d'une demande que la France cesse ses préparatifs » (Doc. angl. 319). Alors, un État qui demandera à l'autre de cesser des préparatifs de guerre fera acte d'agression !

A quoi reconnaîtra-t-on qu'il y a préparatifs ? «Au premier mouvement de trains qui indiquera une mobilisation, a dit encore M. Paul Boncour ; il constituera le cas d'agression avec toutes ses conséquences » ${ }^{1}$. Cependant, on a affiché sur nos murs, en 1914, que l'ordre de mobilisation générale n'était pas la guerre.

Faisons confiance, dira-t-on, à l'impartialité du Conseil de la Société des Nations. Rien ne sera moins impartial que lui. Ses membres représenteront des États qui auront plus ou moins d'intérêt à soutenir ou à ne pas soutenir tel ou tel des États en conflit. Si les États en conflit étaient par exemple aujourd'hui l'Italie et la Yougoslavie, ou l'Allemagne et la Pologne, le représentant de la France serait-il bien qualifié pour dire impartialement qui serait l'agresseur?

1 Journal L'Euvre du 13 février 1925. Voir L'Évangile du Quai d'Orsay, page 89. 
Voyez ce qui se passe pour la guerre de 1914. Bien que de bienfaisantes révolutions aient jeté aux quatre vents de la publicité les archives qui semblaient les plus inviolables, bien qu'on puisse saisir sur des documents authentiques les pensées les plus secrètes des gouvernements d'alors, la question de savoir qui fut l'agresseur est encore, au bout de quinze ans, l'objet d'acharnées controverses. Le Conseil de la Société des Nations serait-il d'ailleurs composé 'des hommes les plus impartiaux du monde qu'il n'en serait pas plus avancé. La désignation de l'agresseur est le plus insoluble des problèmes du droit international : crux juris-consultorum. Le $\mathrm{D}^{\mathrm{r}}$ Unden, professeur suédois de droit, ancien Ministre des affaires étrangères, membre du Conseil de la Société des Nations, a écrit une étude sur Les guerres d'agression en tant que problème de droit international ${ }^{1}$. En voici un passage : «Lorsque le Comité militaire permanent de la Société fut invité, en 1923, à rédiger un commentaire sur la notion de guerre d'agression, il ne choisit aucunement comme signe décisif et caractéristique du fait d'agression l'initiative des mesures violentes. Parmi les facteurs d'importance, permettant d'établir qu'il y a eu vraiment agression, on envisagea entre autres les mesures prises en vue d'une mobilisation industrielle et économique, et le caractère agressif de la politique suivie par l'une des parties à l'égard de l'autre partie, pendant telle période ayant précédé les hostilités. Le fait d'avoir le premier franchi les frontières ne signifiait pas toujours aux yeux de ce Comité qu'il y ait eu réellement acte d'agression. Une rapide offensive menée sur le territoire de l'autre partie pouvait constituer une mesure défensive, et il pouvait arriver que l'État ayant pris l'initiative des hostilités se trouvât en fait dans une position de défense ». Si on songe d'une part que quatre ans avant il s'était trouvé vingt-quatre gouvernements pour rendre l'Allemagne responsable de la guerre européenne parce que, menacée sur deux fronts par la mobilisation de deux armées redoutables, elle avait pris l'initiative des hostilités, d'autre part que la Société des Nations prétend assurer la paix en soutenant les États attaqués contre les États agresseurs, et on voit s'il sera facile de les distinguer, on est amené à penser que, si le sort des peuples était entre les mains d'une bande de fous, les choses n'iraient pas très différemment.

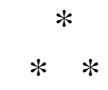

Mais, dira-t-on, nous avons aujourd'hui le pacte Kellogg. Ses quelque soixante signataires ne renoncent pas seulement par l'article premier à la guerre comme instrument politique, ils s'engagent par l'article 2 « à ne chercher la solution de leurs différends que par des moyens pacifiques ». L'agresseur sera l'État qui aura refusé cette solution. On pourrait d'abord objecter

1 Publications de la Fondation Carnegie pour la paix internationale, 1930, bulletin, $\mathrm{n}^{\circ} 6$. 
qu'aucune personne sérieuse ne croit à la valeur des procédures pacifiques pour empêcher la guerre entre États armés. Car pourquoi seraient-ils armés s'ils voulaient s'y soumettre? On ne se présente pas devant un arbitre le pistolet au poing. L'arbitrage n'a jamais empêché la guerre que dans des cas mineurs, où les parties ne voulaient pas se battre. Mais laissons ce côté de la question, et voyons seulement si le refus d'accepter une procédure pacifique suffira à désigner l'agresseur.

Supposons donc qu'un État appelé par un autre en conciliation ou en arbitrage s'y refuse, et soit attaqué par cet autre ; alors il sera l'agresseur bien qu'étant attaqué. Si deux États entrent en guerre sans avoir cru utile de recourir aux moyens pacifiques, ils seront tous les deux agresseurs. Si ayant cherché une solution dans ces moyens, mais ne l'ayant pas trouvée, ils en viennent aux mains, ils seront tous les deux attaqués.

Il pourrait arriver, par exemple, que l'Allemagne demande à la Pologne de soumettre à l'arbitrage la révision de leurs frontières. La Pologne refuse. L'Allemagne l'attaque. C'est la Pologne qui est l'agresseur. On a déjà envisagé l'hypothèse. Pour tourner la difficulté, M. Paul Boncour, le grand oracle du pacifisme officiel, aurait déclaré qu'on ne saurait assimiler à un agresseur l'État qui, se voyant réclamer un territoire en sa possession, refuserait de soumettre le conflit à l'arbitrage. Alors ce n'est plus l'arbitrage, mais l'arbitraire.

La question de savoir qui sera l'agresseur n'est donc pas tranchée par le pacte Kellogg, qui d'ailleurs n'a pas cette prétention. M. Kellogg lui-même n'a-t-il pas dit que ni le pacte qui porte son nom, ni un autre ne pourrait priver un gouvernement du droit de décider par lui-même s'il est en état de légitime défense ou, dans une guerre donnée, quel État est ou non en état de légitime défense?

On dit que le pacte Kellogg met la guerre « hors la loi ». Rien de plus inexact. Il ne consiste lui aussi, sous une autre forme, qu'à proscrire les guerres d'agression. C'est à «renoncer aux guerres d'agression» que M. Briand, initiateur du pacte, avait convié M. Kellogg. Précisément à cause de la facilité pour un agresseur de se camoufler en attaqué, M. Kellogg écarta la formule française de renonciation "aux guerres d'agression », et fit adopter celle de renonciation «à la guerre comme instrument politique ». Mais, en fait, cette seconde formule revient si bien au même qu'on communiquait de Genève le 25 février 1930 : «Le gouvernement français tient à affirmer que le pacte de Paris vise la guerre d'agression et ne saurait porter atteinte au droit de légitime défense ». Mais de définition de l'agression, point. Autant dire que le pacte de Paris est le modèle des coups d'épée dans l'eau !

C'est ce qui permit au gouvernement des Soviets, en 1929, de répondre avec une ironique désinvolture aux gouvernements américain et français, qui 
le rappelaient à l'observation de ce pacte dont il était signataire : d'abord, qu'ils n'étaient pas spécialement chargés de sa garde ; ensuite que, les Chinois ayant massacré des Russes et violé la frontière, il était en état de légitime défense ; enfin, que les réserves dont était entouré le pacte l'autorisaient, s'il le jugeait nécessaire, à faire la guerre.

En fait, personne ne croit à la possibilité de désigner l'agresseur avec certitude. Quand la Société des Nations condamna les guerres d'agression, le représentant de l'Italie fit froidement observer « qu'un gouvernement qui veut faire la guerre trouve toujours le moyen de se faire attaquer ». Au cours des négociations du pacte Briand-Kellogg, le Ministre des affaires étrangères anglais Chamberlain exprima aux Communes la même idée : «Le véritable agresseur saura se donner les apparences de l'innocence ». C'est par hostilité à l'idée d'être entraînés dans une guerre contre un État prétendu agresseur que les États-Unis ont refusé d'entrer dans la Société des Nations. Lors de la signature du pacte Kellogg, le Sénat a expressément déclaré que «le pacte n'engageait, ni implicitement ni explicitement, ses signataires à prendre part à des mesures punitives ou coercitives contre l'État qui le violerait ».

L'Angleterre a refusé pour des raisons analogues d'adhérer au projet de convention dit Protocole de Genève soumis à la Société des Nations en 1924. Pendant la Conférence navale de Londres de 1930, un grand journaliste anglais, M. Garvin, écrivait dans The Observer : "Alors que les partisans des sanctions armées croyaient qu'il n'y aurait plus d'États neutres, il y en aura plus que jamais, car aucun ne voudra s'engager sans avoir pu juger par luimême de la situation. Les neuf-dixièmes suivront à cet égard l'exemple de l'Angleterre et des États-Unis ».

Imaginez en effet une guerre entre la France et l'Italie. Croit-on que d'autres États entreraient en guerre contre l'une de ces puissances, sous prétexte qu'elle aurait été désignée comme l'agresseur, si leurs sympathies ou leurs intérêts les poussaient du côté de l'autre, ou à rester neutres ?

Enfin, même si le Conseil de la Société des Nations était composé d'hommes assez subtils pour désigner avec certitude le véritable agresseur et assez impartiaux pour faire table rase de toute préférence, il resterait encore à la gendarmerie internationale à exécuter son arrêt. Or on n'imagine guère cette gendarmerie mettant la main au collet de l'armée française ou de la flotte anglaise, qui seraient peut-être soutenues l'une par les armées polonaise, tchéco-slovaque, roumaine et serbe, l'autre par la flotte américaine ! En 1914 il a fallu quatre ans au monde presque entier pour triompher de l'Allemagne, réputée l'agresseur! 
«Mars, a écrit un Américain, n'a jamais mieux travaillé que le jour où il a persuadé les pacifistes qu'il suffisait, pour sauvegarder la paix, de proscrire les guerres d'agression $\gg{ }^{1}$.

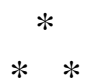

En effet, les États dépensent en armements plus d'argent encore qu'en 1914. Lors de la Conférence navale de Londres, M. Snowden, Ministre des finances d'Angleterre, l'a démontré par des chiffres qu'il est difficile de contester. Qu'est-ce à dire sinon que, si chaque État se prétend incapable de commettre le crime d'agression, il croit, et ne s'en cache pas, les autres capables de le commettre. Quelle ironie ! Tous ces beaux messieurs qui, plusieurs fois par an depuis dix ans, se réunissent pour fonder la paix, ont un revolver dans leur poche, quand ils ne le mettent pas sur la table!

«Ardemment pacifiste, dit chacun, ne m'étant jamais battu que pour me défendre, je suis prêt à changer mon revolver à six coups contre un revolver à trois coups, quand vous m'aurez tous fait la promesse de venir à mon secours si je suis attaqué. Ma sécurité d'abord ». Mais cette promesse les autres ne veulent pas la faire, d'abord parce qu'ils se détestent tous cordialement, ensuite parce qu'ils savent que la légitime défense est un prétexte dont joue tout gouvernement qui entre en guerre, enfin parce qu'ils ne sont aucunement disposés à se battre pour autre chose que leurs intérêts les plus égoïstes. Alors chacun reste armé, et ne songe plus qu'à faire valoir les droits qu'il tient soit de sa population, soit de ses colonies, soit de la nature ou de l'étendue de ses frontières terrestres ou maritimes, soit de son infériorité industrielle, à avoir ou plus de soldats, ou plus de vaisseaux, ou plus d'avions, ou plus de canons, ou plus de sous-marins, que les autres ne jugent qu'il devrait en avoir pour sa taille. Voilà la pièce qui tient l'affiche à chaque saison au Théâtre des Nations. Faut-il que les spectateurs soient patients, ou stupides !

Il n'y a donc rien de changé à la situation d'avant-guerre, sinon que la guerre de légitime défense ayant été officiellement déclarée la seule licite, le premier soin d'un gouvernement entrant en guerre sera plus que jamais de se dire provoqué, menacé ou attaqué. Le 27 octobre 1930, dans un discours sur la politique extérieure, M. Mussolini à dit : «L'Italie fasciste arme proportionnellement aux autres États, car tous arment. Elle désarmera si tout le monde désarme. Qu'il soit clair de toutes les manières que nous armons matériel-

Outlawry of War, by Charles MORRISON, editor The Christian Century. Avis aux associations d'anciens combattants qui, dans leurs congrès, déclarent compter sur cette proscription pour éviter de nouvelles guerres. 
lement et spirituellement pour nous défendre, non pas pour attaquer. L'Italie fasciste ne prendra jamais l'initiative d'une guerre ».

Ici on s'indigne ou on raille. Mais c'est exactement ce que ne cessent de dire de la France démocratique nos propres hommes d'État. D'ailleurs, en même temps que les déclarations de M. Mussolini, les journaux nous apprenaient que le général Pershing, qui commandait en chef les troupes américaines pendant la guerre, vient, dans une revue, de mettre en garde ses compatriotes contre le désarmement : «Certes, écrit-il, nous ne provoquerons jamais la guerre, mais qu'est-ce qui nous autorise à penser que personne n'en provoquera plus ? Il faut donc que nous soyons en état de défendre notre merveilleux pays au cas où quelque État qui, lui, croirait encore à la guerre, viendrait nous attaquer ».

Dans le fameux pacte de Locarno, les parties s'engagent à ne plus faire la guerre, à moins qu'il ne s'agisse du droit de légitime défense, ou que la Société des Nations ne décide d'attaquer un État agresseur. Ces réserves excitent la verve de Clemenceau dans son ouvrage posthume : «Je le demande, depuis qu'il y a des nations et des guerres, quelle est donc la nation qui, jamais, a prétendu faire une guerre qui ne fût pas simplement défensive... Une nation qui veut faire la guerre est toujours en état de légitime défense ». ${ }^{1}$

Donc tout le monde invoquera la légitime défense et personne n'y croira. Comme on donne d'autant plus de mauvaises raisons qu'on en manque de bonnes, moins une guerre sera défendable, plus elle sera dite défensive. L'hypocrisie sera légalisée, et même primée. C'est le seul résultat acquis jusqu'ici par une propagande de paix, aussi outrageante pour la raison que l'était la propagande de guerre. Ce n'est pas étonnant. Les propagandistes sont les mêmes.

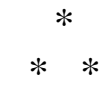

Votre scepticisme, me dira-t-on, englobe tous les gouvernements, alors qu'il y en a au moins un de la sincérité duquel vous ne devriez pas douter : le vôtre. Ignorez-vous que la France n'a jamais fait que des guerres lumineusement défensives, qu'elle a subi quatre invasions en un siècle, qu'insuffisamment armée elle serait une tentation, et que par conséquent c'est son amour même de la paix, qu'elle ne cesse de proclamer, qui l'oblige à rester forte.

Grandeurs et misères d'une victoire, page 282. Mais naturellement, le pauvre homme n'admet pas un seul instant que ce soit son pays qui recoure à ce prétexte ; ç'a été et ce sera toujours et seulement l'Allemagne. 
Je n'ignore pas ces arguments, puisqu'on les trouve chaque jour dans les discours des gouvernements et les écrits des journaux ${ }^{1}$. Mais ma conscience m'oblige à répondre que, loin de me convaincre, ils me font grincer des dents. N'est-il pas écrit dans l'histoire que la France fut un des États qui firent le plus souvent la guerre, et qui ouvrirent le plus souvent les hostilités ? Quand elle a subi une invasion, n'est-ce pas parce qu'elle n'avait pas pu la porter chez l'adversaire ? Si la France a le droit de rester armée pour sa sécurité, pourquoi les autres États ne l'auraient-ils pas aussi ? En quoi une Allemagne désarmée est-elle moins une tentation que ne le serait une France désarmée ? Si la France disait qu'elle veut rester forte pour garder les fruits de sa victoire, il n'y aurait qu'à s'incliner, car c'est dans la règle du jeu, et ce serait reconnaître qu'on a le droit de s'armer pour les lui reprendre. Mais quand on lui fait dire que, si ses dépenses militaires sont près du triple de celles d'avant-guerre ${ }^{2}$, c'est qu'elle veut être l'Ange gardien du monde, le monde trouve qu'on se moque de lui, et ne se gêne pas pour le dire.

«La France immortelle, a dit M. Paul Boncour, Président de la Commission des Affaires étrangères de la Chambre, veut attacher son char à l'étoile de la paix ». Pourquoi ne l'y a-t-elle pas attachée en 1871 ? C'est quand on est vaincu, non quand on est vainqueur, qu'il y a du mérite à être pacifique. Au début du XVIII ${ }^{\mathrm{e}}$ siècle, l'abbé de Saint-Pierre publia un projet de pacification perpétuelle de l'Europe qui reposait, comme le pacte de la Société des Nations, sur l'acceptation par les divers États du statu quo territorial. Mais, observait l'auteur, comme la France vient d'être dépouillée par le traité d'Utrecht des conquêtes de Louis XIV, on ne pourra l'accuser de vouloir tirer avantage de cette condition. Voilà un scrupule qui paraîtra bien étrange à nos pacifistes gouvernementaux.

À l'occasion du douzième anniversaire de l'armistice, M. Paul Boncour a dit encore : «La victoire de l'Allemagne en 1871 avait imposé à l'Europe la course aux armements. La victoire de la France du 11 novembre 1918 doit l'en délivrer ». Pourquoi cette différence ? Si en 1871 l'Allemagne, sous le prétexte qu'elle avait été attaquée, avait exigé que la France réduisît son armée à cent mille hommes, livrât sa flotte, détruisît ses forts et ses canons, puis avait mis comme condition d'une réduction de ses propres armements qu'on créerait une armée internationale pour assurer l'inviolabilité du traité de Francfort, enfin avait prétendu fermer ainsi le temple de la guerre, et mettre la clef dans sa poche, aurions-nous pensé que l'Allemagne montrait, comme M. Herriot vient de le dire de la France au congrès du parti radical-socialiste (octobre

1 Le pacifisme français n'est pas d'aujourd'hui, ni même d'hier, il date de nos origines (Le Temps, 24 septembre 1930).

219.019 millions de francs contre 7.360, d'après les calculs de M. ANTONELLI, député (La Lumière, novembre 1930). 
1930), sous une rafale d'applaudissements, qu'elle avait « l'âme la plus juste et la plus généreuse »?

Le narcissime national n'est pas seulement la plus sotte des vanités, il est le bouillon de culture des guerres. Nos hommes d'État, au pouvoir ou en disponibilité, le cultivent plus que personne ${ }^{1}$. Il n'y a donc aucune raison de les croire plus pacifiques que d'autres.

1 Voir La Mobilisation des consciences, pages 305 et suivantes. 


\section{Chapitre VII}

\section{Au mythe de la légitime défense, il faut opposer la vérité sur l'explosion de la guerre de 1914 et sa conséquence : plus de guerre sans un vote du peuple}

Supposons maintenant qu'une enquête internationale sur l'explosion de la guerre ait démontré que pas un des belligérants n'a fait une guerre purement défensive, que ceux qui l'ont fait croire le plus étaient ceux qu'on aurait dû croire le moins, que l'aveu extorqué aux vaincus dans le traité de paix d'être seuls responsables de la guerre par leur agression est contraire aux faits les mieux établis. Supposons aussi que la presse de tous les pays ait honnêtement fait à cette enquête la plus large publicité.

On peut espérer qu'il se trouverait alors chez tous les peuples, et surtout chez ceux qui ont pris part à la guerre, assez d'honnêtes gens pour former une sorte de «Ligue du droit des peuples », qui rédigerait un manifeste de ce genre : 
«Ce qui caractérise la guerre de 1914, ce n'est pas tant son étendue; les guerres de coalition du XVIII ${ }^{\mathrm{e}}$ siècle, les guerres napoléonniennes ont mis autant et plus d'États en ligne, et on se battit alors plus loin encore, jusques dans le Nouveau-Monde. Ce n'est pas non plus la quantité de sang versé ; les dix mille victimes d'une petite guerre sont autant à plaindre que les dix millions d'une grande. Ce n'est pas non plus son atrocité ; les guerres où on passait régulièrement les prisonniers au fil de l'épée et les villes au pillage étaient plus atroces encore. Non, ce qui fait aux guerres de 1914-1918 une place à part dans l'histoire des folies humaines, c'est le cynisme et la facilité avec lesquels les gouvernements ont fait accepter la guerre par les peuples en jouant de la légitime défense. Théoriquement maîtresses du droit de guerre puisque l'argent pour la faire ne peut être voté que par leurs députés, les masses sont en fait, sur cette question vitale entre toutes, esclaves des gouvernements qui, pour obtenir cet argent, n'ont qu'à se présenter comme victimes d'une agression de l'adversaire. Qui pourrait contredire les gouvernements, puisque seuls ils disposent des moyens d'information et mettent la presse dans leur poche, puisque leur ordre de mobilisation n'admet pas de réplique, puisqu'ils ne demandent les crédits de guerre aux parlements que lorsque la guerre est déjà engagée ? Chaque gouvernement qui joue de l'argument de la guerre défensive fait ainsi deux victimes : le peuple adverse qu'il accuse à tort, le sien qu'il trompe. Que devient alors, ô peuples, notre prétendue souveraineté ? Que signifient toutes les phrases sur la liberté, la démocratie, dont on nous assourdit, s'il suffit de la volonté d'un Ministre éphémère pour nous envoyer à la mort la plus injurieuse, celle de l'homme qui croit sacrifier sa vie à une cause et qui tombe pour une autre, quand ce n'est pas celle de l'homme qui sait qu'on le trompe et qui doit tomber tout de même. Dix millions sont tombés ainsi.

Or, après dix années de palabres contre la guerre, que nous proposent les gouvernements pour nous en préserver ? De ne faire la guerre que s'ils sont attaqués. Vit-on jamais dérision plus cruelle ! Comprenons donc enfin que la véritable protection contre le fléau de la guerre est en nous. On ne cesse de nous flagorner en nous disant que nous sommes les maîtres. Eh bien, montrons qu'effectivement nous le sommes. Dans chaque pays, ne votons aux prochaines élections que pour les candidats qui s'engageront à introduire dans la Constitution cet article : La mobilisation ne peut être ordonnée qu'après un vote au suffrage universel, signé, et à la majorité des deux tiers ».

Qu'y aurait-il à répondre ? L'Assemblée Constituante française proclama, le 22 mai 1790, que le droit de guerre appartenait à la nation, non au roi. Dans son Essai sur la paix perpétuelle, cinq ans après, Kant estimait que si tous les peuples étaient en république, il n'y aurait plus de guerre, car « chaque citoyen devrait concourir, par son assentiment, à décider si l'on fera la guerre ou non, et aucun n'irait de propos délibéré s'en infliger la charge et les souffrances ». Or jamais aucun peuple, en république ou non, n'a été appelé à voter une 
guerre. Ses députés la votent pour lui. Mais la souveraineté ne se délègue pas, a dit Rousseau. S'il y a un cas où ce soit vrai, c'est bien celui de la guerre, car le droit de guerre est bien le droit souverain par excellence. Puisque les peuples sont souverains, comment se fait-il qu'ils ne l'exercent pas eux-mêmes !

Dans The great illusion, Norman Angell écrivait, quatre ans avant la guerre : «On ne peut lire le discours d'un homme d'État, même de premier ordre, ou un article de fond, même dans nos plus grands journaux, traitant des relations internationales, sans y trouver comme admis que les gouvernements européens ont les instincts des sauvages congolais, la prévoyance des voleurs de bétail, et la moralité commerciale d'aventuriers sud-américains ${ }^{1}{ }^{1}$. La grande guerre et la grande paix ont prouvé, au-delà de toutes prévisions, que c'est bien ainsi que se comportent les gouvernements européens en matière de politique extérieure. Alors qu'est-ce qu'on attend pour les déposséder du droit de guerre ? Et comment Norman Angell lui-même peut-il leur faire encore crédit au point de demander qu'on confie à la Société des Nations, qui n'est que leur émanation, et à une force armée qui serait à ses ordres, la mission de faire régner la justice internationale ? Ne serait-ce pas remettre les tribunaux et la gendarmerie aux voleurs?

Avant la guerre mondiale, il y avait dans tous les pays, notamment en Allemagne ${ }^{2}$ et en Angleterre, des éléments pacifistes très importants. Pendant la période de tension, une grande partie des journaux allemands et anglais, et non des moindres, se montra opposée à la guerre, les premiers ne voulant pas entendre parler d'une guerre pour l'Autriche, et les seconds d'une guerre pour la Serbie ; cette opposition s'exprima, même chez des journaux de droite, avec une extraordinaire véhémence. Elle fut balayée comme un fétu par les ordres de mobilisation. La volonté de paix des peuples n'avait donc servi à rien. Mettez la guerre aux voix, et cette volonté prendra toute sa valeur, puisqu'il dépendra d'elle que la guerre soit ou ne soit pas. "Si mes soldats commençaient à penser, aucun d'eux ne resterait dans les rangs », disait Frédéric II. À plus forte raison en serait-il ainsi des soldats d'aujourd'hui qui, non soldats de métier, mais soldats malgré eux, ont tout à perdre et rien à gagner dans une guerre. Le rôle du pacifisme doit être de leur apprendre à penser. Ne seraientils pas forcés de penser s'il dépendait d'eux que la guerre soit ou ne soit pas?

Voilà le premier coup à frapper. Pour justifier leur guerre et leur paix, les vainqueurs de 1918, qui avaient passé la guerre à disposer des peuples dans leurs traités secrets, comme d'une marchandise, eurent l'audace de prétendre, l'empire russe et l'empire austro-hongrois s'étant écroulés contre leur désir, qu'ils avaient fait la guerre « pour que les peuples puissent disposer d'euxmêmes ». Eh bien, il faut les prendre au mot. Est-ce que le premier droit d'un

Page 71 de l'édition française.

Voir La Mobilisation des consciences, première partie, chapitre IV. 
peuple à disposer de lui-même n'est pas de n'aller en guerre que de son consentement? Les menaces de la guerre aéro-chimique sont une raison de plus pour remettre aux peuples le droit de guerre. On dit qu'il n'y aura plus de non-combattants, et même que les moins exposés seront ceux du front. La population tout entière étant exposée à la mort, c'est bien le moins que la population tout entière soit appelée à dire si elle veut la guerre.

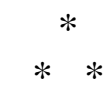

Donner aux peuples le droit de se refuser à la guerre, c'est aussi, dira-t-on, leur donner le droit d'y consentir. Pourquoi ne pas recourir au désarmement général et intégral, ou à la mise de la guerre hors la loi, qui supprimeraient la guerre ?

Pendant que j'attendais les épreuves de ce livre, M. Léon Blum a publié Les Problèmes de la Paix. Il y expose que, seul, le désarmement intégral et universel peut la garantir. Mais il ne se dissimule pas les obstacles que rencontrera une réorganisation internationale de cette envergure, et il estime « qu'elle ne sera réalisable que dans la mesure où la classe ouvrière aura pénétré et inspiré de son esprit les gouvernements » (p. 183).

L'Américain Morrison, qui voit la solution dans la mise de la guerre hors la loi, dit de son côté : «Cette révolution ne sera pas accomplie par une conférence de diplomates, la Société des Nations ou quelque autre organisme de ce genre. Elle ne pourra l'être que par l'action directe des peuples, dont la volonté devra s'exercer sur chaque parlement » (op. cit., p. 71)

Si c'est des peuples qu'on attend la suppression de la guerre par un de ces deux moyens, quel mal y aurait-il, d'ici là, à leur transférer le droit de guerre ? De deux choses l'une. Si on arrive à supprimer la guerre, il n'y aura aucun inconvénient à avoir donné aux peuples le droit de la décider puisqu'ils n'auront plus à l'exercer. Si on n'arrive pas à la supprimer, ou en attendant qu'on la supprime, on ne pourra que se féliciter d'avoir donné aux peuples le droit de s'y opposer.

Il faut bien admettre que la guerre ne sera pas supprimée en un jour, non seulement parce qu'il y aura à vaincre des résistances qu'on ne connaît que trop, et dont la question d'une simple réduction des armements est un exemple, mais encore parce qu'à la guerre il faudra substituer un autre mode de règlement des conflits internationaux. La suppression de la guerre implique l'obligation, pour l'État le plus fort, de soumettre à des tribunaux internationaux tout différend qu'il pourrait avoir avec un autre État, fût-ce le plus faible, 
et le droit, pour l'État le plus faible, d'y citer le plus fort sur toute question sans exception, et notamment la revision des traités nés d'une guerre. Elle implique le droit pour tout peuple colonisé, pour toute minorité nationale, de porter leurs revendications d'indépendance devant ces tribunaux. Elle implique le libre échange sans réserves, toute la terre ouverte à tous. Elle implique enfin l'institution d'un Code du droit international adapté au nouveau régime. On en est loin, n'est-ce pas ? Or, prétendre supprimer la guerre tant qu'on ne se sera pas mis d'accord sur tous ces points, c'est s'exposer à la voir renaître après l'avoir supprimée, ce qui serait bien la pire des aventures.

Mais ce qu'on peut faire tout de suite, c'est une campagne pour que le droit de décider la guerre n'appartienne qu'aux peuples. Tous les pacifistes devraient former sur cette question un front unique, une espèce d'union sacrée. Et ici je m'adresse à ceux qui, à l'exemple de Tolstoï, veulent opposer à la guerre la non-résistance, le refus individuel de tuer : aux Bertrand Russell, aux Einstein, aux Margueritte. Au moment où éclata la guerre, il y avait sur les murs de Paris des affiches dont la colle n'était pas sèche, où le parti socialiste et la Confédération générale du travail exhortaient leurs adhérents à répondre à la guerre par la grève générale. On sait le résultat. Serait-il très différent aujourd'hui ? Dans la plupart des États du monde des « objecteurs de conscience » sont en prison. Est-ce eux qui empêcheront la guerre ? Mais qu'au refus individuel et insurrectionnel on substitue le refus collectif et légal par le bulletin de vote, et tout change. A moins d'être poussé au désespoir, se trouverait-il un peuple pour voter la guerre?

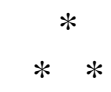

S'il arrive qu'un peuple vote la guerre, on saura qu'il l'a voulue, et pourquoi. Pour que son adversaire l'accepte, il faudra aussi qu'il l'ait votée. Elle sera donc débarrassée de ce cortège de mensonges, de faux, d'hypocrisies, de lâchetés qui accompagne aujourd'hui les guerres de légitime défense entre gouvernements. La guerre ne pourra plus être présentée, comme en 1914, sous la stupide caricature du paisible passant attaqué au coin d'une rue par un bandit. Elle apparaîtra sous sa vraie figure, un duel entre des peuples qui recourent volontairement aux armes. Mais cette volonté, il faut qu'ils l'expriment.

Autre avantage. Dans Le Matin du 5 janvier 1921, l'illustre Président de l'Université américaine Columbia, actuellement Président du grand Institut pacifique Carnegie dont il sera question plus loin, nous disait : «Les peuples, pour peu qu'ils soient habilement manœuvrés par les démagogues de la tribune et de la presse, voteront pour dix guerres, tandis qu'un gouvernement 
conscient de ses responsabilités hésitera toujours à en déclarer une seule ». Un sociologue français, Élie Halévy, est allé récemment exposer aux étudiants anglais les causes de la guerre de 1914 . «Il faut les chercher, dit-il, non dans les agissements de tels ou tels hommes d'État, non dans les incidents de l'histoire diplomatique, mais dans les mouvements d'ensemble de l'opinion publique, dans une force collective, anonyme qui travaillait à la rupture, et contre quoi les hommes d'État étaient sans pouvoir». Cette force serait le fanatisme national. Parlant de la Russie, l'auteur dit notamment que « l'enthousiasme patriotique des masses » balaya les quelques chefs socialistes restés fidèles à l'idée de paix à tout prix ${ }^{1}$.

Bien. Mais il y a d'autres personnes qui imputent les guerres non aux peuples, mais aux gouvernements. Le général Broussilof, un des rares généraux russes qui tinrent tête aux Allemands, dit dans ses Mémoires: «Presque personne en Russie ne savait qui étaient ces Slaves pour lesquels on se battait. Ce qu'ils étaient restait également obscur pour les soldats. Pourquoi, à cause des Serbes, les Allemands avaient voulu nous faire la guerre, personne ne le savait. On menait les hommes à l'abattoir sans savoir pourquoi, c'est-àdire pour un caprice du Tsar. Notre paysan n'avait pas entendu parler des ambitions de la Germanie ; il ignorait même l'existence de ce pays. Il savait encore moins ce qu'était l'Autriche. Il n'avait même pas une idée de ce qu'était sa mère : la Russie » ${ }^{2}$. Il y a un moyen bien simple d'empêcher la responsabilité d'une guerre d'osciller ainsi entre gouvernements et gouvernés, c'est d'exiger le consentement des gouvernés.

Les journaux (novembre 1930), nous apprennent ces déclarations de M. le Maréchal de la Diète de Pologne à un journaliste français, le correspondant du Petit Parisien, qui les admet conformes à la réalité : «Il n'est pas un paysan, pas un bûcheron qui ne soit décidé à défendre par les armes le principe de l'intégrité territoriale. À la plus minime rectification de frontière nous préférons la mort ». Il s'agit du corridor de Dantzig ! Si c'est vrai, comment ne senton pas que la plus élémentaire honnêteté, le plus élémentaire pacifisme exigent que ces paysans et ces bûcherons polonais, qui furent parmi les plus pitoyables martyrs de la guerre européenne puisqu'ils étaient entre l'enclume et le marteau, le disent eux-mêmes.

Notez que si M. le Maréchal de la Diète affirme avec tant de superbe que les paysans polonais préféreraient la mort à la plus minime rectification de frontière, c'est qu'il escompte l'alliance de la France, à qui on dit que sa frontière est désormais sur la Vistule ${ }^{3}$. Mais s'il savait que les paysans français

La revue Les libres propos, septembre 1930.

J'emprunte cette citation à un article de M. JUDET dans La Volonté du 29 septembre 1930.

Le déplacement des frontières dans l'espace est très utilisé pour justifier la légitime défense. Les frontières de l'Empire britannique en Europe, disait lord Kitchener, c'est la 
auraient d'abord à dire s'ils entendent mourir pour le corridor, il changerait vraisemblablement de ton. $\mathrm{Si}$ on objecte que des paysans ne peuvent rien entendre aux questions internationales, alors qu'on ne dise pas qu'ils veulent mourir pour elles. Et d'ailleurs pourquoi ne seraient-ils pas aptes à dire s'ils veulent ou non la guerre, puisqu'on les juge aptes à choisir les députés qui auront à le dire pour eux ?

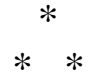

Une autre conséquence de cette réforme serait, ce qui a été beaucoup demandé et non obtenu, de placer la politique étrangère sous le contrôle de la nation. La diplomatie ne pourrait plus être secrète. Des mesures internationales seraient nécessairement prises pour qu'en cas de conflit chaque peuple eût le temps et la faculté de se rendre compte de ses raisons, et au besoin de demander l'avis d'arbitres. L'institution de ces délais n'offrirait pas de difficultés. Le principe en a été admis dans des traités passés peu avant la guerre par les États-Unis, et dans le pacte même de la Société des Nations, à qui d'ailleurs il appartiendrait de prendre toutes autres dispositions utiles. J'ai souvent parlé de la Société des Nations sans ménagement, parce qu'elle ne veut pas se dégager de la fange du traité de Versailles ${ }^{1}$, et se traîne dans l'ornière des guerres défensives. Il en serait tout autrement si, au lieu d'être une Société de gouvernements, elle devenait une Société des peuples. Cela aussi, on l'entend demander souvent. Mais comment pourrait-elle être une Société des peuples si le droit de guerre reste aux mains des gouvernements?

Il y a des États où le suffrage universel n'existe pas. On recourrait alors à un autre mode de consultation populaire. Il n'y a pas de pays où on ne puisse connaître si la population veut ou non la guerre.

Il y a des pays à dictature. Supposons qu'un conflit éclate entre l'Italie, pays à dictature, et un pays à face de démocratie comme la France. Sous le régime actuel il sera impossible, si la guerre suit, de désigner le responsable. Mais si le droit de guerre appartenait en France au peuple, de deux choses l'une, ou l'Italie attendrait loyalement que le peuple français ait voté, et alors il

ligne de la Meuse. Celle de l'empire russe est à Belgrade, disait Sazonow. Notre guerre au Maroc, a dit M. Barthou, se confond, comme sur le Rhin, avec la défense nationale.

1 Cette expression ne fait que donner une forme synthétique à l'opinion exprimée par nombre de personnages appartenant aux nations ex-ennemies de l'Allemagne, et qu'on ne saurait accuser d'indulgence pour elle. J'en ai cité de suffisants exemples dans La Mobilisation des consciences (p. 199-201). Mais depuis dix ans le nombre de ces témoignages s'est singulièrement augmenté. 
ne la ferait que de son consentement, ou l'Italie commencerait les hostilités sans attendre; alors elle serait vraiment l'agresseur, et la France, attaquée avant d'avoir accepté la guerre, serait vraiment en état de légitime défense.

Si d'ailleurs seuls les États à dictature refusaient de remettre au peuple le droit de guerre, ils seraient vraisemblablement en mauvaise posture devant l'opinion publique universelle, et l'idée démocratique y gagnerait énormément. Ce qui fait tort à l'idée démocratique, c'est qu'en ce qui concerne précisément la guerre, la différence entre les États soi-disant en démocratie et les États non démocratiques est plus apparente que réelle, réside plus dans les mots que dans les choses. Alors les peuples s'en désintéressent, et avec raison. Voyez comment les choses se sont passées en Angleterre, qui passe pour le pays où l'opinion a le plus de poids. Le 25 juillet 1914 le premier Ministre Asquith disait au parlement : «Nos relations avec le grand empire allemand, je suis heureux de le dire, sont en ce moment, et je me sens assuré qu'elles le resteront, des relations d'amitié et de bonne volonté ». Onze jours après les deux États étaient en guerre.

Une des suppositions les plus admises est que la guerre européenne n'aurait pas eu lieu si le gouvernement anglais, dès ce 25 juillet où la Serbie mobilisa en remettant sa réponse à l'Autriche, et où celle-ci mobilisa en rappelant son Ministre, avait dit nettement qu'il serait aux côtés de la Serbie, de la Russie et de la France. Le Ministre Grey a toujours objecté qu'il ne pouvait prendre cette décision sans le consentement du parlement. Le malheureux, on est tenté d'écrire le misérable, ne pouvait donc pas le consulter. Mais il prévoyait une opposition qui aurait empêché l'Angleterre d'entrer dans la guerre, et il a avoué qu'il aurait démissionné plutôt que d'y renoncer. Il préféra donc attendre que le cours prévu des choses eût amené l'Allemagne à déclarer la guerre à la France. Alors l'Angleterre put dire qu'elle allait au secours d'un ami «wantonly attacked», et ce gentleman philosophe, ami de la paix des champs et des animaux, put ainsi présider tranquillement au plus grand carnage d'êtres humains qu'on ait jamais vu.

On dira qu'il a fallu la complicité passive des peuples pour se laisser aussi docilement mener à l'abattoir. Sans doute, et on ne prétend pas innocenter les peuples. Mais tout de même ce n'est pas eux qui ont machiné la guerre, c'est les gouvernements. Et la précaution que les gouvernements prirent de garnir du foin «de la légitime défense » la route de l'abattoir, prouve bien que les peuples n'y seraient pas allés d'eux-mêmes.

Examinant les moyens d'empêcher la guerre, il y a quatre-vingts ans, le grand économiste Bastiat, qui n'avait rien d'un révolutionnaire, écrivait : « Le moins de contact possible entre les gouvernements, le plus de contact possible entre les peuples. Pourquoi ? Parce que le contact des gouvernements compro- 
met la paix, tandis que le contact des peuples la garantit ${ }^{1}$. Un autre économiste, non moins illustre et non moins conservateur, Paul LeroyBeaulieu, a exprimé la même opinion tout au long de son livre Recherches sur les guerres contemporaines, en 1869. Tant que les peuples ne seront pas libres de choisir entre la paix et la guerre, on n'aura pas le droit, quoi qu'en pense M. Murray-Butler, de dire que c'est eux qui poussent les gouvernements à la guerre.

\section{II}

Cependant, l'idée de transférer aux peuples le droit de guerre est extrêmement peu répandue. Par un discours du 31 décembre 1922 du Chancelier allemand Cuno, on apprit que, pour faire cesser l'occupation de la Rhénanie, il avait proposé au gouvernement français de convenir que, pour la durée d'une génération, les deux gouvernements s'engageraient à ne pas se faire la guerre sans y être autorisés par un plébiscite. Il pensait donner ainsi à la France une nouvelle garantie de cette sécurité qu'elle réclame toujours. M. Poincaré, qui était alors le chef du gouvernement français, avait répondu « que le droit de guerre et de paix appartenait au parlement français, qu'on ne pouvait songer à le lui retirer sans une révision de la Constitution, que d'ailleurs un parlement français ne prendrait jamais l'initiative d'une guerre $»^{2}$. À la même époque, la revue Foreign-Affairs de Londres (janvier 1923) demanda à certains personnages s'il ne serait pas de l'intérêt de la paix que la guerre ne pût être décidée que par un référendum populaire. M. Poincaré répondit qu'en France «c'était déjà la souveraineté nationale qui, seule, était maîtresse ».

La proposition du Chancelier allemand d'autant plus intéressante qu'elle lui avait été suggérée par d'éminents Américains. Elle fut remise à $M$. Poincaré par l'intermédiaire du Ministre des affaires étrangères américain. M. Poincaré ayant objecté que, «pour qu'elle eût quelque valeur, il faudrait qu'elle fût garantie par l'Angleterre et l'Amérique », le Chancelier lui fit remettre, toujours par le même canal, cette autre formule : «Les gouvernements allemand, anglais, français et italien s'engagent solennellement les uns vis-àvis des autres et promettent à celui des États-Unis de ne pas se faire la guerre pendant une génération, soit trente ans, à moins que la chose ne soit décidée par un vote populaire, ce qui rendrait la guerre virtuellement impossible ». Rien n'y fit. On était à la veille de l'occupation de la Ruhr. M. Poincaré répondit aux Américains qu'il ne voyait dans la proposition des Allemands «qu'une manœuvre grossière pour échapper à leurs engagements, qu'un piège, qu'une dangereuse hypocrisie ». Il ne s'est pas demandé s'il n'y avait pas une

Paix et liberté, 1849. Cité par la revue Les libres propos.

Voir dans Les Libres propos du 3 février 1923 une excellente relation de cet épisode. 
hypocrisie autrement dangereuse à présenter le peuple français comme suffisamment protégé contre la guerre par sa Constitution et le pacifisme de ses gouvernants, car si jamais peuple souverain fut jeté dans une guerre les yeux bandés et la bouche cousue, ce fut assurément lui en 1914. En 1928, M. Houghton, Ambassadeur des États-Unis à Londres, ayant été nommé docteur honoris causa de l'Université de Harvard, prononça à cette occasion un discours où il demandait que le droit de déclarer la guerre appartînt aux peuples. Un notable citoyen américain, M. Shartid, de Duluth, a soutenu la même idée dans une série d'articles sur la guerre dans le Herald de cette ville, en 1929. Sans doute elle a pu avoir d'autres défenseurs que j'ignore. Ce qui est sûr, c'est qu'elle est complètement absente de ces débats officiels sur la paix qui font couler partout tant d'encre et de salive, et est restée plus inconnue en France que partout ailleurs. Or que faudrait-il pour la répandre ? Simplement faire pénétrer dans la masse des peuples qui ont subi les tortures de la grande guerre cette implacable vérité : qu'on n'a obtenu leur consentement qu'en faisant croire à chacun qu'il était en état de légitime défense ou que son allié y était, alors que ce n'était vrai d'aucun.

Ce serait le devoir de la Société des Nations d'ouvrir une enquête internationale sur l'explosion de la guerre. Après une épidémie, on en cherche les causes pour en éviter le retour. Puisqu'elle était instituée pour empêcher désormais la guerre, la Société des Nations devait faire, et immédiatement, la lumière sur les causes de celle de 1914 : sublatâ causâ, tollitur effectus. Elle s'en garde bien, n'a pas répondu aux quelques naïfs, dont je suis, qui le lui ont demandé. Création des vainqueurs, elle sait que cette enquête tournerait à leur confusion.

Ce serait le devoir des historiens de mettre leur science au service de la vérité. Quelques-uns l'ont fait. Mais les autres se taisent, ou s'ils parlent, c'est pour étrangler la vérité sous leur dialectique. Ils sont ces savants, dépeints par Romain Rolland, « qui savent étirer, tordre et nouer ensemble les documents comme des pâtes de guimauve, et en faire sortir aussi bien le blanc que le noir ». Quelle occasion ils avaient cependant d'utiliser ce qu'ils appellent leurs disciplines scientifiques! Vit-on jamais plus riche provision de documents que celle qui s'est échappée des coffres-forts éventrés de la diplomatie ! Il y a des congrès pour tout. Pourquoi pas un congrès historique sur les causes de la guerre mondiale ? Mais non. Il s'est tenu il y a trois ans un congrès international historique en Norvège ; il a décidé d'écarter cette question!

Ce serait le devoir des partis dits radicaux, puisque l'étymologie ellemême signifie qu'ils ont pour principe d'aller à la racine des choses, d'étudier les causes de la grande catastrophe. Leurs journaux se vantent d'être "les pères nourriciers de la démocratie ». Quand donc la démocratie fut-elle plus bafouée que par la guerre de 1914, guerre préparée, déchaînée et conduite par la diplomatie secrète ! 
Ce serait le devoir des chefs socialistes, dont le mot d'ordre est : " Prolétaires de tous les pays, unissez-vous », d'expliquer pourquoi, pendant quatre ans, ils ont excité les prolétaires de tous les pays, pour des intérêts qui leur étaient aussi étrangers qu'à un Huron, à s'écharper comme des chiens enragés. Ils n'ont, eux aussi, que cette explication : défense nationale. Dans leurs congrès, ceux d'ici s'épuisent à trouver de ces formules, baptisées «nègreblanc », qui anathémisent la guerre en général, mais la sanctifient quand elle est de légitime défense, tout comme en août 1914.

Ce serait le devoir des sociétés civiques et humanitaires, des sociétés morales, des sociétés pacifistes, comme notre Union pour la vérité, notre Ligue pour l'éducation morale, notre Ligue des droits de l'homme et du citoyen, notre Paix par le Droit, de venger la justice et la vérité, en faisant la lumière sur le procès de Versailles comme elles l'avaient fait sur le procès Dreyfus. Elles l'ont rayé de l'histoire.

Ce serait le devoir enfin des intellectuels de tout genre. La guerre avait été la faillite, l'assassinat de la raison. Comment ne se sont-ils pas dressés, dès que la liberté de parler et d'écrire leur a été rendue, contre le mensonge, dépassant tous les autres, qui avait présenté cette guerre comme dûe uniquement à l'agression soudaine d'un État barbare contre des États civilisés. N'était-ce pas leur rôle de faire comprendre aux peuples qu'ils n'étaient, les uns et les autres, que de pitoyables victimes du mythe de la légitime défense et de leur propre crédulité ? Hélas ! ils sont restés dans la paix ce qu'ils avaient été pendant la guerre : les serviteurs des pouvoirs. Il n'y eut pas alors de sottise, de fourberie dont ils ne se soient faits les colporteurs. Plutôt que de faire leur meâ culpâ, ils continuent ou se taisent.

Le comble est que tous ces gens se disent pacifistes, ne jurent que par la Société des Nations, créent des écoles, des chaires, des concours de la paix. C'est la mode. Mais la première condition de la paix, comme de toute morale, n'est-ce pas de traiter les autres comme on voudrait être traité soi-même ? Quand un homme entend dire que c'est à tort que nos ex-ennemis ont été accusés d'être seuls responsables de la guerre, et qu'il se détourne, quel genre de pacifiste est-il ? Le congrès international d'éducation morale, qui vient de se tenir à la Sorbonne, avait à son ordre du jour cette mirifique question : De l'utilisation de l'histoire en vue de l'éducation morale. Un des rapporteurs y aurait rappelé cette pensée de Leibniz : «La place d'autrui est le vrai point de perspective, en politique aussi bien qu'en morale ». Alors le congrès a dû tirer de la question des responsabilités de la guerre un fameux enseignement moral. Mais on n'a pas entendu dire qu'il s'en soit seulement occupé.

Le juriste canadien John Ewart a écrit dans son grand ouvrage The roots and causes of wars 1914-1918: «Que des millions de combattants soient 
morts avec une idée fausse de la raison pour laquelle ils se battaient, voilà assurément une des plus grandes tragédies de l'histoire ». Le commodore anglais Kenworthy a écrit dans Paix ou guerre : "Les peuples civilisés ne sauraient être mieux comparés qu'à des rameurs de galères. Ils sont enchaînés à leurs bancs par leurs préjugés et leurs peurs. Les galères s'abordent pour se couler réciproquement, et c'est eux qui, forçant sur leurs rames dans les entreponts, consomment leur propre destruction ». Si nos pacifistes étaient sincères, quelles belles conférences ils pourraient faire sur ces textes ! Mais il leur faudrait parler des responsabilités de la guerre, donc de leurs mensonges. Alors ils préfèrent laisser les peuples dans l'ignorance, l'erreur et les entreponts.

Renseignés sur les causes des guerres à peu près autant qu'un sauvage l'est sur celles du tonnerre, comment les peuples les devineraient-ils, comment songeraient-ils à prendre directement leurs intérêts en mains ? «Il n'est pas étonnant, écrivait Spinoza il y a plus de deux siècles, que, pour la plèbe, il n'y ait pas de vérité et qu'elle soit sans jugement, alors que les plus grandes affaires de l'État sont traitées en dehors d'elle, et qu'elle n'a aucun moyen d'en rien savoir, quelques indices mis à part qu'il est impossible de dissimuler. Vouloir traiter ces affaires à l'insu des citoyens et demander en même temps qu'ils ne portent pas sur elles des jugements faux, qu'ils n'interprètent pas de travers les événements, c'est folie pure ${ }^{1}$.

1 Cité par la revue Les Libres propos (novembre 1930). 


\section{Chapitre VIII}

\section{La vérité peut-elle être faite sur l'explosion de la guerre?}

On se trouve alors en face de la plus surprenante des objections : existe-t-il une vérité sur l'explosion de la guerre, et peut-elle être faite?

Dans le numéro du $1^{\mathrm{er}}$ avril 1929 de la revue L'esprit international a paru un article intitulé : Le problème des responsabilités de la guerre dans la politique internationale. L'auteur, M. Renouvin, Professeur de l'histoire de la guerre à la Sorbonne, et Conservateur de la Bibliothèque de la guerre, a écrit un livre sur Les origines immédiates de la guerre. La revue est l'organe du département européen de la grande société pacifiste américaine la Fondation Carnegie, créée en 1910 par le célèbre métallurgiste américain de ce nom, au capital de 10 millions de dollars, soit 250 millions de francs, pour en employer le revenu à abolir la guerre, « cette souillure de notre civilisation ».

Voici le résumé de l'article : «Sans contester le moins du monde la responsabilité de l'Allemagne et de ses alliés, on doit reconnaître qu'il était superflu de l'inscrire dans le traité de Versailles. Les gouvernements de 
l'Entente ont voulu par là donner satisfaction à l'opinion publique. Le gouvernement allemand a profité de cette maladresse pour ouvrir ses archives diplomatiques, et organiser sur la question des responsabilités une campagne de propagande, qui n'a eu de résultats que « dans les milieux où la curiosité est plus grande que la compétence ». Cependant, si cette propagande n'a eu aucun effet en France, où le grand public ignore à peu près tout de la question, et s'en accommode fort bien, elle a trouvé de l'écho à l'étranger. Mais elle ne peut aboutir à rien de pratique. Son but est de provoquer la constitution d'une Commission d'enquête ou d'une sorte de tribunal international, devant qui le problème serait porté. Où trouver les hommes qui sauront se dégager suffisamment de toute préférence nationale ? Même pas chez les neutres, qui ne sont pas toujours neutres en esprit, et même ne le sont pas souvent. Un tel débat ne mettrait en présence que des adversaires, n'aboutirait qu'à attiser les antagonismes. D'ailleurs sur quoi les commissaires ou les juges pourraient-ils fonder leur opinion? Sur les documents publiés. Mais quelle garantie pourraient-ils avoir que les auteurs de ces recueils n'auront pas omis à dessein quelque document important, mais gênant pour leur gouvernement? Il faudrait donc qu'ils se fissent ouvrir les archives elles-mêmes. Mais il est souvent difficile de découvrir l'existence d'un document qu'un gouvernement peut avoir intérêt à dissimuler, si même il ne l'a pas fait disparaître. La vérité historique, c'est-à-dire celle que l'on essaie d'établir d'après les documents, est toujours imparfaite, toujours subjective. Inutile donc de chercher à établir une vérité officielle, car elle donnerait prise aux mêmes critiques que le fameux article 231 du traité de Versailles. Il faut au contraire éviter tout débat public, rayer la question des responsabilités du domaine de la politique, la cantonner sur le terrain scientifique. Laissons les historiens travailler individuellement. Avec le temps ils parviendront à établir un récit des faits qui ne provoquera plus de controverses sérieuses. Ainsi la question des responsabilités cessera de troubler les relations internationales ». J'ai déjà dit ailleurs que, pour des raisons personnelles, il me déplaît d'avoir à contredire M. Renouvin. Mais, s'il est un sujet où les questions de personnes doivent s'effacer devant la nécessité d'arriver à la vérité, c'est bien celui-ci. Or la thèse de M. Renouvin s'oppose radicalement à celle que je viens de soutenir. Je réclame une enquête sur les responsabilités de la guerre. Il la repousse. Comment ne discuterais-je pas son opinion! Si je la laissais ignorer au lecteur, ne m'exposerais-je pas au reproche absolument justifié d'agir malhonnêtement en lui cachant les objections que peut soulever la mienne?

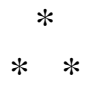

La thèse de M. Renouvin suscite d'abord une critique d'ordre général. Il fait du débat sur les responsabilités une question purement allemande, qui 
aurait sa source dans l'article 231 du traité de Versailles. Rien n'est plus inexact. La question des responsabilités est née le jour, qui fut le premier de la guerre, où les gouvernements de l'Entente, dans leurs déclarations à leurs parlements respectifs, rejetèrent toute la responsabilité sur l'Allemagne à cause de son «agression ». Tout de suite, cette thèse a soulevé partout à l'étranger des protestations, et sa réfutation a suscité, pendant les cinq années qui séparent l'explosion de la guerre du traité de paix, des ouvrages de toutes sortes, dont l'intérêt et la valeur ne le cèdent en rien aux ouvrages publiés ensuite, et qui n'avaient guère à voir avec la propagande allemande, alors encerclée. En France, où la censure empêchait une réfutation publique, l'opposition s'est manifestée dans une Société d'études critiques et documentaires sur la guerre, qui n'avait d'autre but que de combattre la thèse officielle des responsabilités et ne connaissait rien des journaux et livres allemands. $\mathrm{M}$. Renouvin ignore tout cela moins que personne, puisque par sa fonction même il a sous la main tous les ouvrages sur le sujet.

Cette question préjudicielle réglée, reprenons l'argumentation de $\mathrm{M}$. Renouvin : Il trouve « superflu » d'avoir inscrit dans le traité de Versailles que l'Allemagne est seule responsable de la guerre. Si c'est vrai, pourquoi serait-ce superflu ? Il prétend que les gouvernements auteurs du traité eurent la main forcée par l'opinion publique. Il n'ignore cependant pas, pour ne parler que de la France, que c'est MM. Poincaré et Viviani qui, à la séance du 4 août 1914, lancèrent devant le parlement la légende de «l'agression odieuse, traîtresse » de l'Allemagne contre la Russie et la France «surprises ». Il n'ignore pas que pendant chaque jour des cinquante mois de carnage, princes de la politique, de la presse, de l'université, des académies, de l'église et de l'argent, stylés par le gouvernement, luttèrent à qui ferait entrer le plus profondément cette légende dans l'esprit public. Alors comment peut-il renverser les rôles au point de faire entendre que c'est le gouvernement qui eut le «crâne bourré » par le peuple ? D'ailleurs comment l'opinion publique aurait-elle imposé un article du traité ? M. Renouvin ne se souvient-il pas que les négociations eurent lieu sous le régime de la censure, et que le parlement lui-même fut tenu complètement à l'écart?

Le motif de l'article 231 fut tout bonnement que les vertueux, les pacifiques gouvernements alliés et associés, voulurent donner une base morale à l'énorme indemnité de guerre qu'ils exigeaient sous le nom de « réparations des dommages de la guerre »; ce n'était pas le vaincu, mais l'agresseur qui paierait. L'avalanche d'acier qui s'était abattue pendant quatre ans sur la terre de France, les canons français et anglais en avaient bien vomi la moitié ; mais il s'agissait de séparer l'ivraie du bon grain, les obus défensifs des obus agressifs. On installait le mythe de la légitime défense dans le plus grand traité de l'histoire, après en avoir fait la justification de la plus grande guerre. Voilà la signification de l'article 231 : proclamer une fois de plus l'innocence des gouvernements de l'Entente, donner à cette innocence, ils l'ont assez dit 
euxmêmes, la force de la chose jugée ${ }^{1}$. Il ne fut donc pas, comme dit M. Renouvin, « superflu».

M. Renouvin reproche aux Allemands d'avoir saisi l'occasion de l'article 231 pour organiser une campagne de propagande sur la question des responsabilités de la guerre. Il ne s'est donc jamais demandé ce qu'il aurait fait s'il était Allemand. Existe-t-il un peuple qui se serait incliné devant une pareille condamnation, l'estimant injuste? Ah, si c'était le nôtre ! La guerre a fait en moi table rase de tout orgueil national. Mais je sais bien que si la même injure avait été faite à la France, nos Poincaré, nos Clemenceau, nos Lavisse auraient trouvé pour la repousser des accents autrement vigoureux que les Allemands. Et ce n'est pas d'eux qu'on aurait pu dire qu'ils avaient des âmes de vaincus.

Toute la question est de savoir si, dans leur réfutation de l'accusation portée contre eux, les Allemands disent la vérité ou non. M. Renouvin insinue que leurs travaux n'intéressent que les milieux où la curiosité est plus grande que la compétence, mais reconnaît qu'ils ont trouvé de l'écho à l'étranger. Il résulte en effet d'une enquête récente que, sur cent professeurs d'histoire américains, trois seulement estiment que l'Allemagne est seule responsable de la guerre ${ }^{2}$. M. Renouvin s'en console en disant que ce n'est pas le cas en France où d'ailleurs, dit-il avec une franchise dont il faut lui savoir gré, « on ignore à peu près tout de la question des responsabilités ». Mais, ajoute-t-il « on s'y accommode fort bien de cette ignorance ». Je doute que tous les Français prennent cette phrase pour un compliment. Il doit y en avoir tout de même qui préféreraient savoir.

À la demande que font depuis dix ans les Allemands d'une enquête ou d'un arbitrage, M. Renouvin objecte qu'on ne saurait trouver des hommes assez impartiaux pour s'en acquitter honnêtement ${ }^{3}$. Alors pourquoi veut-on faire de l'arbitrage la base du droit international ? Si on ne peut trouver des hommes capables de juger impartialement les causes d'une guerre passée, à une heure où les haines paraissent éteintes, on en trouvera bien moins encore pour arbitrer un conflit en pleine acuité, où des intérêts énormes seront peut-être engagés, les pires passions aux prises. C'est au contraire une excellente occasion d'apprécier dans quelle mesure on peut compter sur l'arbitrage pour

1 Voir La Mobilisation des consciences, chapitre du Jugement de Versailles, pages 222250.

2 Enquête de la revue The World Tomorrow (Le monde de demain), numéro d'octobre 1930.

3 Dans un article de La Volonté du 16 octobre 1927, M. Victor BASCH, Président de la Ligue des Droits de l'homme, a développé la même idée : «Soumettre la question des responsabilités à la Société des Nations ou à la Cour de La Haye ? Faut-il être assez peu psychologue pour admettre un seul instant que leurs nombres feraient passer la cause de la justice objective avant leurs préoccupations nationales... Des conflits comme celui de 1914 ne peuvent être jugés comme des causes qui mettent aux prises des individus ». Soit. Mais la Ligue a été créée, lors de l'affaire Dreyfus, pour opposer la justice objective à la raison d'État, et veut supprimer la guerre par l'arbitrage. Alors ! ! ! 
la solution des difficultés internationales. Si l'expérience rate, on saura à quoi s'en tenir.

M. Renouvin ne se défie pas seulement des juges. Il se défie aussi des documents qui leur seront soumis. Depuis la guerre, les Chancelleries ont publié, ou sont en train de publier, sous le contrôle d'historiens, la partie de leurs archives relative aux origines et à l'explosion de la guerre. Pas de vérité réelle à en attendre, dit $\mathrm{M}$. Renouvin, parce qu'on ne peut compter que les dossiers seront complets. Sans insister sur le caractère inquiétant que revêt cette déclaration sous la plume du secrétaire de la Commission chargée de la publication des documents français, il en résulte qu'appuyés sur l'aveu de l'historien Renouvin qu'il n'y a pas de vérité historique, les gouvernants seront plus que jamais à l'aise pour tromper les gouvernés sur les causes d'une guerre. Quand on leur reprochera de n'avoir pas dit la vérité, ils n'auront qu'à répondre, comme Pilate : «Qu'est-ce que la vérité ? » et à se laver les mains du sang versé.

Certes, l'histoire n'est pas une science exacte. Elle se prête à des différences d'appréciation et aussi, hélas, à des déformations et même des falsifications. Il y aura toujours des Père Loriquet; il n'y en a jamais eu tant que depuis quinze ans. Mais est-ce une raison, pour un homme qui a fait de l'enseignement de l'histoire sa profession, de nier que l'histoire puisse jamais être objective, des historiens jamais impartiaux, des documents jamais probants?

D'ailleurs, s'il n'y a pas de vérité historique, les conclusions de l'ouvrage de M. Renouvin sur les origines immédiates de la guerre sont elles-mêmes sans valeur, et l'accusation portée contre l'Allemagne une simple conjecture. Alors que penser des hommes : politiques, journalistes, et surtout professeurs, qui, en exploitant sans relâche pendant la guerre cette accusation, se sont faits les pourvoyeurs des champs de bataille sur une simple conjecture !

Est-il nécessaire d'observer que, lorsqu'on demande une enquête sur les responsabilités de la guerre, il ne s'agit pas, comme affecte de le craindre $\mathrm{M}$. Renouvin, de faire édicter par un concile une histoire officielle de l'ensemble de ses causes lointaines et immédiates, devant laquelle tout le monde devrait s'incliner? Il s'agit seulement de faire examiner impartialement si « l'Allemagne et ses alliés sont seuls responsables de la guerre par leur agression ». Si c'est une tâche au-dessus des forces des historiens, à quoi sont-ils bons ?

En demandant la révision de l'article 231 du traité de Versailles, dit encore M. Renouvin, le but des Allemands est de faire dériver la question des responsabilités dans la politique; il faut déjouer cette manœuvre, « revenir sur le terrain scientifique ». Ne saute-t-il pas aux yeux que c'est tout le contraire, que l'article du traité de Versailles, comme l'a dit l'historien américain Sidney Fay, 
d'ordinaire si réservé, si mesuré dans ses appréciations, «est le produit de l'aveuglement, de l'ignorance, de la haine », donc un acte politique au premier chef, et que demander qu'il soit l'objet d'une expertise historique, c'est précisément rentrer sur le terrain scientifique. Nous acceptons les conséquences de notre défaite, disent les Allemands, et exécuterons le traité dans la limite de nos capacités, mais parce que vaincus, et non parce que seuls responsables de la guerre. Ils ne cherchent donc pas à tirer des avantages politiques du débat. Ils en font une question d'honneur, et on devrait comprendre ici que notre honneur y est aussi engagé que le leur.

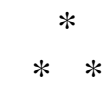

Pour finir, M. Renouvin déclare que le meilleur, le seul moyen de faire la vérité, est de s'en tenir aux travaux individuels des historiens : elle en sortira avec le temps. Pour que la vérité en sorte, encore faudrait-il que ces travaux s'affrontent, que leurs auteurs discutent. Mais, alors que les adversaires de la thèse officielle ne demandent qu'à discuter, ses partisans s'y refusent ${ }^{1}$, et $\mathrm{M}$. Renouvin tout le premier. Un Allemand, directeur de la revue qui se consacre uniquement depuis neuf ans à l'étude des causes de la guerre, a entrepris de discuter point par point, en se plaçant sur le terrain purement historique, le rapport sur les conclusions duquel la Conférence de la paix condamna l'Allemagne. C'était là une occasion admirable pour M. Renouvin, tenant de la thèse française, d'entrer en lice. «Polémique », dit-il dédaigneusement du livre de M. von Wegerer, et il passe. Voyez-vous un avocat, devant un tribunal, refuser de discuter la plaidoirie de son adversaire sous prétexte que c'est de la polémique !

S'il y a une question qui soit du ressort des historiens et doive les passionner, c'est bien celle de savoir quel rôle a joué l'alliance russe dans l'entrée de la France dans la guerre, non seulement à cause de son importance intrinsèque, mais encore parce que c'est une des rares où règne encore une certaine obscurité. M. Poincaré prétend que c'est à l'insu de la France, et même contre son avis, que la Russie a mobilisé contre l'Allemagne. M. Renouvin l'admettant, je lui ai demandé comment il concilie cette assertion avec tels faits et documents que j'énumérais ${ }^{2}$. Une revue historique américaine, qui fait une grande place à la question des responsabilités, lui a ouvert

1 Une exception doit être faite pour M. Poincaré, qui a accepté, ce dont on ne saurait trop le louer, avec M. René Guérin la controverse que l'on sait. Les réponses de M. Poincaré sont la meilleure justification d'une enquête.

2 Voir les revues Libres propos (avril 1928) et Evolution (mai), ainsi que l'édition française de The genesis of the War, du professeur américain Elmer BARNES. 
ses colonnes pour le débat. Ce fut en vain. Autant vouloir entrer en communication avec une planète.

Pour que la vérité pût sortir des travaux individuels des historiens, il faudrait au moins que la liberté d'opinion fût effective, c'est-à-dire que toutes les opinions eussent les mêmes moyens de se faire connaître. "Supposons, a dit Bertrand Russell, que de deux thèses pouvant chacune se soutenir avec de bons arguments, l'une ait un million de livres à dépenser pour sa propagande, et l'autre seulement cent mille. Il est clair que la première sera beaucoup plus répandue que la seconde, et triomphera. Sa victoire sera naturellement plus facile encore si elle a pour elle le gouvernement ${ }^{1}$. Dans la question des responsabilités de la guerre dont dépend l'organisation de la paix et le sort des peuples, l'inégalité de diffusion entre la thèse officielle et celle de l'opposition, en France tout au moins, n'est pas de un à dix, mais de un à cent ou à mille. Pendant la guerre on répandit à plus de dix millions d'exemplaires, et à nos frais, les ouvrages des grands professeurs de la Sorbonne qui écrivaient l'histoire d'après le Livre jaune. Celui où j'ai démontré que ce Livre jaune était un repaire de faux a été tiré à deux mille, et n'a pas reçu l'ombre d'une publicité, pas plus d'ailleurs que d'une contradiction.

S'il n'y en a pas en France, il y a à l'étranger des historiens de profession qui, tout à l'opposé de M. Renouvin, pensent que la question des responsabilités n'est pas seulement un sujet de controverse entre historiens, mais intéresse au plus haut point tout le monde. Je n'en citerai qu'un. C'est un Allemand, mais à qui $\mathrm{M}$. Renouvin ne peut reprocher d'être un agent de la propagande innocentiste allemande puisque, dans son histoire des Trente-neuf jours critiques, il ne ménage pas plus le gouvernement allemand que les autres, au contraire. On ne peut pas non plus contester sa compétence, puisqu'il est Secrétaire général de la Commission d'enquête parlementaire allemande sur les responsabilités de la guerre. C'est le $\mathrm{D}^{\mathrm{r}}$ Eugen Fischer, universitaire éminent, directeur de la bibliothèque du Reichstag. Invité à donner son avis, à l'occasion du dixième anniversaire du traité de Versailles, sur l'utilité de l'étude des causes de la guerre, il a dit : «La leçon capitale à en tirer est que la légitime défense est un mythe, qui sert partout à dissimuler le véritable caractère de la politique des armements. Par là cette étude peut révolutionner l'idéologie en cours, et est le meilleur appui que puisse trouver la cause de l'entente internationale $»^{2}$. Ou la question des responsabilités de la guerre a cette importance, ou elle ne l'a pas. Mais comment les peuples s'en rendraient-ils compte ? Qu'est-ce que leur ont appris les discussions individuelles entre historiens ? Combien, parmi les êtres innombrables exposés aux

$1 \quad$ Free tought and official propaganda (La liberté d'opinion et la propagande officielle). Dans cette brochure, le grand mathématicien et philosophe anglais montre que la propagande applique, dans le domaine de la politique et de l'esprit, les procédés de la publicité commerciale.

2 Berliner Monatshefte für internationale Aufklärung, juin 1929. 
horreurs d'une nouvelle guerre, savent qu'il y a une question des responsabilités ? Combien, parmi ceux qui en ont entendu parler, sont en état de se faire une opinion raisonnée ? Combien, parmi ceux qui croient la connaître, et mettent tout sur le dos de l'Autriche et de l'Allemagne, savent seulement qu'à peine la guerre finie, ces damnés États agresseurs ont étalé au grand jour leurs archives diplomatiques sur l'explosion de la guerre, tandis qu'on attend encore que les innocentes victimes de l'agression, la France et la Serbie, publient les leurs ? À une époque d'information à outrance, où les merveilles de l'industrie s'emploient à inonder chaque jour le globe des nouvelles les plus grotesquement insignifiantes, les foules misérables sont tenues dans l'ignorance de ce qui est pour elles, à proprement parler, une question de vie ou de mort !

Sauf démonstration contraire, les raisons pour lesquelles M. Renouvin estime qu'une enquête sur les causes de l'explosion de la guerre serait inopportune et inopérante, apparaissent donc comme totalement dépourvues de fondement, et même de sérieux. S'il pensait que l'enquête dût faire triompher sa thèse, est-ce qu'il la repousserait ? C'est donc qu'il est persuadé du contraire. Cette constatation s'applique non seulement à lui, mais au gouvernement, dont il est l'avocat, et à tous ceux, hommes politiques, journalistes, professeurs, dont le rôle est d'éclairer l'opinion, et qui repoussent la lumière.

Et maintenant, veut-on savoir le résultat du silence organisé sur les responsabilités de la guerre ? Un journal ${ }^{1}$ a publié un discours adressé par un colonel à son régiment, à l'occasion de la représentation du film A l'ouest rien de nouveau. C'est la plus farouche excitation du soldat français à la haine du soldat allemand. Toute la propagande des années de guerre y passe. Voici le leitmotiv. «Les Allemands ont déchaîné la guerre pour prendre, nous l'avons subie pour garder. Criminelle de leur part, elle fut sacrée pour nous. Telles furent nos positions respectives hier, telles elles seront demain et peut-être toujours ». Le Ministre de la guerre lui-même, à la séance de la Chambre du 24 février 1931, parlant de la limitation des armements, a dit : «Traiter tous les peuples sur un pied d'égalité ? Non. Si l'on veut la justice internationale, il est juste que ceux qui ont été les agresseurs subissent des limitations plus sévères que ceux qui n'ont commis aucune agression et se refusent à en commettre ». Qu'en pense M. Renouvin, Secrétaire général de la revue pacifiste L'esprit international ?

L'Éclair de Montpellier, du 26 janvier 1931. 


\section{Chapitre IX}

\section{Requête à la Fondation Carnegie}

Je me tourne alors vers vous, messieurs de la Fondation Carnegie. Votre Institut est américain. Mais il est installé aussi en Europe. La revue L'esprit international est l'organe de sa section européenne, dont le siège est à Paris. Vous ne sauriez donc trouver mauvais qu'un Européen, qu'un Français s'adresse à vous.

Votre Institut a été créé pour travailler à la suppression, suivant l'expression même de votre fondateur, « de cette souillure : la guerre », et votre charte constitutive vous impose dans ce but, comme premier devoir, « de provoquer une recherche scientifique et approfondie des causes des guerres, de répandre toutes les informations possibles au sujet de ces causes et des moyens de les éviter ». Je vous adjure d'organiser cette enquête. Tout vous désigne : vos immenses ressources, puisque votre Institut jouit d'un revenu de 500.000 dollars, le prestige des hommes qui le dirigent, puisqu'ils appartiennent à la plus haute élite intellectuelle et morale des États-Unis, enfin la place que tient 
actuellement votre pays dans les relations internationales, et qui en fait comme l'arbiter mundi.

Dans votre revue L'esprit international, on lit d'ailleurs cette profession de foi : «L'objet de la Dotation Carnegie se définit ainsi : restreindre, dans la mesure du possible, les sujets de disputes entre les peuples; fournir aux hommes éminents de toutes les nations les moyens d'exposer leurs idées, et s'entendre avec eux sur les modes de conciliation entre ces idées et celles qui, à première vue, leur paraissent opposées ; faire partout l'éducation de l'opinion publique en lui présentant, sur tous sujets de controverses, des vues claires, désintéressées, calmantes; développer par tous les moyens et chez toutes les nations l'esprit international ». Que pourrais-je dire de mieux et de plus pour justifier ma demande?

Sans doute, je ne suis pas de ces hommes éminents dont vous parlez. Mais je me suis livré dès le début de la guerre à l'étude de ses causes, et c'est à ce titre que je me permets de solliciter votre intervention. Quand au début de 1916 quelques Parisiens, dont l'illustre professeur Charles Gide, que vous connaissez bien, créèrent une «Société d'études critiques et documentaires sur la guerre », j'eus l'honneur d'ouvrir ses discussions. Mon premier soin fut d'y exposer, quinze ans avant que $\mathrm{M}$. Poincaré consentît à le reconnaître, que nous avions été trompés sur les dates des mobilisations. Je démontrai que ces mobilisations avaient joué un rôle décisif dans l'explosion de la guerre, et qu'on pouvait tout dire de cette guerre, sauf que la Russie et la France n'y étaient entrées que pour se défendre. Depuis, ces idées ont trouvé dans le monde politique et scientifique, notamment dans votre propre pays, l'appui d'hommes de premier rang, si bien qu'aujourd'hui cette grande question des causes de la guerre, et surtout de ses causes immédiates, d'où dépend si directement l'organisation de la paix générale, est « un sujet d'incessantes controverses entre des hommes éminents de toutes les nations », et se trouve par suite toute désignée pour vos bons offices.

Mais, me dira-t-on, ne savez-vous pas que la Fondation Carnegie s'est jusqu'ici tenue à l'écart du débat sur les responsabilités de la guerre, avec un parti-pris qui indique suffisamment qu'elle n'en veut pas entendre parler ? Je l'ignore si peu, messieurs, que j'en ai déjà marqué mon étonnement, il y a cinq ans, dans un autre ouvrage ${ }^{1}$. Je n'ignore pas non plus que, depuis, certains de vos propres compatriotes vous ont directement exprimé le même étonnement, et n'ont même pas reçu de réponse ${ }^{2}$. Aussi ne vais-je pas vous demander les raisons de votre attitude, mais essayer de les trouver moi-même. Qu'ayant accepté la mission d'étudier les causes de guerre, la Fondation Carnegie laisse délibérément de côté cette étude, et n'ait pas encore consacré un cent à celle

L'Évangile du Quai d'Orsay, pages 158-160.

Le numéro d'avril 1928 de The progressive Magazine. 
des causes de la guerre mondiale qui, quatre ans après, est venue si cruellement justifier les nobles soucis de son créateur, c'est un fait si stupéfiant qu'on ne peut s'en désintéresser. Si vos raisons sont bonnes, il n'y a qu'à s'incliner. Si elles ne le sont pas, et si vous persistez dans votre inaction, on a le droit de vous juger en conséquence. Observant donc cette règle élémentaire de toute honnête discussion qu'avant de les critiquer il faut se mettre à la place des gens dont on ne partage pas l'opinion, je vais me demander quelles peuvent être les raisons pour lesquelles vous tournez si opiniâtrement le dos à la question des responsabilités de la guerre.

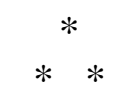

Créée en 1910 pour délivrer le monde de cette souillure : la guerre, la Fondation Carnegie assiste en 1911 à la guerre franco-marocaine et à la guerre italo-turque, en 1912 à la première guerre balkanique, en 1913 à la seconde. Or, quand la guerre européenne éclate en 1914, que voit-on ? Votre grande association pacifiste se jeter dans la fournaise, non pas pour essayer de séparer les combattants, mais pour prendre le parti d'un des camps. A l'heure où le Président Wilson disait que «personne n'était en état d'établir qui avait déchaîné la guerre », que les Américains sauraient «se montrer trop fiers pour s'en mêler », où il souhaitait que la guerre « se terminât par une paix sans victoire », et se faisait réélire par le peuple américain «pour l'avoir tenu à l'écart de la guerre », la Fondation Carnegie disait que «cette neutralité lui pesait », employait son or à persuader le peuple américain qu'il devait entrer dans la guerre, et la poursuivre jusqu'à la défaite de l'Allemagne, parce que « le salut de la démocratie » l'exigeait.

Je sais bien que vous n'avez pas inventé la formule. Dès le début de la guerre, les gouvernements de Paris et de Londres avaient déclaré qu'ils se battaient pour défendre non seulement leurs frontières et la sainteté des traités, mais la démocratie. Ils auraient aussi bien dit qu'ils défendaient la lune s'ils y avaient trouvé avantage. Le mythe de la défense du sol ou de la sainteté des traités ne pouvant être invoqué aux États-Unis, puisque la guerre se passait à des milliers de lieues d'eux, et qu'ils n'étaient pas partie au traité de neutralité de la Belgique, et comme il faut toujours un mythe pour entraîner un peuple à la guerre, le mythe de la défense de la démocratie devait y rencontrer un succès particulier. Avant même l'entrée des États-Unis dans la guerre, leurs fournitures de vivres, de matériel et de munitions à l'Entente se réclamèrent toutes du fameux slogan : To made the world safe for the democracy. 
J'ignore si les Établissements métallurgiques Carnegie ont tiré profit de la guerre. Mais personne n'oserait soupçonner un instant la Fondation pacifique Carnegie d'avoir prêché la guerre pour la démocratie dans un intérêt mercantile quelconque.

Vous étiez certainement de la plus absolue bonne foi. Mais qu'est-ce qui pouvait bien vous faire penser que, si l'Allemagne avait déclaré la guerre à la Russie, à la Russie tsariste, c'était pour étouffer la démocratie ? Était-ce le régime politique de l'Allemagne ? Sans doute il était monarchique, et les Ministres y étaient responsables devant le monarque, non devant le Reichstag. Mais c'est comme aux États-Unis, où ils le sont devant le Président et non devant le Congrès. Une monarchie présidentielle, dit-on des États-Unis ; «le Président a les pouvoirs du Tsar», disait même Anatole Leroy-Beaulieu, directeur de notre École des sciences politiques. Était-ce la personne du monarque allemand ? Mais un an avant la guerre, M. Nicholas Murray Butler, aujourd'hui votre Président, écrivait dans le New-York Times : «Si l'Empereur d'Allemagne n'était pas un monarque héréditaire, il serait monarque électif, ou chef du pouvoir exécutif, car il aurait été l'élu du vote populaire dans toute nation moderne où son destin l'aurait placé ». Était-ce l'attitude du personnel politique et administratif de l'Allemagne ? Au cours des études auxquelles je me livrais, avant la guerre, sur le service public, j'ai eu l'occasion de citer ce mot de Laboulaye, un des plus nobles caractères de la France du XIX ${ }^{\mathrm{e}}$ siècle, qui se vantait d'être « radical » sous l'empire, qui a contribué plus que personne à l'avènement de la République : «L'organisation politique et sociale de la démocratie préoccupe beaucoup plus le gouvernement prussien que le nôtre ». C'était écrit, il est vrai, en $1843^{1}$, mais c'était encore vrai, sous bien des rapports, en 1914. Bien entendu, je ne dis pas que l'Allemagne était une sorte de Salente moderne. Je vous demande seulement comment vous avez pu accuser ce pays, où le tiers des électeurs était alors socialiste, de personnifier l'autocratie, et de menacer la liberté du monde.

Mais une chose est certaine. C'est qu'à la base de votre erreur s'en trouvait une autre : vous croyiez que l'Allemagne était seule responsable de la guerre. $\mathrm{Si}$ vous aviez pensé que la guerre avait été sciemment provoquée par ses ennemis, comment auriez-vous pu l'accuser de faire la guerre pour étrangler la démocratie ? Votre Président Elihu Root, Sénateur, ancien Ministre de la guerre et des Affaires étrangères, aurait-il pu dire en 1918, devant l'Association américaine pour le droit international, que les Allemands «étaient un peuple encore à demi barbare ? » Certainement non. Il faut toujours en revenir à la question des responsabilités.

Et alors de deux choses l'une. Vous croyez toujours que l'Allemagne fut seule responsable de la guerre. Dans ce cas votre intérêt s'accorde avec vos

1 Du noviciat administratif en Allemagne. 
obligations statutaires ; une enquête sur les causes de la guerre montrerait que vous avez vu juste.

Vous ne le croyez plus. Allez-vous donner à penser que si vous vous refusez à cette enquête, c'est pour ne pas avouer que vous vous êtes trompés ? D'autres que vous se sont laissé prendre à certaines apparences, et dans les ténèbres intellectuelles qui ont accompagné la guerre, ont cru et dit que l'Allemagne était seule responsable de la guerre. Mais quand, ces ténèbres dissipées, ils virent leur erreur, ils la confessèrent. Rien ne les forçait cependant à parler. Simples particuliers, ils auraient pu, après tout, se contenter de garder le silence, d'autant plus qu'ils se heurtaient généralement à des difficultés matérielles, à une hostilité qui auraient suffit à les excuser, et que certains durent prendre sur leurs ressources pour se faire imprimer. Mais vous, les champions attitrés de la paix et de la justice internationales, vous à qui un revenu annuel de douze millions cinq cent mille francs a été assuré pour étudier et dire la vérité sur les causes des guerres, vous laisseriez se perpétuer l'erreur que vous avez commise sur les causes de la plus sanglante de toutes! Songez à l'admirable leçon que serait pour les peuples l'aveu de cette erreur : «Comment, se diraient-ils, voilà des savants qui étaient chargés de faire des causes des guerres une étude scientifique et approfondie, et toute leur science ne les a pas empêchés de se laisser tromper sur les causes d'une guerre qui se déroulait sous leurs yeux. Alors nous, la multitude, nous qui ne savons rien et n'avons le moyen de rien savoir, quelle proie nous devons offrir au mensonge quand, dans le fracas d'une mobilisation, on nous jette à la frontière en nous donnant cette seule et toujours même raison que l'ennemi a tous les torts, et qu'il nous force par son agression à nous battre. Le moyen d'échapper aux horreurs de la guerre n'est donc pas de nous en remettre à l'assurance de nos gouvernements que nous ne la ferons que si nous sommes attaqués, ce qui serait perpétuer les massacres entre dupes, mais de ne faire la guerre que de notre consentement, et après avoir pris toutes mesures et tous délais pour nous prononcer en connaissance de cause ». Votre Président a écrit que, neuf fois sur dix, c'est les peuples, trompés par des excitations démagogiques, qui poussent les gouvernements à la guerre. Vous leur devez bien ce meâ culpâ.

Au lieu de donner au monde cet exemple de droiture, allez-vous laisser les peuples vaincus sous le coup d'une injuste flétrissure, et les peuples vainqueurs, dont vos propres concitoyens, dans la béate et absurde conviction, génératrice des guerres futures, qu'ils ne furent que des justiciers ? Et pourquoi ? Dans le plus vil intérêt personnel, pour ne pas avouer, vous les grandsprêtres de la morale internationale, que vous vous êtes trompés. Sans doute il ne manque pas ici de personnages ou de groupes qui disent avoir la passion de la vérité et de la justice, et fuient toute discussion des causes de la guerre pour n'avoir pas à faire cet aveu ; j'ai dit assez souvent ce que je pensais d'eux. Tout de même, ils n'ont pas reçu dix millions de dollars pour étudier les causes des guerres! 


\section{* \\ * *}

Cette première et insultante hypothèse écartée, en voici une seconde, c'est qu'à vos yeux la Société des Nations, et les engagements pris par les gouvernements de renoncer à la guerre, ont rendu inutile la recherche des causes des guerres, puisqu'il ne doit plus y en avoir.

Comment oublier que, depuis qu'il y a des guerres, il y a des gouvernements pour se promettre des paix perpétuelles! Ce n'est pas une raison pour croire à l'éternité de la guerre, mais c'en est une pour se défier des promesses des gouvernements de ne plus la faire.

Dans son Histoire grecque, le célèbre historien Duruy raconte la guerre du Péloponnèse, qui fut la guerre mondiale de l'époque. Elle éclata quatorze ans après qu'une trêve solennelle de trente ans avait été signée entre Sparte et Athènes, à un moment où Périclès, le Briand d'alors, avait projeté de convoquer à Athènes des députés de la Grèce entière pour étudier les moyens de garantir la sécurité des mers et établir la concorde entre tous les Grecs, alors que la Grèce possédait l'institution amphictyonique, qui correspondait à l'actuelle Société des Nations, et que Socrate, qui d'ailleurs fut au front, avait déjà lancé la formule : «Je ne suis ni Athénien, ni Grec, mais citoyen du monde ».

Écoutons maintenant Duruy exposer les causes de cette guerre fameuse : «La rivalité commerciale de Mégare, d'Egine et de Corinthe, et la haine séculaire de Sparte avivée par les intrigues de la Perse, voilà, bien plus que la prétendue ambition d'Athènes, les vraies causes de la guerre du Péloponèse, ... Sparte, qui avait eu la prépondérance dans la Grèce, l'avait perdue, mais n'y avait pas renoncé ; cette suprématie était entre les deux cités le procès toujours pendant, et qui voulait être jugé par les armes, un peu plus tôt, un peu plus tard. Des causes secondaires, seules avouées publiquement, servirent d'occasion... Les oppresseurs des Hilotes et de la Messinie, devenus tout à coup les hypocrites défenseurs du droit et de la liberté, demandaient qu'Athènes renonçât à un empire honoré par des bienfaits, qu'aucune cruauté n'avait encore souillé, et que depuis quatorze années aucune conquête n'avait accru... Athènes, pour avoir protégé une alliée fidèle, dont la cause était juste, fut considérée comme ayant commencé les hostilités. Cependant, bien que toutes ses forces fussent prêtes, et qu'elle eût pu attaquer, elle préféra laisser à ses ennemis l'odieux de l'agression ». Je ne me laisserai pas aller au jeu facile des rapprochements avec la guerre d'hier. Mais je puis bien dire que, depuis les deux mille trois cents ans qui nous séparent de cette guerre mémorable, on 
voit les guerres succéder aux traités de paix, leurs causes véritables toujours dissimulées sous des prétextes, les gouvernements se rejeter la responsabilité de l'agression. Les pacifistes officiels d'aujourd'hui méritent-ils plus de confiance ? Ne sont-ils pas les hommes de la guerre d'hier, dont ils se repentent si peu qu'ils continuent à prétendre qu'ils ont sauvé le Droit, la Liberté, la Civilisation, et autres majuscules, et qu'ils brûlent sur les mânes ou sous le nez de leurs "grands capitaines » autant d'encens que s'ils avaient conquis le monde, alors qu'ils ont dû l'appeler à leur secours? D'où vient donc leur pacifisme ? De l'énormité du prix dont ils ont dû payer leur victoire, de l'ampleur des nouveaux procédés de destruction qui ne distingueront plus les civils des militaires, de la crainte des troubles sociaux qu'entrainerait probablement le retour d'une grande guerre. "Si les requins, a écrit un des rares journalistes indépendants d'ici, M. Pierre Scize, imitent aujourd'hui les sirènes, c'est que blessés, exsangues, ruinés par leur propre voracité, chancelants et sur le point de voir leurs victimes unies les dévorer à leur tour, ils éprouvent impérieusement qu'il est temps pour eux de changer de musique ».

Mais si la musique a changé, les paroles sont restées les mêmes. Tout ce pacifisme réside dans la promesse que les États ne feront la guerre que pour se défendre, et l'histoire des causes de la dernière prouve précisément que la valeur de cette promesse vient immédiatement au-dessous de zéro. Vous ne pouvez donc pas dire que le pacifisme des gouvernements rend inutile l'étude de cette histoire, puisqu'au contraire elle démasque l'insincérité de leur pacifisme.

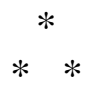

Voici une troisième hypothèse. Vous trouveriez la question des responsabilités trop irritante. Qu'elle soit irritante, c'est incontestable. Mais c'est précisément parce qu'on s'obstine à ne pas la résoudre. Le noble anglais Morel l'a appelée « un cancer qui ronge le monde ». Vous avez tout ce qu'il faut pour l'opérer : l'autorité morale et les moyens matériels. Pourquoi ne l'opérez-vous pas? Quand on s'attaque aux grandes plaies sociales, il faut savoir retrousser ses manches, même quand on est une grande dame comme la Fondation Carnegie.

Si vous étudiez les causes des guerres, un rapprochement a dû se présenter à votre esprit. Pendant longtemps, une cause de guerre a été la religion. Les hommes se battaient pour s'imposer réciproquement leur croyance. Les religions subsistent, mais les guerres de religion ont cessé. Est-ce parce qu'on a créé une Société des religions et une Haute-Cour pour juger leurs différends, solennellement renoncé à faire de la guerre un instrument de la religion, 
soumis à l'arbitrage les dogmes de la Transsubstantiation ou de l'Immaculée conception ? Non. Les guerres de religion ont cessé, parce que les intellectuels d'alors en ont dénoncé la stupidité et l'infamie. Sous Louis XIV, en pleines persécutions contre les protestants, le philosophe Bayle osait écrire : «À voir les crimes qu'on commet au nom de la religion, on peut se demander si on ne ferait pas mieux de s'en passer». Puisque la guerre est à vos yeux une souillure, pourquoi ne dites-vous pas : À voir les crimes qu'on commet au nom de ce qu'on appelle le patriotisme, on peut se demander si on ne ferait pas mieux de s'en passer.

Ce serait, direz-vous, porter atteinte à des sentiments respectables. Souffrez que je mette sous vos yeux ce passage de Voltaire: "Quoi, vous adorez un morceau de pâte que les souris viendraient manger si vous laissiez le ciboire ouvert. Un gueux qu'on aura fait prêtre, un moine sortant des bras d'une prostituée, vient, pour douze sous, revêtu d'un habit de comédien, me marmotter en une langue étrangère ce que vous appelez une messe, fendre l'air en quatre avec trois doigts, se courber, se redresser, tourner à droite et à gauche, par devant et par derrière, et faire autant de dieux qu'il lui plaît, les boire et les manger, et les rendre ensuite à son pot de chambre. Et vous n'avouerez pas que c'est la plus monstrueuse idolâtrie qui ait jamais déshonoré la nature humaine ${ }^{1}$. Voltaire, qui avait alors 75 ans, ne s'attaquait pas seulement à des «sentiments respectables". On était à une époque où la religion catholique était religion d'État, où le dogme de l'eucharistie était dogme d'État, au lendemain du supplice du jeune chevalier de la Barre, «dont le crime était d'avoir dans son cabinet des livres défendus, ce qui, joint à l'abomination de n'avoir pas ôté son chapeau pendant la pluie devant une procession de capucins, engagea les tuteurs des rois à lui faire couper le poing, à lui arracher la langue, et à faire jeter sa tête d'un côté et son corps de l'autre $»^{2}$.

Si cette citation froisse les pacifistes catholiques, je m'en excuse. Il y a actuellement, notamment dans le clergé allemand, des prêtres qui condamnent du point de vue religieux la théorie de la guerre défensive, et auxquels je suis trop heureux de rendre hommage. Mais je tiens à rappeler ce passage de Voltaire (qui attaque d'ailleurs non la religion, mais un dogme repoussé par une partie de la chrétienté, et qui fut même, paraît-il, combattu par des pères de l'Église), parce qu'il prouve deux choses essentielles : la première, c'est que les intellectuels d'alors ne rampaient pas, comme ceux d'aujourd'hui, devant tous les pouvoirs et savaient les braver; la seconde, c'est qu'il ne faut pas craindre, quand c'est nécessaire, de frapper fort, car vingt ans plus tard la Déclaration des droits de l'homme proclamait: «Nul ne peut être inquiété pour ses opinions, même religieuses ». La liberté de conscience était fondée.

\footnotetext{
Le dîner du comte de Boulainvilliers, dans les Entretiens Philosophiques.

Correspondance générale, lettre du 18 février 1771 à Monsieur le Maréchal de Richelieu.
} 
Écoutez maintenant Voltaire parler de la guerre : «Elle réunit tout ce que la perfidie a de plus lâche dans les manifestes, tout ce que la friponnerie a de plus bas dans la fourniture des armées ». Voilà la propagande de la guerre du Droit et le patriotisme des plaques blindées jugés en deux lignes. Il disait des guerres européennes de son temps : «On voit à la fois cinq ou six puissances belligérantes, tantôt trois contre trois, tantôt deux contre quatre, tantôt une contre cinq, se détestant toutes également les unes les autres, s'unissant ou s'attaquant tour à tour, toutes d'accord sur un seul point, celui de faire tout le mal possible ». Voilà pour la Croisade contre la Barbarie. «Il n'y a pas de lois de la guerre. Le mal qu'elle ne fait pas, c'est la crainte ou l'intérêt qui l'arrête ». Voilà pour les prétendus défenseurs des traités et des neutralités. «Il n'y a des deux côtés que des bêtes féroces ». Voilà pour la question des atrocités. «Toutes les guerres sont agressives ». Voilà pour le mythe de la légitime défense.

Imaginez ce que Voltaire eût dit de l'empoisonnement systématique des esprits par les hommes mêmes qui ont pour mission de les éclairer. Vous avez certainement dans vos bibliothèques, et je suppose que vous avez lu cette littérature, signée des noms les plus illustres de la politique et des académies, où la haine de «l'agresseur » a été plus bassement, plus lâchement exploitée que ne l'a jamais été aucune superstition. "Ce qui rend la guerre détestable, a dit un Grec ancien, c'est qu'elle fait plus de méchants qu'elle n'en tue ». Jamais guerre n'en fut un meilleur témoignage! Qu'attendez-vous pour le dire aux peuples ? Quel meilleur moyen de les dégoûter de la guerre que de mettre et de tenir sous leurs yeux, comme dans un miroir, l'image de l'avilissement où on les a plongés! Si cette tâche est au-dessus de vos forces ou contraire à vos goûts, il ne fallait pas accepter un legs de dix millions de dollars pour balayer de la terre cette souillure : la guerre. Vous devriez, soit dit sans vous offenser, donner votre démission, et rendre l'argent.

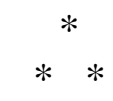

J'arrive alors à une dernière hypothèse. Votre Institut est étroitement lié aux cercles officiels. Deux des délégués, non des moindres, des États-Unis à la Conférence de la paix, vous appartenaient: M. Lansing, Secrétaire d'État aux Affaires étrangères, qui a été votre Vice-président, et le professeur Brown Scott, qui est votre Secrétaire général. C'est eux qui représentaient les ÉtatsUnis à la Commission dite des responsabilités, sur le rapport de laquelle s'est appuyée la Conférence pour condamner l'Allemagne. En procédant à une révision de la question des responsabilités, vous prendriez une initiative qui pourrait déplaire à votre gouvernement, puisque celui-ci a jusqu'ici refusé de 
la prendre lui-même. Au cours d'une tournée en Allemagne, M. Brown Scott s'est vu demander s'il n'avait pas changé d'opinion depuis Versailles. Bien des indices le font supposer. Mais il répondit qu'il ne lui appartenait pas de rétracter l'opinion qu'il avait émise comme représentant des États-Unis, aussi longtemps que ce gouvernement n'en aurait pas changé lui-même.

Cette explication peut valoir pour M. Brown Scott personnellement. Elle ne vaut certainement pas pour la Fondation Carnegie, car ce n'est pas elle qui représentait le gouvernement des États-Unis. Je ne suis pas de ceux qui traitent ce gouvernement de Shylock. Je pense toutefois qu'ayant pris en mains la liquidation de la guerre, il ne devait pas s'arrêter à la liquidation matérielle, mais entreprendre aussi sa liquidation morale, et qu'après avoir réparti les dettes, et même avant, il aurait dû s'occuper de la répartition des torts. Loin de se retrancher derrière sa politique pour ne pas toucher non plus à la question des responsabilités, la Fondation Carnegie devrait le supplanter. Si quelqu'un peut et doit se montrer indépendant des gouvernements, c'est bien elle. Il serait contraire au sens commun de supposer que, voulant supprimer la guerre, et vous chargeant dans ce but d'en étudier les causes, votre fondateur ait entendu subordonner votre action à l'agrément des auteurs des guerres. Vos statuts vous imposent d'étudier les causes des guerres. Ils ne disent pas que vous ne pourrez étudier celles des guerres où participe votre gouvernement qu'avec sa permission.

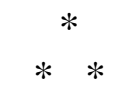

J'ignore qui a rédigé vos statuts, mais ils sont admirables. Ils ne se contentent pas de vous ordonner de rechercher les causes des guerres. « $\mathrm{La}$ Fondation, disent-ils aussi, doit perfectionner le sens de la justice entre les nations, cultiver les sentiments d'amitié et de compréhension mutuelle entre elles ». Quelle justice voulez-vous qu'il existe entre les nations, tant que le gouvernement et le peuple allemand demanderont vainement à être lavés de l'accusation portée contre eux d'avoir «commis le plus grand crime de l'histoire. »?

Vous ne pouvez arguer ici ni du caractère irritant de la question, car demander justice n'est pas une chose irritante, ni des arrangements du pacifisme officiel, car ils n'ont rien à voir avec le tort fait aux Allemands. La paix serait-elle pleinement garantie pour l'avenir que l'injure faite au Droit n'en serait pas diminuée d'un iota, que «le sens de la justice entre les nations », n'en resterait pas moins obnubilé. Vous ne pouvez pas davantage dire qu'il faut «s'en remettre au jugement de l'histoire ». On n'attend pas l'histoire pour réparer une injustice, c'est l'affaire des générations présentes, de celles qui 
l'ont commise. Et c'est avant tout votre affaire, puisque votre raison d'être est de faire régner la justice entre les nations.

Vous n'objecterez pas non plus, je suppose, que par la signature du traité de Versailles et par son entrée dans la Société des Nations, l'Allemagne a renoncé à discuter la question des responsabilités. Primo vivere. Il lui fallait d'abord vivre. Vous savez mieux que personne qu'elle n'a accepté l'article 231 du traité de Versailles que le poignard sur la gorge, et qu'à l'occasion de son entrée dans la Société des Nations, comme lors des accords de Locarno et de la signature des plans Dawes et Young, son gouvernement a toujours publiquement réservé la question des responsabilités. Tous les partis, même ceux qui sont obsédés par la crainte que cette question puisse être exploitée par les partisans du régime déchu, sont là-dessus derrière lui. À part quelques infimes exceptions individuelles, on peut dire que l'unanimité des Allemands qui pensent refuse de reconnaître l'Allemagne comme seule responsable de la guerre, et se considère comme outragée par cette accusation ${ }^{1}$. Peut-on parler de « compréhension mutuelle entre les peuples », tant qu'on laissera au cœur de l'un d'eux un pareil ressentiment ? Est-ce que vous, Américains, accepteriez de porter au cou ad aeternum une pancarte vous accusant d'être seuls responsables d'une guerre mondiale si c'était faux ? Alors pourquoi voudriezvous que les Allemands l'acceptent?

Il faut même aller plus loin. Si les Allemands, tous les Allemands trouvaient un avantage politique à enterrer la question, elle n'en subsisterait pas moins pour vous, qui n'êtes pas des politiques, mais des moralistes et des historiens. La vérité a son intérêt propre en dehors de toute utilité. Il n'est pas utile au marin, pour se guider sur le soleil et les étoiles, de savoir que ce n'est pas eux qui tournent autour de la terre, mais la terre qui tourne sur elle-même, ni au cultivateur, pour faire ses semailles, de savoir que les saisons sont causées par la translation de la terre autour du soleil, et l'inclinaison de son axe de rotation vers lui. La découverte du mouvement des astres en est-elle moins sublime ? Même si la question des responsabilités devenait politiquement indifférente, elle mériterait de passionner tous ceux qui aiment la conquête du vrai pour lui même, et je suppose que vous en êtes.

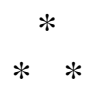

On fait grand bruit des Mémoires du prince de Bülow. Il ne reproche pas à son successeur d'avoir déchaîné volontairement la guerre, mais de s'être laissé manœuvrer par ses adversaires. 
Voici la proposition que j'ai l'honneur de vous faire. Un Comité, formé par vos soins, et composé pour parties égales de partisans et d'adversaires de la thèse adoptée par les plénipotentiaires de Versailles et consacrée par le traité, établirait une nomenclature des arguments pour et des arguments contre. Chacun de ces arguments serait l'objet d'un débat contradictoire écrit, chaque partie ayant droit à une réplique. L'ensemble de la question serait ainsi présenté sous ses deux faces. Il conviendrait que les personnes appelées à prendre part au débat appartinssent à des nations aussi diverses que possible.

L'ensemble du dossier serait soumis à un autre Comité, dont les membres seraient tirés au sort parmi les professeurs d'histoire et de droit des universités des pays n'ayant pas pris part à la guerre mondiale. Il aurait à donner son avis sur la valeur de chacun des arguments en présence, et à dire, en conclusion, si la thèse de Versailles est conforme à la vérité, ou non. Dans ce second cas, il serait invité à donner également son avis sur cette question : que faut-il penser de la distinction entre guerres d'agression et guerres de légitime défense ?

Le dossier et l'avis du Comité seraient, par les soins de la Fondation Carnegie, traduits dans toutes les langues usuelles, et répandus aussi largement que possible dans les différents pays.

Bien entendu, ces modalités ne sont indiquées ici qu'à titre de suggestion. Il appartiendrait à la Fondation, le cas échéant, d'y apporter les compléments ou modifications qu'elle jugerait utiles. L'essentiel est que le débat soit complet, présente impartialement les opinions opposées, soit accompagné d'une conclusion, et reçoive la plus grande diffusion.

Vous pouvez répondre à cette proposition de trois manières.

D'abord en l'acceptant. Je ne crois pas trop m'avancer en disant que vous auriez la reconnaissance de tous ceux, et vous savez qu'ils sont tout de même assez nombreux, qui, dans les différents pays, sont d'avis qu'il est scandaleux de parler de morale internationale et de désarmement moral, tant que la question des responsabilités n'aura pas été vidée.

$\mathrm{Si}$ vous ne l'acceptez pas, je pense que vous en donnerez les raisons. Si elles sont bonnes, si vous prouvez qu'on ne pouvait, pour délivrer le monde de la souillure de la guerre, faire un meilleur emploi de votre fortune que celui que vous en avez fait, que l'étude des causes de la guerre européenne n'offrait à cet égard aucun intérêt, que l'article du traité de Versailles est conforme à la vérité historique, et que par conséquent la voie de la guerre à l'agresseur dans laquelle la Société des Nations tend à organiser la paix est la bonne, ces mêmes hommes ne vous seraient pas moins reconnaissants, puisque vous auriez ainsi rendu la tranquillité à leur conscience, et le repos à leurs plumes. 
Si vous ne répondez, vous aussi, que par le silence, il sera définitivement établi qu'on ne peut espérer aucune justice des hommes, et je cesserai pour ma part, j'ai soixante-dix ans, de la réclamer. Mais vous me permettrez, dans ce cas, de livrer à vos méditations, tout comblés d'honneurs que vous êtes, ce mot de Swift, que notre espèce est « la plus odieuse petite vermine qui ait jamais rampé sur la terre ». J'emprunte cette citation à un de mes compatriotes, qui l'a mise en épigraphe d'une brochure consacrée aussi à la question des responsabilités ${ }^{1}$. Tant il est vrai qu'il n'y a rien comme cette question pour inspirer le dégoût de l'hypocrisie humaine.

1 Les peuples mobilisables. Témoignage pour les enquêtes sur les responsabilités de la guerre, par Maurice GÉRIN. «The most pernicious race of little odious vermine that nature ever suffered to crawl upon the surface of the earth (Gulliver's Travels. deuxième partie, chap. VI). 


\section{APPENDICE}

$\underline{\text { Retour à la table des matières }}$

Pendant que ce livre était à l'impression, a paru le deuxième volume de la troisième série des Documents authentiques français sur les origines de la guerre (février-mai 1912). Quelques-uns doivent être commentés ici.

L'affaire d'Agadir, qui avait envenimé les relations entre l'Allemagne et l'Angleterre, amena les éléments pacifiques des deux pays à chercher un rapprochement. Au cours d'une visite du Ministre de la guerre anglais Haldane à Berlin s'engagèrent des pourparlers aux termes desquels, en retour de certaines concessions de l'Allemagne sur la question navale, l'Angleterre se déclarait prête à lui faire cette déclaration : "L'Angleterre n'attaquera pas l'Allemagne sans provocation, elle ne poursuit pas une politique agressive contre cette puissance. Une agression contre l'Allemagne ne fait l'objet et n'entre dans les dispositions d'aucun traité, entente ou combinaison où l'Angleterre soit actuellement partie, et elle ne prendra part à aucun engagement ayant un tel objet $\gg\left(n^{\circ} 205\right)$.

Chaque gouvernement se défend toujours de poursuivre une politique agressive ou de conclure des alliances agressives contre un autre, et cependant les guerres éclatent tout de même. La déclaration projetée par le gouvernement anglais était donc complètement anodine. Elle n'en souleva pas moins la plus vive émotion chez certains Anglais et chez le gouvernement français. La 
France comptait sur l'appui de l'Angleterre dans une guerre contre l'Allemagne. Qu'arriverait-il si la France, passant pour l'agresseur, voyait l'Angleterre, victime de sa promesse à l'Allemagne, condamnée à la neutralité ?

«Qui peut garantir, disait à M. Poincaré, le 28 mars 1912, l'Ambassadeur d'Angleterre à Paris, que la France, provoquée ou menacée par une mobilisation de l'armée allemande, ne sera pas forcée à prendre l'offensive »? En portant ces paroles à la connaissance de notre Ambassadeur à Londres, M. Paul Cambon, M. Poincaré disait : «Il importe essentiellement que l'Angleterre ne s'engage pas à rester neutre entre la France et l'Allemagne, même dans l'hypothèse où l'attaque semblerait venir de notre fait » $\left(\mathrm{n}^{\circ} 269\right)$.

Le lendemain 29 Paul Cambon répondait : «J'ai mis en garde le Ministre des Affaires étrangères contre la tendance de certains de ses collègues à admettre la neutralité pour le cas d'agression contre l'Allemagne, et insisté sur l'impossibilité de reconnaître le véritable agresseur » $\left(n^{\circ} 271\right)$.

Le lendemain 30 Poincaré revient à la charge : «Si l'Allemagne masse brusquement ses troupes à Aix-la-Chapelle et si la France menacée est obligée de déclarer la guerre, l'Angleterre pourrait-elle dire que l'Allemagne est provoquée $($ sic $)$ ? » $\left(\mathrm{n}^{\circ} 276\right)$

Le 4 avril, le chargé d'affaires de France à Londres écrit à M. Poincaré qu'en l'absence de Grey il a vu le Secrétaire général du Foreign-Office : «La phrase la plus dangereuse de la déclaration, lui ai-je dit, celle qui soulève principalement les objections de votre Excellence, est la première : L'Angleterre n'attaquera pas l'Allemagne sans provocation. Il est très difficile de définir les mots attaque sans provocation, et l'Allemagne peut, par son attitude, amener la France à prendre certaines mesures qui auront les apparences d'une agression, tout en étant réellement des mesures défensives. Telle serait, par exemple, l'entrée des troupes françaises sur le territoire belge, que les états-majors anglais et français considèrent comme nécessaire en certains cas » $\left(n^{\circ} 300\right)$. M. de Fleuriau terminait en disant : «Le Secrétaire général ne m'a pas dissimulé que, pour sa part, il serait très heureux de voir se clore une fois pour toutes les négociations qu'il juge futiles ou dangereuses ».

Pour en être plus certain, M. Poincaré écrivit à notre Ambassadeur à Londres, huit jours après : «Sir Ed. Grey nous a fait savoir qu'il fallait entendre dans le sens le plus inoffensif les mots «n'attaquera pas sans provocation ». Vous pouvez l'assurer qu'une déclaration de ce genre, si atténuée qu'elle soit, sera interprétée en France comme un abandon volontaire de toute la politique suivie depuis $1904 »\left(n^{\circ} 329\right)$. 


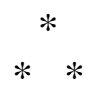

Reportons-nous maintenant au volume XXXI de la grande collection de documents allemands : Die grosse Polilik. Ce que voulaient les Anglais, c'était que les Allemands admettent la supériorité navale de l'Angleterre. Ce que voulaient les Allemands, c'était que les Anglais leur consentent en échange une convention formelle de neutralité dans une guerre où serait engagée l'Allemagne. Dans l'esprit des Allemands les deux questions étaient liées : que les Anglais restent les plus forts, mais alors qu'ils s'engagent à ne pas nous tomber dessus si nous sommes en guerre avec une ou plusieurs autres puissances. La déclaration qui inquiétait si fort Paris leur semblait donc, à eux, tout à fait insuffisante. Haldane proposa alors que les deux puissances s'engagent «à une neutralité bienveillante dans une guerre où l'une d'elles serait partie et où on ne pourrait désigner l'agresseur $\gg\left(n^{\circ} 11.361\right)$. Berlin observa que cette clause pourrait donner lieu à des interprétations contradictoires, que par exemple « on pourrait désigner comme agresseur l'État qui aurait déclaré la guerre, alors qu'il ne serait pas nécessairement l'agresseur, qu'un État peut être en état de légitime défense et cependant avoir pris l'offensive ». Haldane reconnut « que l'histoire elle-même en était la preuve » $\left(n^{\circ}\right.$ 11.370). Pour ne pas laisser tomber les pourparlers, le Chancelier allemand, qui faisait tous ses efforts pour arriver à une entente, proposa la formule : «dans une guerre qui aurait été imposée à l'Allemagne » $\left(\mathrm{n}^{\circ}\right.$ 11.395), qui suscitait d'ailleurs à peu près les mêmes critiques. Mais, chapitré par Paris, le cabinet de Londres était décidé, au contraire, à rompre les négociations. Il désavoua Haldane et déclara s'en tenir à la formule du début dont ne voulaient ni les Français ni les Allemands. Et ce fut fini.

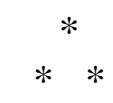

Ai-je tort d'avoir consacré un livre à dénoncer le mythe des guerres de légitime défense ? Sa justification n'est-elle pas là, noir sur blanc ? Quel crédit ajouter à la distinction entre la guerre agressive et la guerre défensive, quand on voit les augures, dans le secret de leur correspondance, convenir de l'impossibilité de désigner le véritable agresseur ? Insister serait supposer que le lecteur est plus stupide qu'une borne. Contentons-nous de tirer de ces documents quelques renseignements supplémentaires.

Six mois après avoir constaté que l'expression «agression non provoquée » était d'une ambiguïté qui permettait toutes les interprétations, les 
gouvernements anglais et français, par un accord passé les 22-23 novembre 1912 et complètement secret (ah ! ces démocraties), s'engageaient à se concerter, «en cas de menace d'une agression non provoquée », sur les moyens de se porter un mutuel appui. C'est donc qu'ils se réservaient d'apprécier à leur guise l'agression et la provocation. On s'en aperçut en 1914. La Russie et la France mobilisèrent contre l'Allemagne. Le gouvernement français ayant exposé à l'anglais, en février 1912, qu'une mobilisation allemande le justifierait à déclarer la guerre à l'Allemagne, l'Allemagne, menacée non par une seule mobilisation mais par deux, était, de leur propre aveu, doublement justifiée à répondre à ces mobilisations par la guerre. Pour l'avoir fait, elle fut rendu responsable de la guerre européenne par son agression, comme telle couverte d'outrages dont l'ignominie et condamnée à un traité de paix dont la férocité n'ont pas d'équivalents dans l'histoire.

L'Angleterre prétendit, en 1914, n'être entrée en guerre que pour sauver la Belgique. Elle avait un moyen plus simple, c'était de dire à l'Allemagne en 1912 : «Je serai neutre si vous respectez le territoire belge, et contre vous si vous le violez ». Mais elle avait promis à la France son appui à condition, nous apprend le $\mathrm{n}^{0} 240$ des documents français, que l'armée française ne passerait pas la première par la Belgique. Elle ne pouvait donc promettre sa neutralité à l'Allemagne à la même condition. Sa politique n'était pas de préserver la Belgique, mais de se procurer, elle aussi, un pieux motif d'entrer en guerre. Ne pouvant invoquer sa propre défense puisqu'elle savait que personne ne l'attaquerait, elle s'est arrangée de manière à pouvoir invoquer la défense de la Belgique, qui s'est elle-même, dans une certaine mesure, prêtée à la combinaison ${ }^{1}$.

En 1914, M. Poincaré a voué l'Allemagne à l'exécration du genre humain pour avoir répliqué à la mobilisation russe comme, en 1912, il se déclarait prêt à répliquer à une mobilisation allemande, c'est-à-dire pour un acte identique à celui qu'à la place de l'Allemagne il aurait commis lui-même. C'est une preuve de plus que, martyr de son patriotisme incendiaire, il lui a sacrifié la vérité et le sens moral comme le reste, sans peut-être en avoir même conscience. «Il faut bien admettre, a dit le philosophe Benda, qu'il y a des circonstances où la vérité cesse complètement d'exister pour certains hommes, et que c'est le mensonge qui devient pour eux la vérité ». On peut dire, sans injurier M. Poincaré, que dans tout ce qu'il a dit et écrit sur les causes de la guerre, et ce n'est pas peu, il n'y a pas un mot qui mérite confiance. Plus coupables que lui sont les gens qui, sachant à quoi s'en tenir, en font un historien modèle.

Puisqu'en 1912 M. Poincaré était prêt à riposter à une mobilisation allemande par une déclaration de guerre, c'est que, contrairement à sa fameuse

Voir dans La Mobilisation des consciences, le chapitre consacré à la violation de la neutralité belge. 
affiche et en dépit de ses folles dénégations, la mobilisation peut signifier la guerre. Or, à la deuxième séance du 21 juin 1927 de la Chambre, comme M. Renaudel demandait que la mobilisation ne pût être ordonnée qu'après avis du parlement, M. Maginot, futur ministre de la guerre, répliqua : «Vous confondez la mobilisation et la déclaration de guerre, c'est une mauvaise plaisanterie ». Et M. Painlevé, ministre de la guerre en exercice, confirma : «Il ne faut pas confondre la mobilisation et la déclaration de guerre » (Journal Officiel, débats Chambre, p. 1989). Voilà l'état d'esprit des hommes qui pourraient avoir à signer un décret de mobilisation.

Et maintenant, la Société des Nations va-t-elle encore prétendre assurer la paix du monde par la menace d'une croisade contre «l'agresseur »?

Ce qu'on appelle une guerre de légitime défense

\begin{tabular}{|c|c|}
\hline DANS LES COULISSES & SUR LA SCĖNE \\
\hline $\begin{array}{l}\text { «Songez qu'il s'agit d'envoyer des } \\
\text { milliers et des milliers d'hommes à la } \\
\text { mort » (Le Tsar de Russie au Ministre } \\
\text { des affaires étrangères Sazonow, qui } \\
\text { venait pour la seconde fois, le } 30 \text { juillet } \\
\text { 1914, lui arracher l'ordre de } \\
\text { mobilisation générale. - Souvenirs de } \\
\text { l'Ambas sadeur de France Paléologue, } \\
\text { Revue des Deux-Mondes, } 15 \text { janvier } \\
\text { 1921). }\end{array}$ & $\begin{array}{l}\text { « Je comprends que tu sois obligé de } \\
\text { mobiliser, mais je voudrais avoir de toi } \\
\text { la même garantie que je t'ai donnée, à } \\
\text { savoir que ces mesures ne signifient pas } \\
\text { la guerre, et que nous poursuivrons nos } \\
\text { négociations pour la paix générale si } \\
\text { chère à nos cœurs " (Le Tsar de Russie } \\
\text { à l'Empereur d'Allemagne le } 1^{\mathrm{er}} \text { août } \\
\text { 1914. - Livre faune français, annexe } \\
\text { V). }\end{array}$ \\
\hline $\begin{array}{l}\text { «Le Ministre de la guerre et l'état- } \\
\text { major estiment qu'il n'y a pas pour le } \\
\text { moment de nécessité militaire à } \\
\text { remettre une déclaration de guerre à la } \\
\text { France. Nous ne l'enverrons donc pas } \\
\text { encore, espérant que les Français nous } \\
\text { attaqueront » (Note du Chancelier } \\
\text { impérial à l'Empereur, } 2 \text { août } 1914 \text {. - } \\
\text { Documents allemands, } \mathrm{n}^{\circ} \text { 629). }\end{array}$ & $\begin{array}{l}\text { «Par des jets de bombes d'avion, des } \\
\text { patrouilles de cavalerie, des incursions } \\
\text { de compagnies, bien que l'état de guerre } \\
\text { ne fût pas encore déclaré, les Français } \\
\text { ont rompu la paix et se sont constitués } \\
\text { les agresseurs de fait » (Discours du } \\
\text { Chancelier impérial au Reichstag, le } 4 \\
\text { août 1914). }\end{array}$ \\
\hline $\begin{array}{l}\text { «.J'ai immédiatement communiqué au } \\
\text { Président de la République votre } \\
\text { télégramme annonçant la déclaration de } \\
\text { guerre de l'Allemagne à la Russie. Il } \\
\text { m'a donné l'assurance la plus } \\
\text { catégorique que le cabinet tout entier et } \\
\text { lui étaient complètement décidés à } \\
\text { remplir les obligations d'alliance de la } \\
\text { France envers la Russie. Mais il estime } \\
\text { préférable que la déclaration de guerre } \\
\text { vienne de l'Allemagne et non de la }\end{array}$ & $\begin{array}{l}\text { «La France vient d'être l'objet d'une } \\
\text { agression brutale et préméditée, qui est } \\
\text { un insolent défi au droit des gens; on a } \\
\text { essayé de nous surprendre } \\
\text { traîtreusement en pleine conversation } \\
\text { diplomatique » (Message aux } \\
\text { Chambres du Président de la } \\
\text { République, du } 4 \text { août 1914). }\end{array}$ \\
\hline
\end{tabular}




\begin{tabular}{|c|c|}
\hline $\begin{array}{l}\text { France, et est convaincu que } \\
\text { l'Allemagne n'attendra pas la } \\
\text { déclaration de guerre de la France et va } \\
\text { l'attaquer incessamment } » \text { (Télégramme } \\
\mathrm{n}^{\circ} 222 \text { d'Isvolsky, Ambassadeur de } \\
\text { Russie à Paris, à son gouvernement, } 1^{\mathrm{er}} \\
\text { août } 1914 . \text { - Correspondance } \\
\text { authentique d'Isvolsky). }\end{array}$ & $\begin{array}{l}\text { contre une agression dont la soudaineté } \\
\text { calculée souligne l'odieuse injustice » } \\
\text { (Discours du Président du Conseil, } \\
\text { même date). }\end{array}$ \\
\hline $\begin{array}{l}\text { «Les Allemands franchissent la } \\
\text { frontière par petits groupes. Cela } \\
\text { permettra au gouvernement français de } \\
\text { présenter au parlement la France } \\
\text { comme attaquée, et d'éviter une } \\
\text { déclaration de guerre » (Id.. télégramme } \\
226 \text { du } 2 \text { août). }\end{array}$ & \\
\hline $\begin{array}{l}\text { "Quoi que nous puissions penser du } \\
\text { mérite des griefs de l'Autriche contre la } \\
\text { Serbie, la question n'est pas là. Elle est } \\
\text { de savoir où est l'intérêt de l'Angleterre. } \\
\text { Il est du côté des Franco-Russes. Il } \\
\text { serait impolitique, pour ne pas dire } \\
\text { dangereux, puisqu'ils se considèrent } \\
\text { comme défiés, de leur faire des } \\
\text { représentations, et d'obscurcir une } \\
\text { situation claire. Du moment qu'ils sont } \\
\text { résolus à la guerre, nous ne pouvons } \\
\text { que nous mettre publiquement de leur } \\
\text { côté » (Note des Secrétaires généraux } \\
\text { du Foreign-Office à sir Ed. Grey, } \\
\text { Ministre, } 24 \text { juillet } 1914 \text {. - Documents } \\
\text { anglais, } \mathrm{n}^{\circ} 101 \text { ). }\end{array}$ & $\begin{array}{l}\text { «Je ne crois pas qu'une nation soit } \\
\text { jamais entrée dans une grande guerre, et } \\
\text { celle-ci sera une des plus grandes, qui } \\
\text { puisse affirmer avec une meilleure } \\
\text { conscience et une plus sincère } \\
\text { conviction qu'elle n'est pas l'agresseur, } \\
\text { qu'elle ne combat pas pour des intérêts } \\
\text { égoïstes, mais va défendre les principes } \\
\text { vitaux de la civilisation du monde » } \\
\text { (Discours du premier Ministre Asquith } \\
\text { aux Communes, le } 6 \text { août 1914). }\end{array}$ \\
\hline
\end{tabular}


Les gouvernements ne trompent pas moins les peuples quand, au lieu d'invoquer la défense de leur territoire ou celui d'un allié, ils invoquent la défense d'un principe. Voici quels différents langages tenait le président Wilson dans ses discours au peuple américain, avant et après l'entrée des États-Unis dans la guerre «pour la défense de la démocratie » :

\begin{tabular}{|l|l|}
\hline \multicolumn{1}{|c|}{ AVANT } & \multicolumn{1}{|c|}{ APRÈS } \\
\hline $\begin{array}{l}\text { « Jamais peuple n'a fait la guerre à un } \\
\text { autre peuple. Ce sont les } \\
\text { gouvernements européens qui sont } \\
\text { entrés en guerre, et non pas les } \\
\text { peuples » (31 janvier 1916). }\end{array}$ & $\begin{array}{l}\text { « Le grand fait qui domine tout le reste } \\
\text { est qu'il s'agit ici d'une guerre de } \\
\text { peuples » (Le « Jour du Drapeau », } \\
1917) .\end{array}$ \\
\hline $\begin{array}{l}\text { « La force n'accomplira rien de } \\
\text { durable » (30 juin 1916). }\end{array}$ & $\begin{array}{l}\text { « La force, la force jusqu'à l'extrême, la } \\
\text { force sans restriction ni limite, qui fera } \\
\text { du droit la loi du monde » (6 avril } \\
\text { 1918). }\end{array}$ \\
\hline $\begin{array}{l}\text { « Avez-vous appris ce qui déchaîna la } \\
\text { guerre actuelle ? Si oui, je voudrais que } \\
\text { vous le publiiez, car personne d'autre ne } \\
\text { le sait » (26 octobre 1916). }\end{array}$ & $\begin{array}{l}\text { « La guerre fut décidée par les chefs } \\
\text { militaires de l'Allemagne » (Le « Jour } \\
\text { du Drapeau », 1917) }\end{array}$ \\
\hline
\end{tabular}

\section{FIN.}

1 Extrait de Shall it be again (Reverrons-nous cela ?) de l'Américain KENNETT TURNER. Sur les causes et circonstances de l'entrée des États-Unis dans la guerre, voir The genesis of the World war, du professeur BARNES, édité en français chez Rivière. 